\title{
Escalonamento de Tarefas em Processadores de Velocidade Variável em Múltiplas Organizações
}

\author{
Pedro Luis Furio Raphael
}

DissERTAÇÃO APRESENTADA

AO

Instituto DE MATEMÁtica e EstatísticA

$\mathrm{DA}$

Universidade DE SÃo Paulo

PARA

OBTENÇÃO DO TÍTULO

$\mathrm{DE}$

Mestre em CiênCIAS

Programa: Mestrado em Ciência da Computação Orientador: Dr. Daniel de Angelis Cordeiro

Durante o desenvolvimento deste trabalho o autor recebeu auxílio financeiro da CAPES São Paulo, Junho de 2015 


\section{Escalonamento de Tarefas em Processadores de Velocidade Variável em Múltiplas Organizações}

Esta versão da dissertação/tese contém as correções e alterações sugeridas pela Comissão Julgadora durante a defesa da versão original do trabalho, realizada em 08/05/2015. Uma cópia da versão original está disponível no Instituto de Matemática e Estatística da Universidade de São Paulo.

Comissão Julgadora:

- Prof. Dr. Daniel de Angelis Cordeiro (orientador) - IME-USP

- Prof. Dr. Luiz Fernando Bittencourt - UNICAMP

- Prof ${ }^{a}$. Dr ${ }^{a}$. Liria Matsumoto Sato- EP-USP 


\section{Agradecimentos}

Dedico este trabalho à minha mãe, Darci Furio Raphael, ao meu pai, George Luis Lasaro Raphael e ao meu irmão Luis Fellipe Furio Raphael, pessoas a quem devo tudo. Dedico-o também à minha companheira Ursula Virginia Coelho, que esteve comigo nos momentos mais difíceis. Sem vocês, nada disso seria possível. 


\section{Resumo}

Raphael, P. L. F. Escalonamento de Tarefas em Processadores de Velocidade Variável em Múltiplas Organizações. 2015. 120 f. Dissertação (Mestrado) - Instituto de Matemática e Estatística, Universidade de São Paulo, São Paulo, 2015.

Problemas de escalonamento cuja função objetivo é o consumo de energia tem sido cada vez mais estudados. Neste trabalho, estudamos o problema conhecido, em inglês, por Dynamic Speed Scaling, um problema de escalonamento de tarefas bem definidas em processadores de velocidade variável, cujo consumo de energia é função da velocidade. Além disso, relacionamos este problema com outro conhecido como MOSP, sigla em inglês para Multi-Organization Scheduling Problem. Neste, queremos escalonar tarefas de múltiplas organizações independentes respeitando certas restrições individuais. Provamos, neste trabalho, que este novo problema é NP-Completo e desenvolvemos várias heurísticas eficientes cujos testes experimentais mostram economia de energia significativa.

Palavras-chave: teoria do escalonamento; escalonamento em múltiplas organizações; minimização de energia; computação verde 


\section{Abstract}

Raphael, P. L. F. Energy-Aware Multi-Organization Scheduling Problem. 2015. 120

f. Dissertação (Mestrado) - Instituto de Matemática e Estatística, Universidade de São Paulo, São Paulo, 2015.

We studied, in this work, the problem of scheduling a set of well-defined tasks in a variable speed processor with the objective of minimizing the energy consumption, that is given as a function of the processor's speed, field known as Dynamic Speed Scaling. Also, we relate this problem to another known as MOSP (Multi-Organization Scheduling Problem), problem in which several independent organizations share tasks and resources to achieve a better global solution, but also respecting selfish restrictions. For the combined problem, we show that it is NP-Complete and designed several efficient heuristics that achieves good results in a experimental setup.

Keywords: scheduling theory, multi-organization scheduling; green computing 


\section{Sumário}

$\begin{array}{ll}\text { Lista de Figuras } & \text { ix }\end{array}$

Lista de Tabelas $\quad$ Xv

1 Introdução $\quad 1$

1.1 Objetivos e Contribuições . . . . . . . . . . . . . . . . . 2

1.2 Organização do Trabalho . . . . . . . . . . . . . . . . . . . 3

2 Escalonamento de Tarefas em Múltiplas Organizações 5

2.1 Definição e Notação . . . . . . . . . . . . . . . . . . . . . . 5

2.1.1 Restrições Locais e Egoístas . . . . . . . . . . . . . . . . . 6

2.2 Análise de Complexidade . . . . . . . . . . . . . . . . . . . . 7

2.2.1 Complexidade . . . . . . . . . . . . . . . . . 9 9

2.3 Heurísticas . . . . . . . . . . . . . . . . . . . . . . 12

2.3 .1 ILBA . . . . . . . . . . . . . . . . . . 12

2.3 .2 LPT-LPT . . . . . . . . . . . . . . . . . 15

2.4 Resultados Experimentais . . . . . . . . . . . . . . . . . 17

2.5 Conclusão . . . . . . . . . . . . . . . . . . . . . . . . . . . 17

3 Escalonamento em Processadores de Velocidade Variável 19

3.1 Definições e Análise . . . . . . . . . . . . . . . . . . . . . . 20

3.2 Algoritmo YDS . . . . . . . . . . . . . . . . . . . 23

3.3 Conclusão . . . . . . . . . . . . . . . . . . . . . . 25

4 Escalonamento em Processadores Paralelos de Velocidade Variável 27

4.1 Definição do Problema . . . . . . . . . . . . . . . . . . . 27

4.2 Análise . . . . . . . . . . . . . . . . . . . . . . . . . . . . . . . 29

4.2 .1 Tarefas com Intervalos Agradáveis . . . . . . . . . . . . . . . . . 32

4.3 Conclusão . . . . . . . . . . . . . . . . . . . . . . . . 33

5 Escalonamento em Organizações com Processadores de Velocidade Variável $\quad 35$

5.1 Definições . . . . . . . . . . . . . . . . . . . . . . 36 
5.2 Análise . . . . . . . . . . . . . . . . . . . . . 37

5.2.1 Impacto das Restrições Egoístas . . . . . . . . . . . . . . . . . . . . 37

5.2 .2 Benefícios da Cooperação . . . . . . . . . . . . . . . . . . . . . . . . . . . . . . . . . . . . . . . . . .

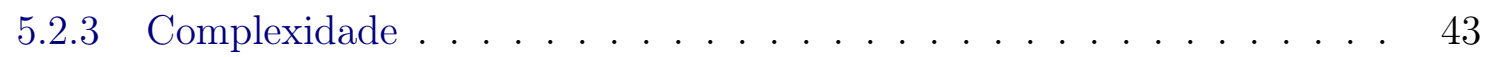

5.3 Heurísticas . . . . . . . . . . . . . . . . . . . . . . 45

5.3.1 Considerações Preliminares . . . . . . . . . . . . . . . . 46

5.3.2 Heurísticas para Duas Organizações . . . . . . . . . . . . . . . . 48

5.3 .3 Heurística para $m$ Organizações . . . . . . . . . . . . . . . . 52

5.3 .4 Resultados Experimentais . . . . . . . . . . . . . 53

5.4 Conclusão . . . . . . . . . . . . . . . . . . . 56

6 Conclusões $\quad 57$

6.1 Sugestões para Pesquisas Futuras . . . . . . . . . . . . . . . . . 58

$\begin{array}{ll}\text { Referências Bibliográficas } & 59\end{array}$ 


\section{Lista de Figuras}

2.1 Exemplo de instância do MOSP. Em (a), vemos a instância original. Temos $n$ organizações dadas por $O^{(1)}, \ldots, O^{(n)}$. $O^{(1)}$ tem duas tarefas de tamanho $N-1$, enquanto $O^{(k)}, 2 \leq k \leq n$, tem $N-1$ tarefas de tamanho 1 . Em (b), vemos a solução ótima, cujo makespan é $N$. Mas esta solução viola a restrição local de $O^{(2)}$. Em (c), vemos a melhor solução que respeita as restrições, com makespan igual a $\frac{3}{2}(N-1) \ldots \ldots \ldots \ldots \ldots \ldots$

2.2 Outro exemplo de instância do MOSP. Em (a), vemos a instância original, onde $O^{(1)}$ tem $N$ tarefas de tamanho $1, O^{(2)}, \ldots, O^{(n-1)}$ tem uma tarefa de tamanho $N-1$ cada e $O^{(n)}$ tem 2 tarefas de tamanho $N-1$. Em (b) vemos a solução ótima para $\mathrm{MOSP}^{(l)}$, com makespan $N$ (note que a restrição local de $O^{(1)}$ não foi violada neste caso). No entanto, a única solução para $\operatorname{MOSP}^{(s)}$ para esta instância é a configuração original dada em (a), com makespan $2(N-1) \ldots \ldots \ldots \ldots \ldots \ldots \ldots \ldots \ldots \ldots \ldots \ldots \ldots \ldots \ldots \ldots \ldots \ldots$

2.3 Exemplo de instância do MOSP a partir de uma instância do problema da 3-Partição, com $4 m$ organizações. As organizações $O^{(1)}, \ldots, O^{(3 m)}$ possuem duas tarefas dadas de tamanho $(m+1) B+11$ e $(m+1) a_{i}+3$. Já as organizações $O^{(3 m+1)}, \ldots, O^{(4 m)}$ tem duas tarefas unitárias cada. . . . . . . . . . . .

2.4 Exemplo de execução do ILBA para uma instância do MOSP com quatro organizações. Em (a), temos a instância inicial, com as organizações numeradas de acordo com $C_{\max }^{(k) \text { local }}$. Em (b), temos a execução da primeira iteração, que tenta balancear $O^{(2)}$. A heurística acha o primeiro instante de tempo em que $O^{(1)}$ ficará vazia e migra a primeira tarefa de $O^{(2)}$ ainda não iniciada para lá, atualizando $C_{\max }^{(1) \text { local }}$ e $C_{\max }^{(2) l o c a l}$. Como $C_{\max }^{(2) l o c a l}$ não é maior que $C_{\max }^{(1) \text { local }}$, ela para. Em (c), temos a execução para a organização $O^{(3)}$. Nesta iteração, duas tarefas conseguem ser migradas, uma para $O^{(1)}$ e outra para $O^{(2)}$. Em (d), temos a iteração para $O^{(4)}$, que migra uma tarefa para $O^{(1)}$ e outra para $O^{(2)}$. Em (e) temos a configuração final do escalonamento, com $C_{\max }=12$. . . . 
2.5 Exemplo de execução do LPT-LPT para uma instância do MOSP com quatro organizações. Em (a), temos a instância inicial, com as organizações numeradas de acordo com $C_{\max }^{(k) \text { local }}$. A instância encontra o primeiro instante de tempo em que uma organização ficará vazia e migra a maior tarefa considerando todas ainda não iniciadas para lá, como mostrado em (b), (c) e (d). Em (e) vemos o escalonamento final, com $C_{\max }=13 \ldots \ldots \ldots \ldots$

3.1 Exemplo de instância com $\mathcal{J}=\left\{J_{1}, \ldots, J_{5}\right\}$. Os números dentro dos retângulos indicam o volume de processamento das tarefas. A densidade de $\left[t, t^{\prime}\right)$ é dada por $\Delta_{\left[t, t^{\prime}\right)}=\frac{w_{1}+w_{2}+w_{3}+w_{4}}{\left|t^{\prime}-t\right|}=\frac{16}{8}=2$. Se a velocidade do processador for menor que 2 neste intervalo, alguma tarefa ficará incompleta. . . . . . . . . . . .

3.2 Outro exemplo de instância com $\mathcal{J}=\left\{J_{1}, \ldots, J_{5}\right\}$. A densidade do subintervalo $\left[t^{\prime \prime}, t^{\prime}\right)$ é maior que a densidade de $\left[t, t^{\prime}\right)$, logo, se a velocidade do processador for fixada em 2, não será possível terminar as tarefas de $\left[t^{\prime \prime}, t^{\prime}\right)$ no prazo. . .

3.3 Dois intervalos $I_{1}$ e $I_{2}$ e os respectivos volumes $W_{1}$ e $W_{2}$. Se a densidade de $I_{2}$ for maior que a densidade de $I_{1}$, qualquer escalonamento ótimo processará apenas as tarefas de $I_{2}$ neste intervalo, com velocidade igual a densidade de $I_{2}$. As tarefas de $I_{1}$ serão processadas em $I_{1}^{\prime}$, com velocidade menor que $\Delta_{I_{2}}$ (se a velocidade fosse maior, a densidade de $I_{1} \cup I_{2}$ seria maior que a de $I_{2}$, veja Lema 3.1.1). . . . . . . . . . . . . . . . . . . . .

3.4 Exemplo de instância com $\mathcal{J}=\left\{J_{1}, \ldots, J_{9}\right\}$. Em (a), temos a instância original, com o intervalo de densidade máxima ( $I_{*}^{1}$ em destaque. Em (b), temos a instância após a primeira iteração, isto é, após "retirar" o intervalo $I_{*}^{1}$ (e suas tarefas) de consideração. Feito isso, identificamos o novo intervalo de densidade máxima, dado por $I_{*}^{2}$. Note que, nesta segunda iteração, a tarefa $J_{7}$ está parcialmente contida no intervalo $I_{*}^{2}$. Ao escalonarmos as tarefas de $J_{I_{*}^{2}}$, $J_{7}$ tem seu prazo atualizado (como mostrado em (c)), já que nenhuma tarefa, a não ser as de $J_{I_{*}^{2}}$ podem ser executadas em $I_{*}^{2}$. O mesmo acontece com a tarefa $J_{2}$ em (c). Por fim, (d) mostra a instância quase em seu final, apenas com duas tarefas ainda a serem escalonadas. . . . . . . . . . . . . . . . .

4.1 Exemplo de instância do problema de escalonamento em $m$ processadores de velocidade variável. Nele temos $3 m$ tarefas, todas com tempo de chegada igual a $r$ e prazo igual a $d$. Os volumes de processamento estão especificados dentro dos retângulos e correspondem a um inteiro $a_{i}$ de uma instância do problema da 3-Partição. O escalonamento ótimo implicaria dividir as tarefas em $m$ subconjuntos distintos de 3 elementos cada, o que implica em resolver o problema da 3-Partição. . . . . . . . . . . . . . . . . . . . . 
4.2 Exemplo de instância do problema construído a partir do problema da 3Partição. Nele, temos $4 m$ tarefas unitárias. As primeiras $3 m$ tem intervalos disjuntos, com $r_{i}=\sum_{j<i} a_{j}$ e $d_{i}=r_{i}+a_{i}$, para uma tarefa $J_{i}$. As tarefas $J_{3 m+1}, \ldots, J_{4 m}$ tem $r_{i}=0$ e $d_{i}=3 d_{3 m} \ldots \ldots \ldots \ldots$

4.3 Exemplo de instância com tarefas que possuem intervalos agradáveis, isto é, para $J_{i}$ e $J_{j}, i \neq j$, se $r_{i} \leq r_{j}$, então $d_{i} \leq d_{j} \ldots \ldots \ldots \ldots$

4.4 Exemplo de escalonamento gerado pelo Algoritmo RR 4.2.1. Ele simplesmente ordena as tarefas segundo seus tempos de chegada (e prazos, em caso de empate) e aloca a tarefa $J_{i}$ para o processador $i \bmod m$. . . . . . . . .

5.1 Exemplo de instância do MOSP-Energy, com $m$ organizações. As organizações $O^{(k)}, 1 \leq k \leq m-1$, tem uma tarefa cada, de tamanho $\epsilon<1$. A organização $m$ tem $m$ tarefas de tamanho $w$ cada. Com as restrições egoístas, o único escalonamento possível é a própria instância original, mostrado em (a). Em (b), vemos o escalonamento ótimo caso não houvessem restrições egoístas. A razão entre o consumo de energia do escalonamento de (a) e (b) define quão pior as restrições egoístas podem deixar a solução. . . . . . . . . . . . . . . .

5.2 Exemplo de como a migração de uma tarefa entre organizações pode aumentar o consumo de energia da organização que a recebe. Em (a), temos uma instância com duas organizações, $O^{(1)}$ e $O^{(2)}$. A tarefa $J_{3}^{(1)}$ será migrada para $O^{(2)}$. Em (b), vemos o intervalo $\left[t, t^{\prime}\right)$ em destaque, com 3 tarefas de $O^{(2)}, J_{2}^{(2)}, J_{3}^{(2)} \mathrm{e}$ $J_{4}^{(2)}$ e a tarefa migrada de $O^{(1)}, J_{3}^{(1)}$. Como a tarefa $J_{3}^{(1)}$ aumenta a densidade do intervalo [t,t') de $O^{(2)}$, todas as tarefas de $O^{(2)}$ neste intervalo passam a requerer mais energia para serem executadas. . . . . . . . . . . . . . . .

5.3 Exemplo de instância em que a cooperação entre as organizações diminui o consumo de energia global sem violar as restrições egoístas. Temos $m$ organizações, $O^{(1)}, \ldots, O^{(m)}$, cada uma com $m$ tarefas de tamanho $w>1$. As tarefas de uma organização tem todas o mesmo intervalo de processamento, e estes intervalos são disjuntos entre as organizações. Em (a), temos a instância original. Em (b), temos o escalonamento ótimo para esta instância. Note que o escalonamento de (b) não viola as restrições egoístas de nenhuma organização. 41

5.4 Redução do problema MOSP-ENERGY a partir do problema da PARTiçÃo. .

5.5 Exemplo de aplicação do algoritmo YDS em um conjunto de tarefas como as que compõe o problema simplificado. Em (a) temos a instância inicial, com 10 tarefas unitárias, todas com tempo de chegada $r_{i}=0$. O intervalo $I_{1}=[0,6)$ em destaque é o intervalo de densidade máxima. Em (b), vemos as tarefas que não pertencem a $I$ com seus tempos de chegada ajustados. O algoritmo YDS para esta instância tem complexidade muito menor do que para uma instância genérica, já que determinar o intervalo de densidade máxima é muito mais fácil. 47 
5.6 Exemplo de instância do problema simplificado com 3 organizações. Para instâncias deste problema sempre consideraremos as organizações numeradas em ordem crescente de prazo máximo do conjunto de tarefas que a organização executará, denotado por $d_{\max }^{(k)}$. Em destaque, temos os intervalos de densidade máxima de $O^{(2)}$, denotados por $I_{1}^{(2)}$ e $I_{2}^{(2)}$. Note que não podemos migrar as tarefas de $I_{1}^{(2)}$, já que a intervalo de execução da tarefa migrada coincidiria com os intervalos de execução de tarefas da organização que a receber. Já para $I_{2}^{(2)}$, tarefas poderiam ser migradas para $O^{(1)}$, modificando o tempo de chegada da tarefa migrada para $d_{\max }^{(1)}$, garantindo assim que a restrição egoísta de $O^{(1)}$ não seja violada. . . . . . . . . . . . . . . . . . .

5.7 Exemplo de execução da heurística gulosa para uma instância do problema simplificado. Em (a), temos a instância inicial, com 2 organizações, $O^{(1)}$ e $O^{(2)}$. A heurística começa identificando o primeiro intervalo de densidade máxima de $O^{(2)}$, dado por $I_{1}^{(2)}$. Como ele não está na borda do escalonamento (i.e. a borda é vazia), suas tarefas são escalonadas em $O^{(2)}$ mesmo, como mostramos em (b). Em seguida, o próximo intervalo de densidade máxima $I_{2}^{(2)}$ é considerado. Para este intervalo, $O^{(1)}$ está na borda. A heurística tenta, então, migrar a maior tarefa de $I_{2}^{(2)}, J_{7}^{(2)}$ para $O^{(1)}$, ajustando seu tempo de chegada para $d_{\text {max }}^{(1)}$, como mostrado em (c). Como, no caso, o consumo de energia de $O^{(2)}$ é diminuído pela migração, a heurística tenta migrar a próxima maior tarefa, $J_{6}^{(2)}$, como mostramos em (d). A migração também é viável e a tarefa será executada em $O^{(1)}$. Nenhuma outra tarefa de $I_{2}^{(2)}$ pode ser migrada melhorando o consumo de energia, caso em que a heurística escalona as tarefas restantes em $O^{(2)}$ e para. 50

5.8 Exemplo de execução da heurística probabilística para uma instância do problema simplificado. Em (a), temos a instância inicial, com 2 organizações, $O^{(1)}$ e $O^{(2)}$. A heurística, a exemplo da gulosa, identifica os intervalos de densidade máxima de $O^{(2)}$ um a um e determina a borda para eles. Caso a borda seja vazia, como para $I_{1}^{(2)}$, nada é feito. Já para $I_{2}^{(2)}$, cuja borda é composta pela organização $O^{(1)}$, a heurística calcula as probabilidades das tarefas serem migradas baseadas no prazo que elas terão para serem executadas em $O^{(1)}$, como visto em (b). Determinadas as probabilidades, a heurística decide migrar ou não as tarefas. . . . . . . . . . . . . . . . . . . 
5.9 Exemplo de uma iteração da heurística para $m$ organizações. Neste exemplo, temos quatro organizações e estamos considerando a iteração que irá balancear $O^{(4)}$. Em (a), temos a instância no inicio da iteração. Note que algumas tarefas de $O^{(2)}$ e $O^{(3)}$ já foram migradas em iterações anteriores. A heurística começa determinando o primeiro intervalo de densidade máxima, $I_{1}^{(4)}$ e calcula a borda para este intervalo. Neste caso, a borda é vazia e as tarefas são escalonadas em $O^{(4)}$. A heurística passa, então, a considerar o segundo intervalo de densidade máxima, $I_{2}^{(4)}$. Para este intervalo, a borda é composta pelas 3 outras organizações e os valores de $d_{\max }^{(k)}$ são $d_{\max }^{(1)}=9, d_{\max }^{(2)}=10$ e $d_{\max }^{(3)}=$ 10. Neste momento, atribuímos valores a $d_{\text {max }}^{(1)}, d_{\text {max }}^{(2)}$ e $d_{\text {max }}^{(3)}$ iguais aos seus respectivos $d_{\max }^{(k)}$ e a heurística tenta migrar as tarefas de $I_{2}^{(4)}$ uma a uma, começando da maior, para a organização que tem o menor $d_{m a x}^{\prime(k)}$, atualizando este valor a medida que as tarefas são migradas, como mostrado em (b). Em (c), vemos o resultado final após a iteração acabar. . . . . . . . . . . . . . 54 


\section{Lista de Tabelas}

5.1 Resultados para duas organizações em relação a economia de energia total do sistema. Nós mostramos o desempenho das diferentes heurísticas quando comparadas a não ter nenhuma cooperação, para quantidades diferentes de tarefas por organização. . . . . . . . . . . . . . . . . . . 55

5.2 Resultados para $m=10$ e $m=20 \ldots \ldots \ldots \ldots$. . . . . . . . . . 55

5.3 Resultados experimentais para duas organizações no segundo cenário em relação a economia de energia total do sistema. . . . . . . . . . . . . . 56

5.4 Resultados experimentais para $m=10$ e $m=20$ organizações no segundo

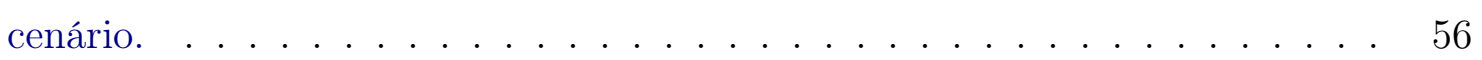


xvi LISTA DE TABELAS 


\section{Capítulo 1}

\section{Introdução}

Este trabalho apresenta um estudo de problemas de escalonamento de tarefas, que são, essencialmente, problemas de gerenciamento de recursos, em que as tarefas precisam ser executadas e queremos determinar qual a melhor maneira de fazê-las.

Os recursos, neste contexto, podem ser variados: máquinas em uma linha de produção, pistas de pouso em um aeroporto e funcionários em uma construção são exemplos. Nestes casos, as tarefas poderiam ser os produtos para as quais a linha de produção foi montada, os aviões que precisam pousar e as várias partes da construção que precisam ser finalizadas.

Estes problemas surgem porque há um interesse em otimizar o uso dos recursos segundo algum critério de desempenho. Nos exemplos dados acima esta otimização poderia ser a minimização do tempo em que os produtos demoram para serem produzidos pelas máquinas, a minimização do tempo de espera dos aviões para pousar e a minimização do número de operários necessários para completar a construção. É fácil perceber a importância do estudo destes problemas para os vários setores industriais e comerciais da sociedade.

O problema estudado neste trabalho combina características de outros dois problemas de escalonamento. Falaremos de cada um separadamente. O primeiro diz respeito à otimização de uma nova função objetivo, o consumo de energia para execução de tarefas computacionais, especificadas por tempo de chegada e prazo, em um modelo em que o recurso (que chamaremos de processador) gasta energia baseado na velocidade com a qual executa as tarefas. A medida que os processadores dos computadores ficam cada vez mais velozes e gastam cada vez mais energia, o desenvolvimento de modelos que relacionam estes dois parâmetros ganham cada vez mais importância. O impacto do desenvolvimento de algoritmos de escalonamento é ainda maior no contexto de aglomerados ${ }^{1}$ de computadores. Este problema é conhecido na literatura pelo termo em inglês Dynamic Speed Scaling, nome relacionado à possibilidade de mudar a velocidade na qual o processador opera em qualquer instante de tempo durante a execução das tarefas.

O outro problema que compõe a base deste trabalho diz respeito à cooperação entre organizações no momento de escalonar suas tarefas. Chamamos de organização qualquer

\footnotetext{
${ }^{1}$ clusters
} 
entidade que esteja interessada em resolver um problema de escalonamento interno. Estas entidades são comuns na prática. Em ambientes computacionais, onde a troca de tarefas ${ }^{2}$ é viável, organizações deste tipo poderiam estar interessadas em se juntar umas as outras, formando um sistema integrado. Neste sistema, os recursos de todas elas seriam compartilhados para melhorar ainda mais a eficiência com que suas tarefas são processadas. Considerar recursos de várias organizações independentes adiciona uma complexidade extra no estudo de problemas de escalonamento. Este problema é conhecido na literatura pela sigla, em inglês, MOSP (Multi-Organization Scheduling Problem).

A combinação dos dois problemas citados formam o problema central estudado neste trabalho: o escalonamento de tarefas entre organizações que estão interessadas em cooperar entre si para economizar energia através do gerenciamento de seus processadores, que podem ter sua velocidade alterada para processar as tarefas com maior eficiência. Nas próxima seções detalharemos os objetivos, contribuições e discutiremos como o trabalho está organizado.

\subsection{Objetivos e Contribuições}

Neste trabalho estudamos um novo problema de escalonamento que combina características de dois outros existentes na literatura: o Problema de Escalonamento em Processadores de Velocidade Variável (Dynamic Speed Scaling Problem) e o Problema de Escalonamento em Múltiplas Organizações (Multi-Organization Scheduling Problem, ou MOSP). Desta forma, podemos enumerar os objetivos da seguinte maneira:

(i) estudar detalhadamente a literatura sobre o Problema de Escalonamento em Processadores de Velocidade Variável;

(ii) estudar detalhadamente a literatura sobre o Problema de Escalonamento em Múltiplas Organizações;

(iii) elaborar e estudar o problema combinado, que chamamos de Problema de Escalonamento em Múltiplas Organizações com Processadores de Velocidade Variável;

(iv) fazer experimentos práticos para comprovar que soluções para este novo problema seriam úteis e gerariam benefícios se implementadas;

Os estudos apresentados neste trabalho resultaram, em conjunto com Daniel de Angelis Cordeiro e Johanne Cohen, na publicação de um artigo cientifico na conferencia europeia chamada Euro-Par 2014, realizada em Porto, Portugal:

- Cohen, Johanne, Daniel Cordeiro, and Pedro Luis F. Raphael. "Energy-Aware MultiOrganization Scheduling Problem."Euro-Par 2014 Parallel Processing. Springer International Publishing, 2014. 186-197.

\footnotetext{
${ }^{2}$ Através de redes de computadores, por exemplo.
} 


\subsection{Organização do Trabalho}

Este trabalho está organizado em 6 capítulos, incluindo este capítulo introdutório e o capítulo final onde apresentamos as conclusões do trabalho. Apresentaremos a seguir um breve resumo dos capítulos intermediários.

O Capítulo 2 apresentamos o Problema de Escalonamento em Múltiplas Organizações, como estudado em Cohen et al. (2010). Nele, definimos o problema formalmente e provamos que este é um problema NP-Completo. Em seguida, mostramos algumas heurísticas que encontram boas soluções para ambientes tipicamente encontrados na prática.

No Capítulo 3 mudamos o foco para o Problema de Escalonamento em Processadores de Velocidade Variável. Este problema foi primeiro proposto em Yao et al. (1995). Mostramos que, para o problema com apenas um processador de velocidade variável, existe um algoritmo polinomial conhecido como YDS que encontra um escalonamento cujo consumo de energia é mínimo. Provamos este fato teórico e descrevemos o algoritmo.

No Capítulo 4 estudamos o Problema de Escalonamento em Processadores de Velocidade Variável para o caso em que há vários processadores para executar as tarefas. Provamos que, neste cenário, o problema é NP-Completo mesmo se restrições forem impostas nas características das tarefas. Apesar disso, mostramos que para um caso especial onde o conjunto de tarefas obedecem uma propriedade específica existe um algoritmo que resolve o problema em tempo polinomial. Estes três capítulos formam a base para o estudo do problema combinado de escalonamento entre múltiplas organizações cujo objetivo é economizar energia.

O estudo deste problema é tratado no Capítulo 5. Nele, apresentamos o modelo que combina escalonamento entre múltiplas organizações com o modelo de escalonamento para minimização de energia. Mostramos que a economia de energia neste modelo pode ser proporcional ao número de organizações que aderirem ao sistema e, também, que este problema também é NP-Completo. Propomos novas heurísticas para uma variante simplificada do problema que atingem bons resultados práticos. Validados estes resultados através de uma série de experimentos com cargas de trabalho (i.e. workloads) gerados aleatoriamente de acordo com distribuições que modelam bem o uso de clusters atualmente.

Finalmente, apresentamos no Capítulo 6, a conclusão dos resultados atingidos bem como sugestões de pesquisas futuras. 


\section{Capítulo 2}

\section{Escalonamento de Tarefas em Múltiplas Organizações}

Neste capítulo falaremos sobre o Problema de Escalonamento de Tarefas em Múltiplas Organizações (também conhecido em inglês por Multi-Organization scheduling problem (MOSP)). Este é um problema de escalonamento entre várias organizações, entidades que possuem tanto recursos computacionais quanto tarefas, e querem executar suas tarefas otimizando seus recursos.

Neste modelo, as organizações são incentivadas a cooperar para atingir um melhor desempenho global. Há, no entanto, restrições no conjunto de escalonamentos viáveis, já que as organizações possuem restrições egoístas, isto é, podem decidir não cooperar se algum objetivo local piorar em relação ao que ela poderia fazer sozinha.

Os estudos sobre o problema começaram com Pascual et al. (2007). Nesse artigo, os autores consideram o problema de escalonar tarefas paralelas produzidas por várias organizações. Como os autores mostram, este problema é uma extensão do problema clássico de escalonamento de tarefas paralelas, que é NP-Difícil (Michael e David (1979)). Independentemente disso, os autores mostram que a cooperação entre as organizações pode trazer benefícios e desenvolvem algoritmos de aproximação para o problema.

Nas próximas seções definiremos o problema formalmente e exporemos alguns dos principais resultados na área.

\subsection{Definição e Notação}

Nesta seção, exporemos o problema como estudado em Cohen et al. (2010). Nesse artigo, os autores estudam o problema de escalonar tarefas de várias organizações que possuem um cluster de máquinas idênticas, considerando dois objetivos, o tempo de término da última tarefa (comumente chamado de makespan) e o tempo médio de término. Neste trabalho exporemos apenas os resultados para o makespan. Este modelo considera que as tarefas são sequenciais, isto é, utilizam apenas uma máquina por um determinado período de tempo. 
Formalmente, considere $N$ organizações, denotadas por $O^{(1)}, \ldots, O^{(N)}$, que fazem parte de um sistema que as permitem migrar tarefas, i.e. delegar a execução de tarefas para outras organizações. Cada organização possui $m^{(k)}$ maquinas idênticas e $n^{(k)}$ tarefas que precisam ser executas, sendo $n=\sum_{k} n^{(k)}$ o total de tarefas do sistema.

Cada tarefa $J_{i}^{(k)}$ é especificada pelo tempo necessário para a tarefa ser completamente executada em uma máquina, denotado por $p_{i}^{(k)}$. Informalmente, nos referiremos ao tempo necessário para execução como o tamanho da tarefa considerada. A maior tarefa da organização $k$ será denotada por $p_{\max }^{(k)}$. A preempção de tarefas não é permitida, isto é, assim que uma tarefa começa a ser executada ela ocupará a máquina por $p_{i}^{(k)}$ unidades de tempo.

O instante de tempo em que a tarefa $J_{i}^{(k)}$ terminar de executar será denotado por $C_{i}^{(k)}$. Definiremos o makespan associado a uma organização $O^{(k)} \operatorname{como}_{m a x}^{(k)}=\max _{1 \leq i \leq n^{k}} C_{i}^{(k)}$, isto é, o instante de tempo em que a última tarefa de $O^{(k)}$ terminar de ser executada, independente da organização que a executar. ${ }^{1}$ O makespan global do sistema é dado pelo maior makespan considerando todas as organizações, e será denotado por $C_{\max }$.

\subsubsection{Restrições Locais e Egoístas}

O problema de escalonar tarefas de múltiplas organizações inclui um conjunto de restrições locais. Informalmente, cada organização não pode ter sua função objetivo piorada em relação ao que ela poderia fazer sozinha, caso deixasse o sistema.

Formalmente, denotaremos por $C_{m a x}^{(k) l o c a l}$ o makespan de $O^{(k)}$ caso ela estivesse sozinha e não pudesse migrar nem receber tarefas. Deste modo, podemos definir o problema MOSP como:

$$
\text { minimizar } C_{\max } \text { sujeito a } C_{\max }^{(k)} \leq C_{\max }^{(k) l o c a l}, \forall 1 \leq k \leq N \text {. }
$$

Além destas restrições locais, o problema pode conter também o que definiremos como restrições egoistas. Estas restrições foram criadas para garantir que uma organização não possa burlar o escalonamento recebido, repriorizando suas tarefas em detrimento de tarefas estrangeiras (isto é, originarias de outras organizações). Definiremos estas restrições formalmente a seguir.

Considere uma tarefa $J_{i}^{(l)}$, isto é, a i-ésima tarefa de uma organização $O^{(l)}$. Suponha que esta tarefa seja escalonada em $O^{(k)}$. Nenhum escalonamento será considerado viável se $J_{i}^{(l)}$ começar a executar antes do que qualquer tarefa de $O^{(k)}$. Note que esta restrição é independente da organização que possa ter recebido uma tarefa de $O^{(k)}$, apenas no tempo em que esta tarefa será iniciada comparada com uma tarefa estrangeira que foi escalonada em $O^{(k)}$. Formalmente, podemos definir as restrições egoístas da seguinte forma:

Restrições Egoístas Considere que existe uma tarefa $J_{i}^{(l)}$ originalmente de $O^{(l)}$ que foi

\footnotetext{
${ }^{1}$ Este fato também implica que o makespan de uma organização não aumenta se ela receber tarefas de outras e as executar depois de todas as suas.
} 
migrada para $O^{(k)}$. A restrição egoísta de $O^{(k)}$ é dada por

$$
C_{i}^{(l)}-p_{i}^{(l)} \geq C_{j}^{(k)}-p_{j}^{(k)}, \forall j, 1 \leq j \leq n^{(k)}
$$

para qualquer tarefa $J_{i}^{(l)}, 1 \leq l \leq N, l \neq k$ que for migrada para $O^{(k)}$.

Neste modelo, nenhum escalonamento que viola a restrição egoísta de alguma organização é considerado viável. Mostraremos, na seção seguinte, como a estas restrições impactam a qualidade das soluções possíveis e analisaremos a complexidade do problema.

\subsection{Análise de Complexidade}

Começaremos analisando como as restrições definidas na seção anterior impactam a solução. Nesta seção, nos referiremos a vários tipos de MOSP, caracterizados por possuírem ou não cada uma das restrições. Sendo assim, chamaremos de $\operatorname{MOSP}^{(*)}$ o problema de escalonamento sem as restrições adicionais, tanto locais quanto egoístas, de $\operatorname{MOSP}^{(l)}$ o problema com as restrições locais e de $\operatorname{MOSP}^{(s)}$ o problema com as restrições egoístas.

Consideraremos primeiro a relação entre $\operatorname{MOSP}^{(*)}$ e o $\operatorname{MOSP}^{(l)}$. Pascual et al. (2007) mostrou, através de um exemplo que detalharemos a seguir que a relação entre as soluções do $\operatorname{MOSP}^{(*)}$ e do $\operatorname{MOSP}^{(l)}$, para tarefas paralelas, é de pelo menos $\frac{3}{2}$. Mostraremos que esta relação também vale para o caso de tarefas sequencias.

Considere uma instância do $\operatorname{MOSP}^{(*)}$, com um número arbitrário $n \geq 2$ de organizações e considere que $O^{(1)}$ possui 2 tarefas de tamanho $N$, enquanto todas as outras $O^{(2)}, \ldots, O^{(n)}$ organizações possuem $N$ tarefas cada, todas de tamanho um, como está ilustrado na Fig. 2.1(a). Nesta configuração, uma solução válida para $\operatorname{MOSP}^{(*)}$ é a dada na Fig. 2.1(b). Nela, dividimos as tarefas de $O^{(2)}$ dando uma para cada organização (inclusive a própria $O^{(2)}$ ) e no lugar colocamos uma das tarefas de tamanho $N$ de $O^{(1)}$. Esta solução tem makespan $N+1$. Note, no entanto, que esta solução não respeita a restrição local de $O^{(2)}$, pois aumenta seu makespan de $N$ (Fig. 2.1(a)) para $N+1$ (Fig. 2.1(b)). A figura 1(c) ilustra a solução ótima que respeita as restrições locais. Migramos metade das tarefas de $O^{(2)}$ para $O^{(1)}$ e uma das tarefas grandes de $O^{(1)}$ para $O^{(2)}$, fazendo o makespan global diminuir para $\frac{3}{2} N$.

Este exemplo mostra que, no pior caso, uma solução para $\operatorname{MOSP}^{(l)}$ é pelo menos $\frac{3}{2}$ pior do que a solução para o $\operatorname{MOSP}^{(*)}$, considerando a mesma instância.

Consideraremos agora a relação entre o problema $\operatorname{MOSP}^{(*)}$ e o problema $\operatorname{MOSP}^{(s)}$. Mostraremos que esta restrição é mais forte que a restrição local, impactando ainda mais a qualidade das soluções possíveis.

Considere a mesma instância já exemplificada anteriormente. Mostraremos que, para esta instância, a única solução possível para $\operatorname{MOSP}^{(s)}$ é duas vezes pior que a solução para $\operatorname{MOSP}^{(*)}$. Esta solução é representada pela própria Fig. 2.1(a), que representa a instância original, ou seja, não é possível migrar nenhuma tarefa sem violar as restrições egoístas neste caso. A solução na Fig. 2.1(c) viola a restrição egoísta de $O^{(1)}$. 

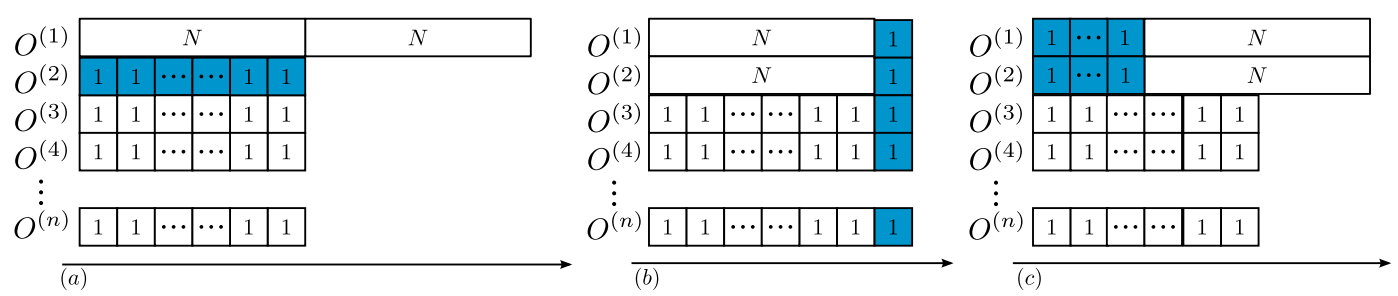

Figura 2.1: Exemplo de instância do MOSP. Em (a), vemos a instância original. Temos $n$ organizações dadas por $O^{(1)}, \ldots, O^{(n)}$. $O^{(1)}$ tem duas tarefas de tamanho $N-1$, enquanto $O^{(k)}, 2 \leq$ $k \leq n$, tem $N-1$ tarefas de tamanho 1 . Em (b), vemos a solução ótima, cujo makespan é $N$. Mas esta solução viola a restrição local de $O^{(2)}$. Em (c), vemos a melhor solução que respeita as restrições, com makespan igual a $\frac{3}{2}(N-1)$.

Este exemplo expõe um fato importante sobre o problema, forçado pelas restrições egoístas: nenhuma organização receberá tarefas de outras antes de terminar todas as suas completamente. Considere a Fig. 2.1. É fácil ver que o fato acima é verdade. Qualquer tarefa executada antes de todas as outras de $O^{(3)}$, por exemplo, violará a restrição egoísta de $O^{(3)}$. O primeiro momento em que uma tarefa pode ser migrada é quando todas as tarefas de uma organização acabarem de ser executadas. Isso sugere que o problema é equivalente à problemas de distribuição de carga.

Agora mostraremos como as restrições egoístas impactam a solução em relação ao problema com as restrições locais. Usaremos um exemplo, ilustrado pela Figura 2.2. Considere, novamente, uma instância com número arbitrário de organizações $n \geq 2$. Nesta exemplo, $O^{(1)}$ tem $N$ tarefas de tamanho um, enquanto $O^{(2)}, \ldots, O^{(n-1)}$ tem uma tarefa de tamanho $N-1$ e $O^{(n)}$ tem duas tarefas de tamanho $N-1$. Para o problema $\operatorname{MOSP}^{(l)}$, a solução ótima tem makespan $N$, como ilustrado em Fig. 2.2(b). Já em $\operatorname{MOSP}^{(s)}$, a única solução possível tem makespan $2 N-2$. A solução da Fig. 2.2(b) viola a restrição egoísta de $O^{(1)}$. Este exemplo mostra que a relação entre a solução para $\operatorname{MOSP}^{(l)} \operatorname{e~} \operatorname{MOSP}^{(s)}$ é de pelo menos $2-\frac{2}{N}$.

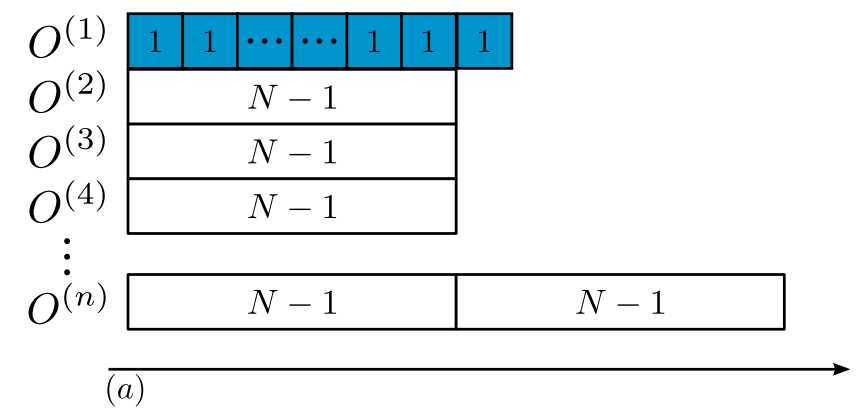

Figura 2.2: Outro exemplo de instância do MOSP. Em (a), vemos a instância original, onde $O^{(1)}$ tem $N$ tarefas de tamanho $1, O^{(2)}, \ldots, O^{(n-1)}$ tem uma tarefa de tamanho $N-1$ cada e $O^{(n)}$ tem 2 tarefas de tamanho $N-1$. Em (b) vemos a solução ótima para $\operatorname{MOSP}^{(l)}$, com makespan $N$ (note que a restrição local de $O^{(1)}$ não foi violada neste caso). No entanto, a única solução para $\operatorname{MOSP}^{(s)}$ para esta instância é a configuração original dada em (a), com makespan $2(N-1)$.

Nesta seção, mostramos como as restrições locais e egoístas impactam na solução para o MOSP de maneira significativa. Vimos que a restrição egoísta é mais forte que a local, de 
modo que nenhum algoritmo para o $\operatorname{MOSP}^{(s)}$ consegue dar uma garantia de que as soluções encontradas serão melhores do que 2 vezes as soluções para o $\mathrm{MOSP}^{(*)}$. Na próxima seção, mostraremos que o problema é NP-Completo.

\subsubsection{Complexidade}

Analisaremos, agora, a complexidade do problema. Provaremos que o problema de decisão do MOSP é NP-Completo. Para isso, definiremos o problema de decisão:

Instância: Um conjunto de $N$ organizações, cada uma com $n^{(k)}$ tarefas e $m^{(k)}$ máquinas e um inteiro $K$.

Questão: Existe um escalonamento em que o makespan global é menor ou igual a $K$ ?

A prova da NP-completude do problema é baseada em uma redução do problema da 3-Partição (Michael e David (1979)). Este problema é definido da seguinte forma:

Instância: Um inteiro $B \in \mathbb{Z}^{+}$e um conjunto de inteiros $A$, com $3 m$ elementos, $m \in \mathbb{Z}^{+}$, com cada $a_{i} \in A$ estritamente entre $\frac{B}{4}$ e $\frac{B}{2}$.

Questão: Existe uma partição de $A$ em $m$ subconjuntos disjuntos $\left\{A_{1}, \ldots, A_{m}\right\}$ de exatamente 3 elementos cada, tal que a soma dos elementos de $A_{i}$ é igual a $B$, para todo $A_{i}$ ?

Provaremos o seguinte teorema:

Teorema 2.2.1 (Cohen et al. (2011)) O problema de decisão MOSP $\left(C_{\text {max }}\right.$ ) é fortemente NP-Completo.

Prova É fácil ver que MOSP $\left(C_{\max }\right)$ está em $N P$. Construiremos, agora, uma instância do MOSP a partir de uma instância do problema da 3-Partição.

Considere uma instância do problema da 3-Partição, com $3 m$ elementos dados por $a_{1}, \ldots, a_{3 m}$. A instância correspondente do MOSP terá $4 m$ organizações ao todo, todas com duas tarefas cada. As tarefas das $3 m$ primeiras organizações serão dadas por $J_{1}^{(k)}$ de tamanho $(m+1) B+11$ e $J_{2}^{(k)}$ de tamanho $(m+1) a_{i}+3\left(a_{i}\right.$ é um inteiro do conjunto $A$ do problema da 3-Partição). As tarefas de $O^{(3 m+1)}$ até $O^{(4 m)}$ serão tarefas unitárias. Um exemplo desta instância é dado na Figura 2.3. Esta instância do MOSP pode ser construída em tempo polinomial dada um instância do problema da 3-Partição. Definiremos o inteiro $K$ como sendo $(m+1) B+11$.

Vamos agora mostrar que existe uma partição dos inteiros de $A$ em $m$ subconjuntos disjuntos, todos de soma $B$ se e somente se existe um escalonamento para o MOSP com makespan $(m+1) B+11$. Em outras palavras, se conseguirmos uma solução com este makespan para o MOSP, conseguiríamos também uma solução para o problema da 3-Partição, e viceversa.

Começaremos assumindo que existe uma partição de $A$ em $m$ subconjuntos, $\left\{A_{i}, \ldots, A_{m}\right\}$ todos de soma $B$, cada $A_{i}$ composto por 3 inteiros, $a_{i 1}, a_{i 2}$ e $a_{i 3}$. Poderíamos escalonar as tarefas do MOSP da seguinte maneira: todas as tarefas de tamanho $(m+1) B+11$ e todas as tarefas unitárias seriam escalonadas em suas próprias organizações. Já as tarefas de tamanho 


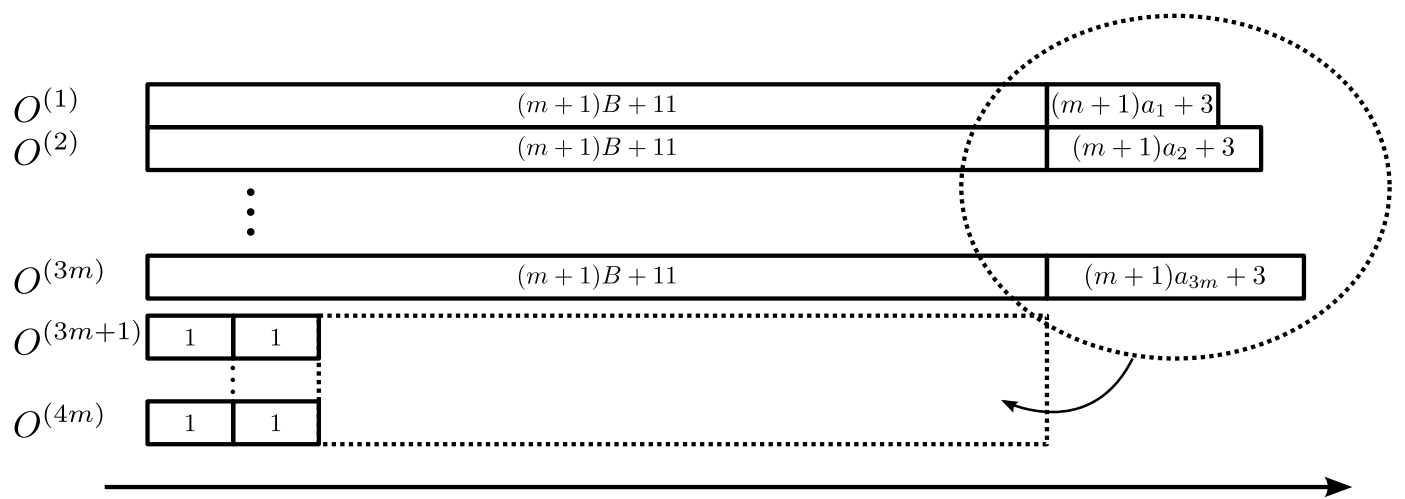

Figura 2.3: Exemplo de instância do MOSP a partir de uma instância do problema da 3-Partição, com $4 m$ organizações. As organizações $O^{(1)}, \ldots, O^{(3 m)}$ possuem duas tarefas dadas de tamanho $(m+1) B+11 e(m+1) a_{i}+3$. Já as organizações $O^{(3 m+1)}, \ldots, O^{(4 m)}$ tem duas tarefas unitárias cada.

$(m+1) a_{i}+3$ seriam migradas para uma organização $O^{(3 m+j)}$ se $a_{i} \in A_{j}, 1 \leq j \leq m$. A Figura 4(b) ilustra esta ideia.

É fácil ver que esta solução é ótima para o MOSP. As organizações $O^{(k)}, 1 \leq k \leq$ $3 m$ executam uma tarefa até o momento $(m+1) B+11$, enquanto as organizações $O^{(k)}$, $3 m+1 \leq k \leq 4 m$ executam 5 tarefas cada, sendo elas as duas unitárias que pertencem a elas mesmas e outras 3 tarefas migradas, que juntas tem tempo de execução igual a $\sum_{i}(m+1) a_{i}+3=(m+1) B+9$. Somadas, as 5 tarefas acabam de ser executadas exatamente no momento $(m+1) B+11$, de modo que o makespan global é igual a $(m+1) B+11$. Além disso, as restrições egoístas do MOSP são respeitadas, já que as organizações que recebem as tarefas só as executam após terminarem as suas.

Falta, agora, mostrar que se existe uma solução para esta instância do MOSP com makespan $(m+1) B+11$ então existe uma partição de $A$ em $m$ subconjuntos de exatamente 3 elementos, todos de soma $B$.

Considere então que existe tal solução. O tempo total necessário para executar todas as tarefas é dado por:

$$
\begin{gathered}
T=3 m((m+1) B+11)+\sum_{i=1}^{3 m}\left((m+1) a_{i}+3\right)+2 m \\
T=3 m((m+1) B+11)+(m+1) \sum_{i=1}^{3 m} a_{i}+\sum_{i=1}^{3 m} 3+2 m \\
T=3 m((m+1) B+11)+(m+1) m B+9 m+2 m \\
T=3 m((m+1) B+11)+(m+1) m B+11 m \\
T=3 m((m+1) B+11)+m((m+1) B+11)
\end{gathered}
$$




$$
T=4 m((m+1) B+11)
$$

Como temos $4 m$ organizações, isto mostra que uma solução com makespan $(m+1) B+11$ é uma solução ótima.

Pelas características da instância que descrevemos do MOSP, nesta solução ótima $3 m$ organizações vão executar apenas uma tarefa de tamanho $(m+1) B+11$. Vamos mostrar a seguir que cada uma das outras $k$ organizações, $3 m+1 \leq k \leq 4 m$ vão obrigatoriamente executar cinco tarefas cada uma, isto é, as duas tarefas unitárias mais três tarefas que foram migradas de outras organizações.

Primeiro, note que cada $O^{(k)}$ executará as suas duas tarefas unitárias, já que migrá-las violaria alguma restrição egoísta. Vamos então mostrar que cada $O^{(k)}$ executará exatamente três tarefas de tamanho diferente de um.

Assuma que este fato é falso e que alguma organização executará menos do que três tarefas não unitárias. Então, alguma outra organização executará mais do que três tarefas. Vamos considerar o makespan desta organização e sem perda de generalidade vamos considerar que esta organização executará quatro tarefas (e a que executará menos, duas). O makespan será dado por:

$$
C_{\text {max }}^{(k)}=2+\sum_{i=1}^{4}(m+1) a_{i}+3,
$$

para algum subconjunto de quatro elementos de $A$. Como cada $a_{i}>\frac{B}{4}$, temos:

$$
\begin{gathered}
C_{\max }^{(k)}>2+4\left((m+1) \frac{B}{4}+3\right) \\
C_{\max }^{(k)}>2+(m+1) B+12
\end{gathered}
$$

Mas isto contradiz o fato da solução ser ótima e prova que cada organização $O^{(k)}$ executará exatamente três tarefas não unitárias.

Construiremos, agora, a solução do problema da 3-Partição a partir desta solução do MOSP. Cada um dos $m$ subconjuntos $A_{i}$ serão compostos por três elementos da seguinte forma: se a tarefa de tamanho $(m+1) a_{i}+3$ for executada por $O^{(k)}$, então $a_{i} \in A_{k}, 1 \leq k \leq m$. Como cada organização $O^{(k)}$ tem makespan igual a $(m+1) B+11$, temos que:

$$
\begin{gathered}
C_{\max }^{(k)}=2+\sum_{a_{i} \in A_{i}}(m+1) a_{i}+3 \\
(m+1) B+11=2+\sum_{a_{i} \in A_{i}}\left((m+1) a_{i}+3\right) \\
(m+1) B=\sum_{a_{i} \in A_{i}}(m+1) a_{i}
\end{gathered}
$$




$$
B=\sum_{a_{i} \in A_{i}} a_{i}
$$

Ou seja, todos os subconjuntos $A_{i}$ tem exatamente três elementos cuja soma é $B$. Isto conclui a prova.

\subsection{Heurísticas}

Nesta seção, discutiremos duas heurísticas para o MOSP, chamadas ILBA (sigla em inglês para "Iterative Load-Balancing Algorithm") e LPT-LPT (LPT também é uma sigla em inglês para "Longest Processing Time First"). Estas duas heurísticas tentam balancear a carga de trabalho das organizações usando estratégias diferentes. Veremos que as duas heurísticas encontram boas soluções na prática.

\subsubsection{ILBA}

A primeira heurística que discutiremos é conhecida pela sigla ILBA ("Iterative LoadBalancing Algorithm", em inglês, Algoritmo Iterativo de Balanceamento de Carga). A ideia da heurística é balancear a carga de trabalho das organizações uma a uma, começando da menos carregada para a mais carregada.

A heurística começa numerando as organizações em ordem crescente de $C_{\text {max }}^{\text {local }}$ e as considera uma a uma, tentando balanceá-las migrando suas tarefas para as organizações

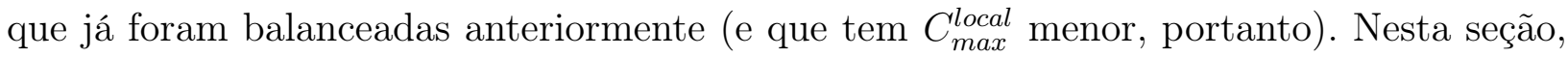
chamaremos de $C_{m a x}^{(k) l o c a l}$ o tempo de término do conjunto de tarefas que forem executadas em $O^{(k)}$, considerando tanto tarefas locais quanto estrangeiras. Esta notação simplificará a explicação.

Começaremos considerando o caso em que cada organização só possui uma máquina. Formalmente, considere o MOSP com $N$ organizações. O ILBA irá considerar as organizações em ordem crescente de $C_{\text {max }}^{\text {local }}$, isto é, $O^{(1)}$ será a organização com menor $C_{\text {max }}^{\text {local }}$, seguida de $O^{(2)}$ e assim por diante. Como o ILBA tenta migrar as tarefas da organização em questão

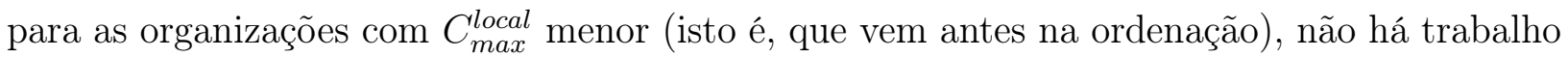
a ser feito para $O^{(1)}$. Começando, então, pela organização $O^{(2)}$, considere que $t$ é o primeiro instante de tempo em que $O^{(1)}$ ficará sem tarefas para executar. Neste momento, o algoritmo migra a próxima tarefa ainda não iniciada de $O^{(2)}$ para $O^{(1)}$. Este processo diminui $C_{\max }^{(2) l o c a l} \mathrm{e}$ aumenta $C_{\max }^{(1) \text { local }}$. Após repetir este processo de migração até que $C_{\max }^{(2) \text { local }}$ seja menor que $C_{\max }^{(1) \text { local }}$, o algoritmo termina a iteração e começa a considerar a próxima organização $\left(O^{(3)}\right.$, neste exemplo). Note que para encontrar $t$, basta manter a lista de $C_{\max }^{(i) \text { local }}, 1 \leq i \leq k-1$, ordenada. De fato, como precisamos apenas do menor $C_{\max }^{(i) l o c a l}$, basta manter este valores em uma fila de prioridade.

Vamos, então, descrever a heurística para uma iteração $k$. Nesta iteração, a heurística 
tentará migrar tarefas de $O^{(k)}$ para as organizações $O^{(1)}, \ldots, O^{(k-1)}$ da mesma maneira que foi descrita acima. Seja $C_{\max }^{(i) l o c a l}$ o instante de tempo em que $O^{(i)}, 1 \leq i \leq k-1$, ficará livre e suponha que $C_{\max }^{(i) l o c a l}$ é o minimo entre todos os $C_{\text {max }}^{\text {local }}$ das organizações $1, \ldots, k-1$. O algoritmo migrará a primeira tarefa de $O^{(k)}$ ainda não iniciada para $O^{(i)}$ e atualizará $C_{\max }^{(i) l o c a l}$. Este processo também diminui $C_{\max }^{(k) \text { local }}$. Nesta iteração, este processo (escolher o menor $C_{\max }^{(i) \text { local }}, 1 \leq i \leq k-1$ e migrar a primeira tarefa ainda nao iniciada de $O^{(k)}$ para $O^{(i)}$ ) se repetirá até que $C_{\max }^{(k) \text { local }}$ não seja maior do que $C_{\max }^{(i) l o c a l}$, para todo $1 \leq i \leq k-1$. Neste momento, a heurística termina a iteração e passa a considerar a organização $k+1$. Este processo está exemplificado na Fig. 2.4. O pseudocódigo abaixo descreve o funcionamento do ILBA. Vamos considerar que as organizações já escalonaram suas tarefas localmente no início da execução do ILBA.

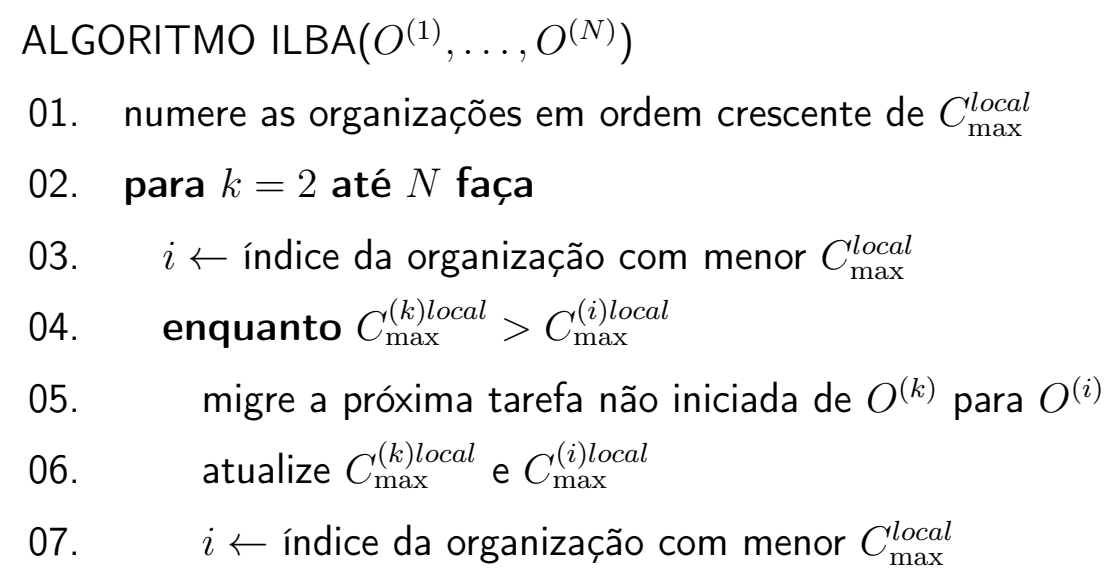

Vamos analisar a complexidade desta heurística. A linha 1 cria, de fato, uma fila de prioridade crescente com as organizações, baseada em $C_{\max }^{(k) \text { local }}$. A linha 3 executa em $O(1)$. A linha 5 também leva $O(1)$ para executar, já que sabemos o tamanho da tarefa sendo migrada, enquanto a linha 6 atualiza a fila de prioridade, em $O(\lg N)$. Falta, agora, verificar quantas vezes os laços das linhas 2 e 4 executam. O laço da linha 2 é trivial, sendo executado $O(N)$ vezes. Considere, agora, o laço da linha 4 . No pior caso, ele será executado $n^{(k)}$ vezes. Este é o caso em que todas as tarefas de $O^{(k)}$ são unitárias e $O^{(1)}, \ldots, O^{(k-1)}$ não tem nenhuma tarefa. Em cada iteração deste laço, uma tarefa é migrada e $C_{\max }^{(k) l o c a l}$ diminui em 1. Desta maneira, podemos concluir que o ILBA leva tempo proporcional a $O\left(N n^{(k)} \lg N\right)$.

Feita a análise de complexidade vamos, agora, estender este algoritmo para o caso genérico do MOSP, isto é, quando cada organização possui um número arbitrário de máquinas. Basta, ao invés de manter uma fila de prioridade com o $C_{\max }^{(k) l o c a l}$ das organizações já consideradas, manter um fila de prioridade com o makespan de cada máquina individual. Deste modo, para migrar uma tarefa de $O^{(k)}$ para outra organização, basta olharmos para a fila de prioridade para saber qual máquina (ao invés de qual organização) deve receber a tarefa. A complexidade, neste caso, fica $\left(N n^{(k)} \lg m^{(k)}\right)$.

Note que a heurística não viola nenhuma restrição egoísta, já que todas as tarefas migradas tem sua execução iniciada em um tempo menor do que teriam em suas organizações originais. 

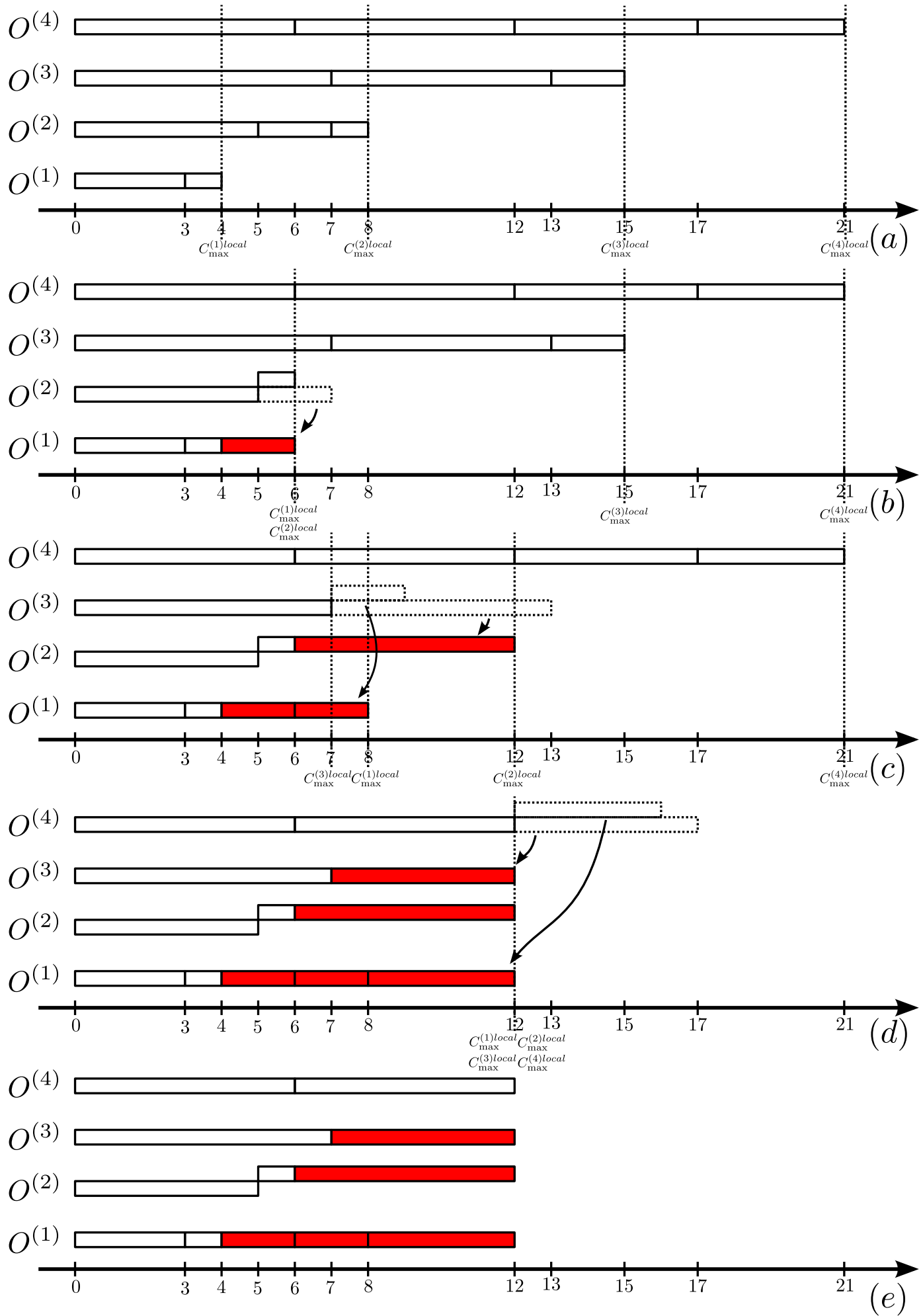

Figura 2.4: Exemplo de execução do ILBA para uma instância do MOSP com quatro organizações. Em (a), temos a instância inicial, com as organizações numeradas de acordo com $C_{\max }^{(k) l o c a l}$. Em (b), temos a execução da primeira iteração, que tenta balancear $O^{(2)}$. A heurística acha o primeiro instante de tempo em que $O^{(1)}$ ficará vazia e migra a primeira tarefa de $O^{(2)}$ ainda não iniciada para lá, atualizando $C_{\max }^{(1) \text { local }}$ e $C_{\max }^{(2) \text { local }}$. Como $C_{\max }^{(2) \text { local }}$ não é maior que $C_{\max }^{(1) \text { local }}$, ela para. Em (c), temos a execução para a organização $O^{(3)}$. Nesta iteração, duas tarefas conseguem ser migradas, uma para $O^{(1)}$ e outra para $O^{(2)}$. Em (d), temos a iteração para $O^{(4)}$, que migra uma tarefa para $O^{(1)}$ e outra para $O^{(2)}$. Em (e) temos a configuração final do escalonamento, com $C_{\max }=12$. 


\subsubsection{LPT-LPT}

Consideraremos, também, uma heurística para o MOSP conhecida como LPT-LPT. LPT é a sigla em inglês para Longest Processing Time, isto é, Tempo de Processamento Maximal. Em Teoria do Escalonamento, a estratégia LPT significa que a maior tarefa ainda não iniciada será alocada ao recurso que ficar disponível. Para o MOSP, esta heurística usará este mesmo conceito, em duas fases.

Na primeira fase, as organizações escalonam suas tarefas localmente, usando a estratégia LPT. Esta estratégia minimiza o makespan local (Graham (1969)). A segunda fase, que é a de maior interesse para este trabalho, é a fase em que tarefas são migradas para melhorar o makespan global. Ela começa no momento em que a primeira organização fica sem tarefas para executar. Neste momento, a maior tarefa (considerando todas as organizações) é migrada para esta organização. A Figura 2.5 mostra o funcionamento desta heurística para uma instância do problema.

O pseudocódigo a seguir descreve o funcionamento da heurística. Novamente, consideramos que as organizações já realizaram seus escalonamentos locais (primeira fase da heurística) no início da execução. Consideramos, também, que ao realizar a primeira fase, a heurística guarda o tempo de início das tarefas.

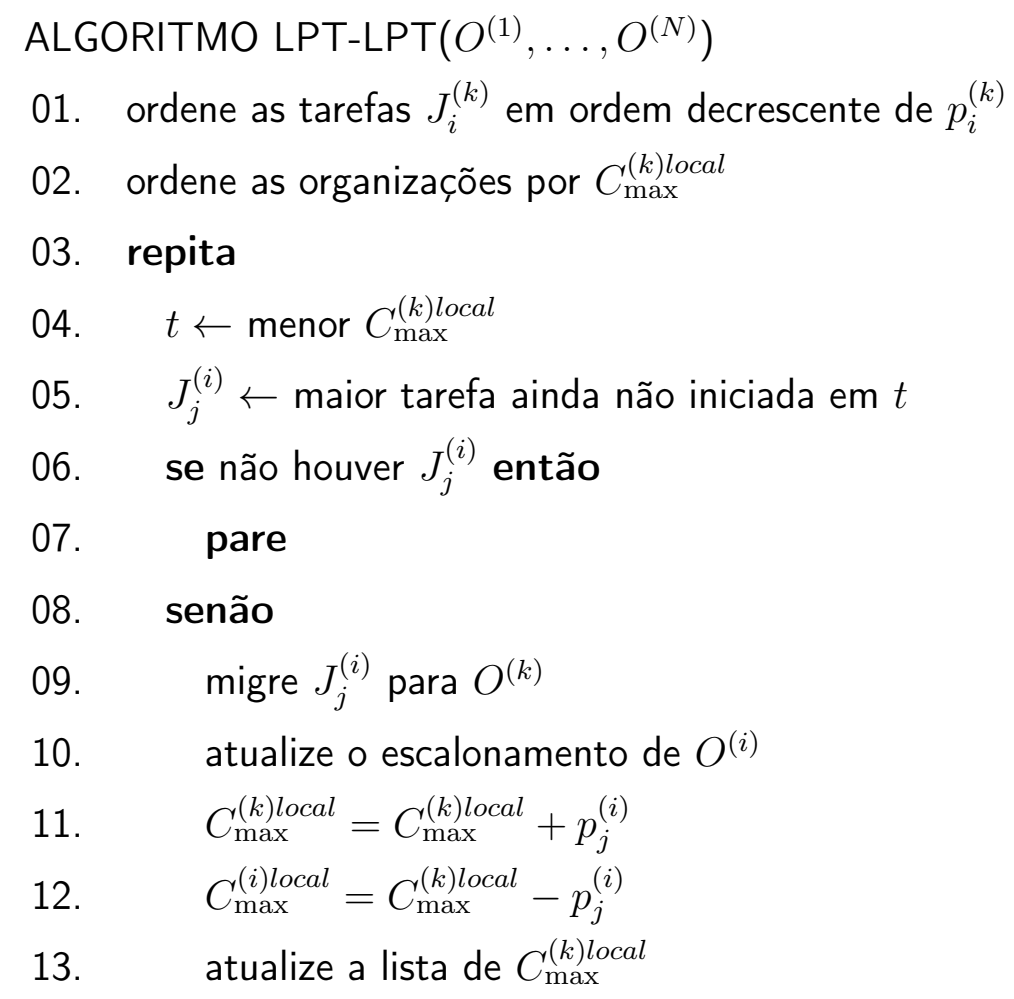

Vamos determinar a complexidade deste algoritmo. A linha 1 ordena todas as tarefas de todas as organizações, tendo complexidade $O(n \lg n)$. A linha 2 cria uma fila de prioridade com os valores de $C_{\max }^{(k) l o c a l}$, logo sua complexidade é $O(N \lg N)$. A linha 4 executa em $O(1)$, dada a natureza da fila de prioridade criada na linha 2. A linha 5 percorre a lista de tarefas, que está ordenada da maior para a menor, e para quando encontra a primeira tarefa cujo 

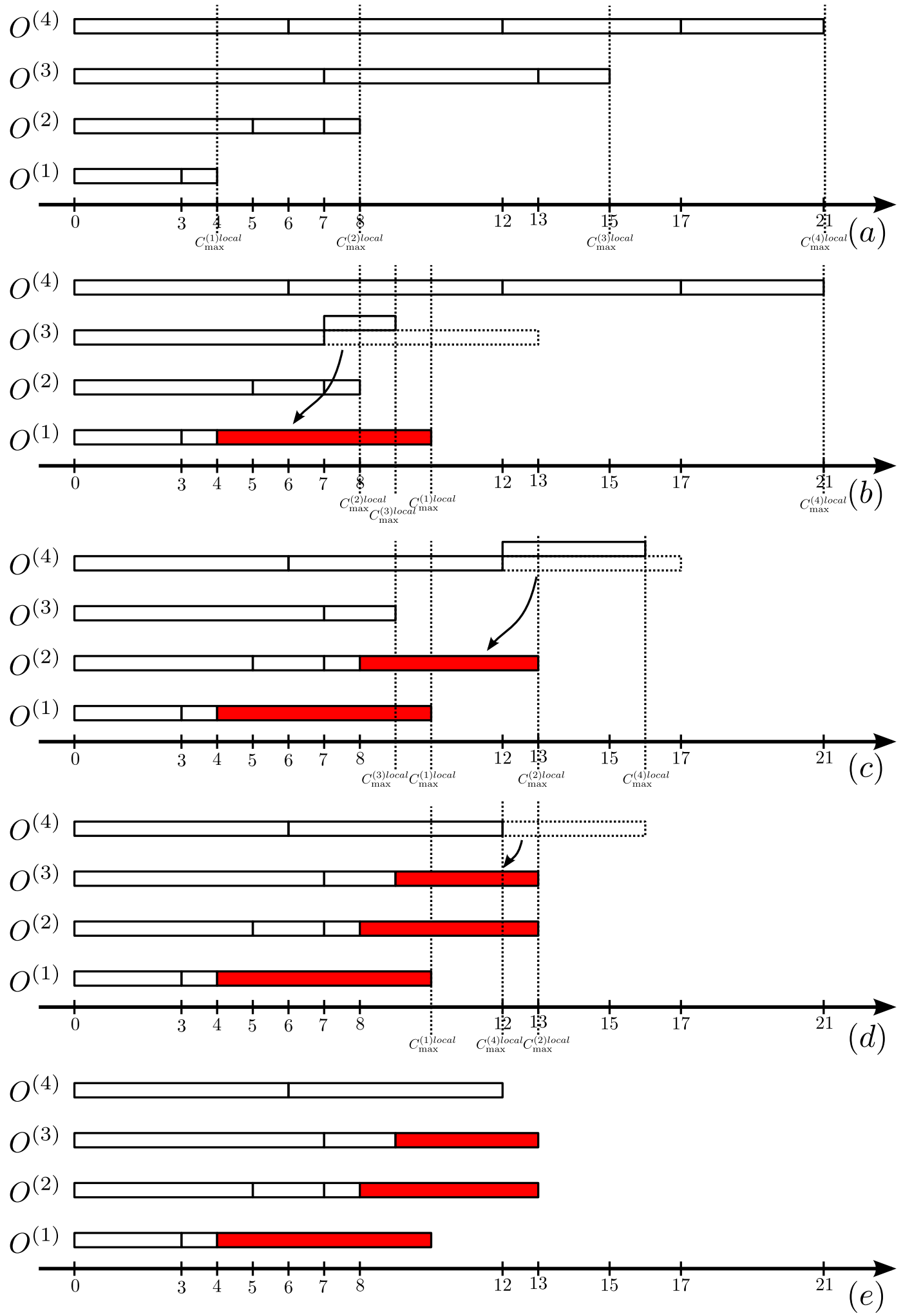

Figura 2.5: Exemplo de execução do LPT-LPT para uma instância do MOSP com quatro organizaçôes. Em (a), temos a instância inicial, com as organizaçôes numeradas de acordo com $C_{\max }^{(k) l o c a l}$. A instância encontra o primeiro instante de tempo em que uma organização ficará vazia e migra a maior tarefa considerando todas ainda não iniciadas para lá, como mostrado em (b), (c) e (d). Em (e) vemos o escalonamento final, com $C_{\max }=13$. 
tempo de execução é maior que $t$, executando, no máximo, $O(n)$ operações. As linhas 9,11 e 12 executam em $O(1)$. A linha 10 percorre as tarefas de $O^{(i)}$ atualizando o tempo em que elas começaram, executando no máximo $O\left(n^{(i)}\right)$ operações. Finalmente, a linha 13 atualiza a fila de prioridade em $O(\lg N)$. Deste modo, podemos concluir que a complexidade deste algoritmo é $O(n \lg n)$.

Note que esta heurística também não viola nenhuma restrição egoísta, já que ela, também, ao migrar uma tarefa, faz com que ela tenha o tempo de início da execução diminuído. Além disso, as organizações que vão receber as tarefas já estão sem tarefas próprias para executar.

\subsection{Resultados Experimentais}

Nesta seção exporemos brevemente os resultados experimentais descritos em Cohen et al. (2010). No artigo, os autores realizaram uma série de experimentos para determinar o quão boas seriam as soluções obtidas pelas heurísticas ILBA e LPT-LPT em relação à solução ótima para cargas de trabalho ${ }^{2}$ aleatórias geradas a partir de distribuições que modelam bem o uso de clusters tipicamente encontrados em organizações.

Em relação ao makespan global, os autores concluíram que tanto o ILBA quanto o LPT-LPT atingem resultados muito próximos ao ótimo, com o LPT-LPT ligeiramente melhor.

Para avaliar a melhora percebida por cada organização, a soma dos makespans de cada organização foi considerada. Neste critério, o ILBA conseguiu os melhores resultados e a diferença entre seu desempenho e o desempenho do LPT-LPT, de fato, fica maior a medida que o número de organizações e o número de tarefas cresce.

\subsection{Conclusão}

Neste capítulo estudamos o problema de escalonamento em múltiplas organizações com o objetivo de melhorar o makespan global, respeitando as restrições egoístas, como descrito em Cohen et al. (2010).

Mostramos que as restrições egoístas impedem que qualquer algoritmo dê uma garantia melhor do que dois em relação a solução que poderia ser obtida para o problema sem restrições e que o problema é NP-Completo.

Em seguida, duas heurísticas para o problema, chamadas de ILBA (Iterative Load Balancing Algorithm) e LPT-LPT foram descritas e analisadas. Como mostrado pelos autores em Cohen et al. (2010) através de experimentos, ambas atingem resultados próximos do ótimo na prática.

Nos próximos capítulos mudaremos o foco e estudaremos o Problema de Escalonamento em Processadores de Velocidade Variável, um problema de escalonamento que tem como

\footnotetext{
${ }^{2}$ workloads
} 
função objetivo a minimização do consumo de energia. Estes dois problemas formaram a base para o estudo apresentado no Capítulo 5. 


\section{Capítulo 3}

\section{Escalonamento em Processadores de Velocidade Variável}

Neste capítulo, discutiremos um modelo que relaciona escalonamento de tarefas com o conceito de energia. Neste modelo, o processador $^{1}$ possui uma velocidade de execução $s \in[0,+\infty)$, que pode ser modificada a qualquer momento. Esta é a velocidade na qual o processador executará as tarefas (que, por sua vez, terão um volume de processamento, explicado adiante). A esta velocidade, está associada uma função potência $P(s)=s^{\alpha}, \alpha>1$ uma constante, que por sua vez está associada a uma função energia, $E(P)=\int P(s(t)) d t$. Esta nova função, a qual nos referiremos como o consumo de energia, será a função objetivo do escalonamento.

As tarefas a serem executadas por este processador também são especificadas de maneira diferente em relação ao capítulo anterior. Neste modelo, as tarefas possuem tempo de chegada $\left(r_{i}\right)$, o tempo em que a tarefa fica disponível para ser processada, prazo, $\left(d_{i}\right)$, ou deadline, o instante de tempo em que a tarefa deve, necessariamente, ter sido executada por completo, e volume de processamento $\left(w_{i}\right)$, isto é, quanto trabalho é necessário ser processado para considerar a tarefa feita, fato que esta intimamente ligado à velocidade de processamento ${ }^{2}$.

Encontrar um escalonamento para este problema significa encontrar uma ordenação das tarefas a serem executadas (respeitando os tempos de chegada e prazos) juntamente com a velocidade a todo instante (respeitando o volume de processamento), de maneira que o consumo de energia seja o menor possível.

Este problema foi primeiro proposto em Yao et al. (1995). Na época, havia a necessidade de maximizar o tempo em que computadores portáteis poderiam ser usados com uma bateria limitada. Além disso, em estudos da mesma época Chandrakasan et al. (1992) mostravam que o consumo de energia poderia ser consideravelmente reduzido através da alteração da voltagem em que os dispositivos operavam, fato que também altera a velocidade em que estes dispositivos operavam. Desta maneira, nasceu a área que ficou conhecida, em inglês, por

\footnotetext{
${ }^{1}$ Correspondente à máquina do capitulo anterior.

${ }^{2}$ Se o processador executa uma tarefa de volume $w$ com velocidade $s$, terá que executar a tarefa por $\frac{w}{s}$ unidades de tempo para processá-la por completo.
} 


\section{Dynamic Speed Scaling.}

Problemas de Dynamic Speed Scaling geralmente são estudados em duas variantes: offline e online. Estas variantes dizem respeito ao conhecimento prévio, ou não, por parte do escalonador, das características das tarefas. Se o problema for offline, uma instância corresponde a um conjunto de tarefas cujas características são conhecidas, enquanto que se for online, as tarefas só se tornam conhecidas pelo escalonador no momento em que elas podem ser executadas, isto é, $r_{i}$.

Neste trabalho, focaremos no estudo do problema offline, cujos resultados e algoritmos usaremos nos capítulos posteriores. Nas próximas seções, definiremos o problema e apresentaremos os principais resultados conhecidos na área.

\subsection{Definições e Análise}

Neste capítulo, definiremos o problema proposto em Yao et al. (1995). Neste problema estamos interessados em escalonar $n$ tarefas, especificadas por $r_{i}, d_{i}$ e $w_{i}$, tempo de chegada, prazo e volume de processamento, respectivamente, em um processador de velocidade variável. Denotaremos pela letra $\mathcal{J}$ o conjunto das tarefas $J_{1}, \ldots, J_{n}$, de tamanho $n$.

O escalonador pode modificar a velocidade do processador a qualquer instante de tempo, para valores no intervalo contínuo $[0,+\infty)$. Se a velocidade no instante $t$ for $s(t), P(s(t))$ corresponde a potência naquele instante, e é dada por $P(s(t))=s(t)^{\alpha}$, para alguma constante $\alpha>1$. Finalmente, o consumo de energia do escalonamento é dado pela integral temporal de $P(s(t))$,

$$
\int_{t_{0}}^{t_{1}} P(s(t)) d t,
$$

$\left[t_{0}, t_{1}\right)$ sendo o intervalo de tempo em que as tarefas de $\mathcal{J}$ devem ser executadas.

A execução das tarefas pode ser intermitente (preemptive, em inglês), isto é, uma tarefa pode ter seu processamento interrompido e reiniciado posteriormente sem perda de trabalho. Para um escalonamento ser realizável, todas as tarefas devem ser processadas por completo, fato que impõe um limitante inferior na velocidade do processador.

Dito isto, partiremos para a caracterização da solução ótima para este problema. Começaremos definindo a noção de densidade de um intervalo de tempo, que nada mais é do que a soma dos volumes de processamento das tarefas contidas neste intervalo, dividido pelo tamanho do intervalo.

Densidade A densidade de um intervalo de tempo $I=\left[t, t^{\prime}\right)$ é dada por

$$
\Delta_{I}=\frac{\sum_{J \in J_{I}} w_{i}}{t^{\prime}-t}
$$

onde $J_{I}$ é o conjunto de tarefas de $\mathcal{J}$ inteiramente contidas no intervalo $I$. 


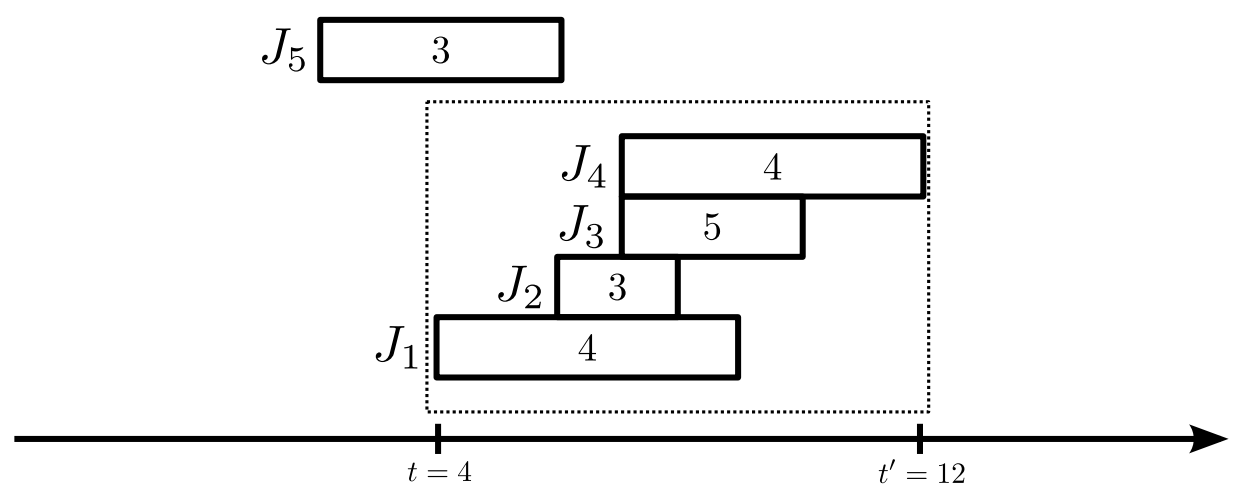

Figura 3.1: Exemplo de instância com $\mathcal{J}=\left\{J_{1}, \ldots, J_{5}\right\}$. Os números dentro dos retângulos indicam o volume de processamento das tarefas. A densidade de $\left[t, t^{\prime}\right)$ é dada por $\Delta_{\left[t, t^{\prime}\right)}=\frac{w_{1}+w_{2}+w_{3}+w_{4}}{\left|t^{\prime}-t\right|}=$ $\frac{16}{8}=2$. Se a velocidade do processador for menor que 2 neste intervalo, alguma tarefa ficará incompleta.

Considere um intervalo de tempo $I=\left[t, t^{\prime}\right) \subseteq\left[t_{0}, t_{1}\right)$, com $\left(t^{\prime} \geq t\right)$, de modo que $t=r_{i}$ para alguma tarefa $J_{i}$ e $t^{\prime}=d_{j}$, para alguma tarefa $J_{j}$, como mostrado na Figura 3.1. Claramente, a densidade deste intervalo é um limitante inferior para a velocidade do processador no mesmo intervalo, já que, se a velocidade for menor, alguma tarefa não seria processada por completo.

Note que esta velocidade é suficiente para realizar todo o "trabalho" das tarefas contidas neste intervalo, o que não necessariamente implica que é possível executar todas as tarefas por completo em seus respectivos prazos, como mostra a Figura 3.2. Nela, existe um subintervalo de densidade maior, isto é, a velocidade para executar todas as tarefas contidas neste subintervalo deve ser maior. Definiremos, então, o conceito de intervalo de densidade máxima.

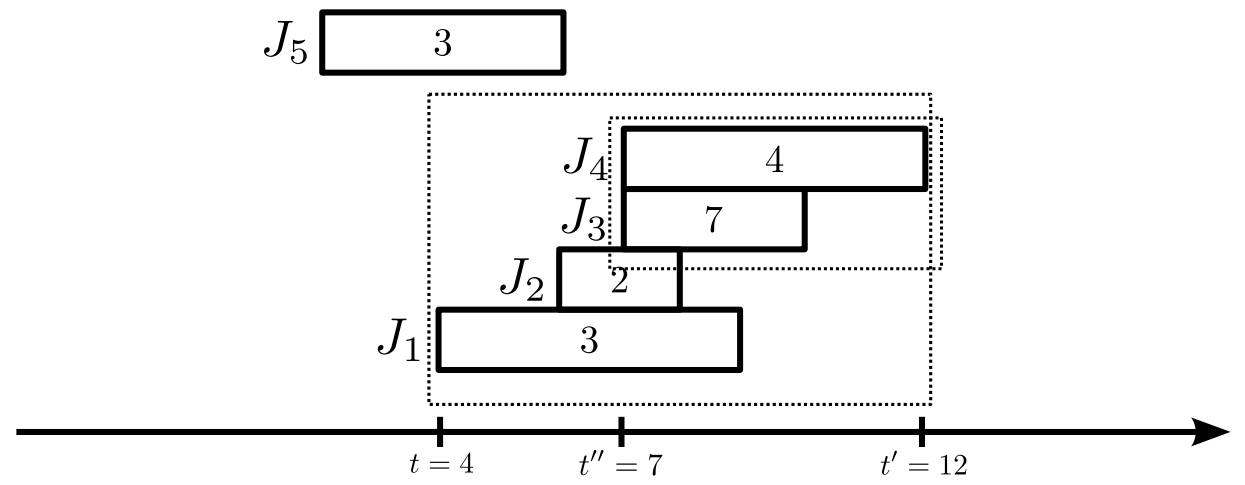

Figura 3.2: Outro exemplo de instância com $\mathcal{J}=\left\{J_{1}, \ldots, J_{5}\right\}$. A densidade do subintervalo $\left[t^{\prime \prime}, t^{\prime}\right)$ é maior que a densidade de $\left[t, t^{\prime}\right)$, logo, se a velocidade do processador for fixada em 2 , não será possivel terminar as tarefas de $\left[t^{\prime \prime}, t^{\prime}\right)$ no prazo.

Intervalo de Densidade Máxima Chamaremos de intervalo de densidade máxima, e o denotaremos por $I_{*}=\left[t, t^{\prime}\right)$, o intervalo de tempo de maior densidade dentro todos os intervalos possíveis.

Claramente, a velocidade mínima para executar as tarefas de $J_{I_{*}}$ é $\Delta_{I_{*}}$, já que uma velocidade menor não terminaria todas as tarefas de $J_{I_{*}}$ em $I_{*}$. Além disso, pela definição de 
intervalo de densidade máxima, não existe nenhum subintervalo dentro dele com densidade maior. Isto significa que, se o processador tiver sua velocidade fixada em $\Delta_{I_{*}}$ durante todo este intervalo, todas as tarefas poderão ser executadas respeitando seus prazos.

Agora, iremos argumentar que em qualquer escalonamento ótimo, $\Delta_{I_{*}}$ é a velocidade máxima e que esta velocidade deve ser usada por todo o intervalo $I_{*}$.

Considere a Figura 3.3. Nela, temos dois intervalos, $I_{1}$ e $I_{2}$, com volumes de processamento $W_{1}$ e $W_{2}$, respectivamente. Suponha que $I_{2}$ é o intervalo de densidade máxima, isto é, $W_{2}>W_{1}$. Note que se o processador executar somente as tarefas de $J_{I_{2}}$ durante $I_{2}$, teremos que executar as tarefas de $J_{I_{1}}$ em um intervalo menor, já que a intersecção dos dois não é vazia. Considere que este intervalo menor é dado por $I_{1}^{\prime}=\left[t_{1}, t_{2}\right)$. Primeiro, provaremos que a velocidade (dada por $\Delta_{I_{1}^{\prime}}$ ) em $I_{1}^{\prime}$ será menor que $\Delta_{I_{2}}$ em $I_{2}$.

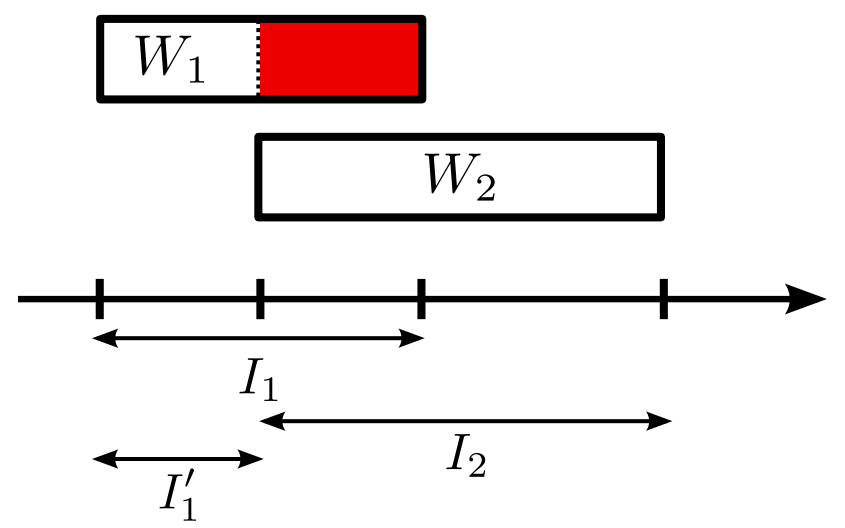

Figura 3.3: Dois intervalos $I_{1}$ e $I_{2}$ e os respectivos volumes $W_{1}$ e $W_{2}$. Se a densidade de $I_{2}$ for maior que a densidade de $I_{1}$, qualquer escalonamento ótimo processará apenas as tarefas de $I_{2}$ neste intervalo, com velocidade igual a densidade de $I_{2}$. As tarefas de $I_{1}$ serão processadas em $I_{1}^{\prime}$, com velocidade menor que $\Delta_{I_{2}}$ (se a velocidade fosse maior, a densidade de $I_{1} \cup I_{2}$ seria maior que a de $I_{2}$, veja Lema 3.1.1).

Lema 3.1.1 Se $\frac{W_{1}}{\left|I_{1}^{\prime}\right|}>\frac{W_{2}}{\left|I_{2}\right|}$ então $\frac{W_{1}+W_{2}}{\left|I_{1}^{\prime}\right|+\left|I_{2}\right|}>\frac{W_{2}}{\left|I_{2}\right|}$.

Prova Provaremos por absurdo. Suponha que $\Delta_{I_{1}^{\prime}}$ seja maior que $\Delta_{I_{2}}$ e

$$
\frac{W_{1}+W_{2}}{\left|I_{1}^{\prime}\right|+\left|I_{2}\right|} \leq \frac{W_{2}}{\left|I_{2}\right|}
$$

Então, temos,

$$
\begin{gathered}
W_{1}+W_{2} \leq \frac{W_{2}\left(\left|I_{1}^{\prime}\right|+\left|I_{2}\right|\right)}{\left|I_{2}\right|} \\
W_{1}+W_{2} \leq \frac{W_{2}\left|I_{1}^{\prime}\right|}{\left|I_{2}\right|}+\frac{W_{2}\left|I_{2}\right|}{\left|I_{2}\right|} \\
W_{1}+W_{2} \leq \frac{W_{2}\left|I_{1}^{\prime}\right|}{\left|I_{2}\right|}+W_{2} \\
W_{1} \leq \frac{W_{2}\left|I_{1}^{\prime}\right|}{\left|I_{2}\right|}
\end{gathered}
$$




$$
\frac{W_{1}}{\left|I_{1}^{\prime}\right|} \leq \frac{W_{2}}{\left|I_{2}\right|}
$$

Mas esta ultima inequação contradiz o fato de $\Delta_{I_{1}^{\prime}}$ ser maior que $\Delta_{I_{2}}$.

O que este lema efetivamente prova é que, se $\frac{W_{1}}{\left|I_{1}^{\mid}\right|}$for maior que $\frac{W_{2}}{\left|I_{2}\right|}$, então a densidade do intervalo $I_{1} \cup I_{2}$ é maior que a densidade de $I_{2}$. Isto significa que se $I_{*}$ é um intervalo de densidade máxima, $\Delta_{I_{*}}$ será a maior velocidade de execução de todo o escalonamento.

Já argumentamos que $\Delta_{I_{*}}$ é a velocidade mínima que o processador pode assumir em $I_{*}$ para executar todas as tarefas de $J_{I_{*}}$. Agora, mostraremos que se ele assumir uma velocidade maior neste intervalo, o consumo de energia do escalonamento será maior.

Isto vem do fato da função potência ser convexa. Considere a Figura 3.3 novamente. Se a velocidade em $I_{2}$ for maior que $\Delta_{I_{2}}$, teremos mais tempo para executar as tarefas de $J_{I_{1}}$, isto é, o intervalo $I_{1}^{\prime}$ aumentaria, e a velocidade $\Delta_{I_{1}^{\prime}}$ poderia diminuir. Seja $s_{2}=\Delta_{I_{2}}, s_{1}=\Delta_{I_{1}^{\prime}}$, $s_{2}^{\prime}>s_{2}$ a velocidade maior que o processador poderia assumir no intervalo $I_{2}$ e $s_{1}^{\prime}<s_{1}$ a velocidade menor que o processador poderia assumir em $I_{1}^{\prime \prime}$ (intervalo de tempo maior que $I_{1}^{\prime}$, já que as tarefas de $I_{2}$ precisam de menos tempo para executar. Mas, pela convexidade da função potência, temos que

$$
P\left(s_{2}\right)+P\left(s_{1}\right)<P\left(s_{2}^{\prime}\right)+P\left(s_{1}^{\prime}\right)
$$

Este fato, junto com o lema 3.1, mostra que em qualquer escalonamento ótimo, a velocidade durante o intervalo de densidade máxima é sempre a mesma, $\Delta_{I_{*}}$.

Teorema 3.1.2 Em toda solução ótima para o problema de escalonar $n$ tarefas especificadas por $r_{i}, d_{i}$ e $w_{i}$ em um processador de velocidade variável, a velocidade máxima é dada por $\Delta_{I_{*}}$, onde $I_{*}$ é o intervalo de densidade máxima e $\Delta_{I_{*}}$ é a soma das densidades das tarefas inteiramente contidas em $I_{*}$ dividido por $\left|I_{*}\right|$.

Este resultado sugere um algoritmo para calcular o escalonamento ótimo, que apresentaremos na próxima seção.

\subsection{Algoritmo YDS}

O teorema 3.1.2 sugere uma estratégia gulosa para encontrar um escalonamento ótimo iterativamente. Basta, a cada iteração, identificar o intervalo de densidade máxima $I_{*}$ bem como as tarefas $\mathcal{J}_{I_{*}}$ e processá-las com velocidade $\Delta_{I_{*}}$. Feito isso, removemos o intervalo $I_{*}$ de consideração, isto é, nenhuma outra tarefa será executada naquele intervalo. Caso alguma tarefa tenha seu intervalo de execução parcialmente dentro do intervalo de densidade máxima, seu tempo de chegada ou prazo são ajustados, isto é, modificados para coincidir com o limite do intervalo a qual intersectam.

O pseudocódigo abaixo descreve o algoritmo: 
$\operatorname{ALGORITMO~YDS}\left(\mathcal{J}=\left\{J_{1}, \ldots, J_{n}\right\}\right)$

01. enquanto $\mathcal{J} \neq \emptyset$ faça

02. $I_{*}, \Delta_{I_{*}}, J_{I_{*}} \leftarrow$ intervalo de densidade máxima, a densidade e o conjunto de tarefas do intervalo

03. execute as tarefas de $J_{I_{*}}$ com velocidade $\Delta_{I_{*}}$ em $I_{*}$ segundo a política $E D F^{3}$

04. $\mathcal{J}=\mathcal{J} \backslash J_{I_{*}}$

05. remova o intervalo $I_{*}$ de consideração

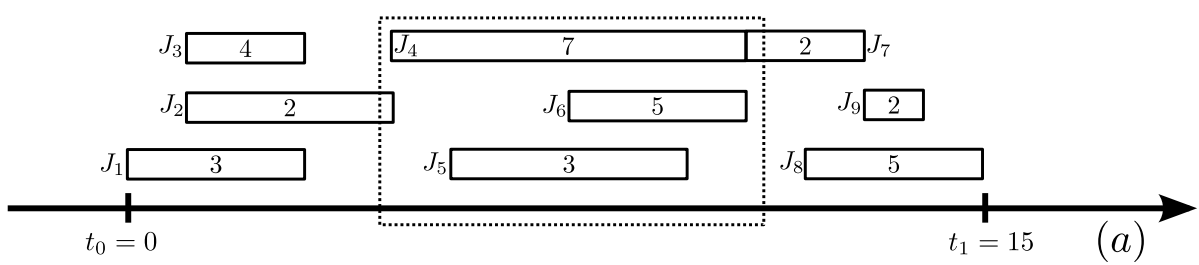

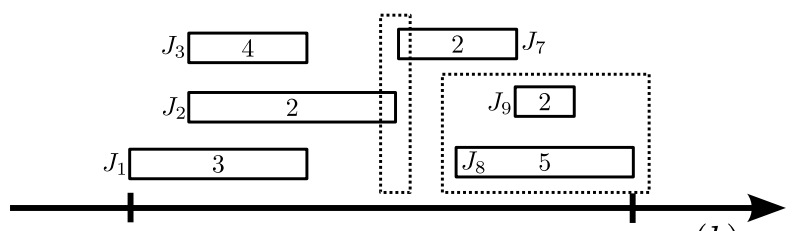

(b)
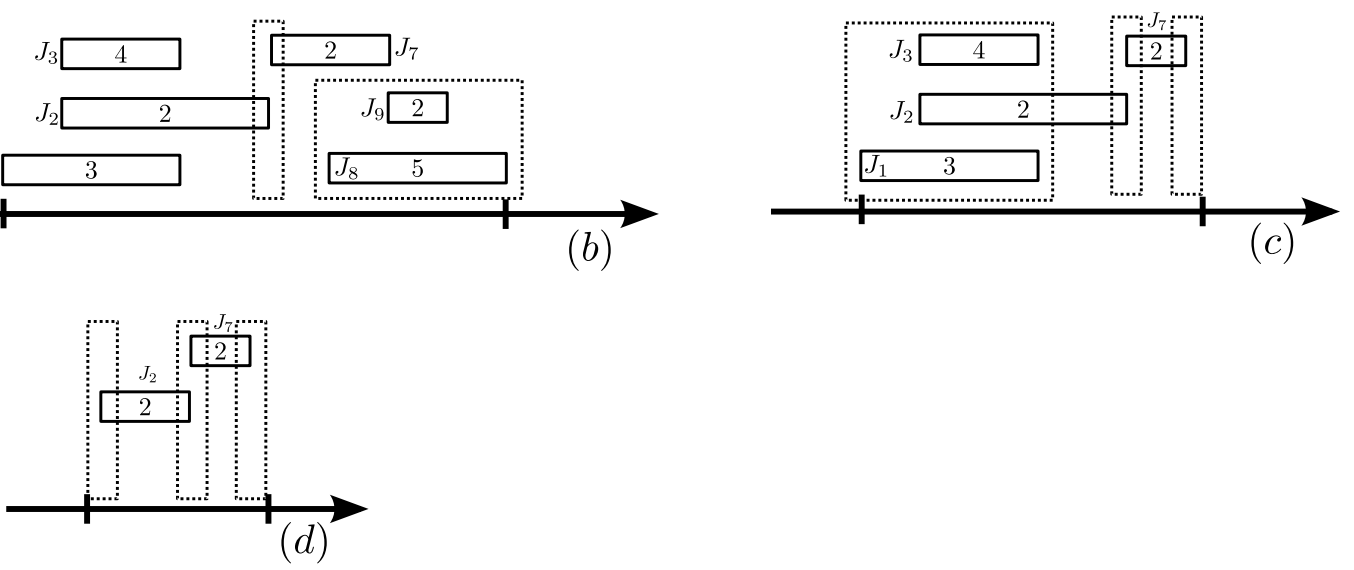

Figura 3.4: Exemplo de instância com $\mathcal{J}=\left\{J_{1}, \ldots, J_{9}\right\}$. Em (a), temos a instância original, com o intervalo de densidade máxima ( $I_{*}^{1}$ em destaque. Em (b), temos a instância após a primeira iteração, isto é, após "retirar" o intervalo $I_{*}^{1}$ (e suas tarefas) de consideração. Feito isso, identificamos o novo intervalo de densidade máxima, dado por $I_{*}^{2}$. Note que, nesta segunda iteração, a tarefa $J_{7}$ está parcialmente contida no intervalo $I_{*}^{2}$. Ao escalonarmos as tarefas de $J_{I_{*}^{2}}, J_{7}$ tem seu prazo atualizado (como mostrado em (c)), já que nenhuma tarefa, a não ser as de $J_{I_{*}^{2}}$ podem ser executadas em $I_{*}^{2}$. $O$ mesmo acontece com a tarefa $J_{2} \mathrm{em}(\mathrm{c})$. Por fim, (d) mostra a instância quase em seu final, apenas com duas tarefas ainda a serem escalonadas.

Vamos exemplificar o funcionamento deste algoritmo. Considere a Figura 3.4. Nela, temos uma instância de 9 tarefas $\mathcal{J}=\left\{J_{1}, \ldots, J_{9}\right\}$, no intervalo $[0,15)$. O algoritmo começa identificando o intervalo de densidade máxima e as tarefas contidas nele, como mostrado em Fig. 4(a). Feito isso, ele as retira de consideração, isto é, "elimina" o intervalo $I_{*}$ alterando o tempo de chegada e/ou prazo das tarefas parcialmente contidas em $I_{*}$. Isto completa uma iteração do algoritmo, que então passa a considerar o novo conjunto $\mathcal{J}$ em busca do intervalo de densidade máxima. Este algoritmo é obviamente polinomial com uma implementação

\footnotetext{
${ }^{3}$ Earliest Deadline First, estratégia de escalonamento que prioriza as tarefas a serem executadas por ordem crescente de prazo.
} 
simples de complexidade $O\left(n^{3}\right)$.

\subsection{Conclusão}

Neste capítulo estudamos o modelo de escalonamento conhecido como Dynamic Speed Scaling. Nele, temos $n$ tarefas especificadas por tempo de chegada, prazo e volume de processamento e um processador de velocidade variável. O objetivo é escalonar as tarefas minimizando o consumo de energia do processador.

Mostramos que para este problema existe um algoritmo polinomial chamado YDS que encontra um escalonamento ótimo. Este algoritmo funciona encontrando repetidamente o intervalo de densidade máxima e executando as tarefas que o compõe com a velocidade mínima necessária para completá-las durante todo o intervalo.

No próximo capítulo estudaremos o mesmo modelo de escalonamento para o caso em que há $m$ processadores de velocidade variável e o consumo de energia é dado pela soma dos consumos de cada um. 


\section{Capítulo 4}

\section{Escalonamento em Processadores Paralelos de Velocidade Variável}

Uma extensão natural para o problema tratado no capítulo anterior é a adição de processadores. Atualmente, a grande maioria dos computadores possui mais de uma unidade de processamento, fato que aumenta o consumo de energia. Desta forma, algoritmos de escalonamento que consigam reduzir o consumo nestes ambientes tem uma grande importância prática.

Neste capítulo estudamos os resultados apresentados em Albers et al. (2007). No artigo, os autores propõem o problema de escalonar $n$ tarefas especificadas por tempo de chegada, prazo e volume de processamento em $m$ processadores idênticos, que possuem a capacidade de executar as tarefas em qualquer velocidade $s \in[0,+\infty)$. Novamente, temos uma função potência associada à velocidade, que por sua vez está associada ao consumo de energia dos processadores. As tarefas não podem ser migradas entre os processadores depois de iniciadas, e cada processador só pode executar uma tarefa de cada vez. Os autores mostram que o problema é NP-Completo mesmo se as tarefas forem unitárias.

Começaremos definindo a notação usada e analisando a complexidade do problema. Veremos que este é um problema difícil a não ser que grandes restrições nas propriedades das tarefas sejam aplicadas. Veremos, também, um caso específico em que existe um algoritmo polinomial simples para resolver o problema e o analisaremos.

\subsection{Definição do Problema}

Considere um conjunto de tarefas $\mathcal{J}=\left\{J_{1}, \ldots, J_{n}\right\}$, de tamanho $n$, com $J_{i}$ especificado por $r_{i}, d_{i}$ e $w_{i}$, como no capítulo anterior. Neste modelo, temos $m$ processadores idênticos, cuja velocidade pode variar no intervalo $[s,+\infty)$. Se uma tarefa for iniciada por um processador, ela deve ser terminada por ele. Entretanto, a preempção (i.e. interromper o processamento de uma tarefa e retomá-lo no futuro sem perda de trabalho) é permitida.

O consumo de energia de um escalonamento neste modelo é dado pela soma dos consumos 
de energia de cada processador individualmente. Este consumo, por sua vez, é dado pelo Algoritmo YDS (3.2), que, como mostrado no capítulo anterior, encontra um escalonamento ótimo para um conjunto de tarefas em um processador.

Este problema é consideravelmente mais difícil do que o para um único processador. De fato, podemos mostrar que, mesmo se o tempo de chegada e o prazo de todas as tarefas forem iguais, encontrar o escalonamento ótimo é NP-Difícil, através de uma redução do problema da 3-Partição. Isto indica que a dificuldade deste problema está relacionada ao fato de encontrar uma partição do conjunto de tarefas em $m$ subconjuntos tal que o consumo de energia seja mínimo.

Considere a Figura 4.1. Nela, temos um conjunto de $3 m$ tarefas, todas com $r_{i}=r$ e $d_{i}=d$, enquanto $w_{i}$ é arbitrário. Queremos escalonar estas tarefas em $m$ processadores. É fácil ver que se conseguirmos encontrar uma partição do conjunto de tarefas em $m$ subconjuntos disjuntos, cuja soma dos elementos dos subconjuntos sejam iguais, teremos um escalonamento ótimo. Mas isto é equivalente a encontrar uma solução para o problema da 3-Partição.

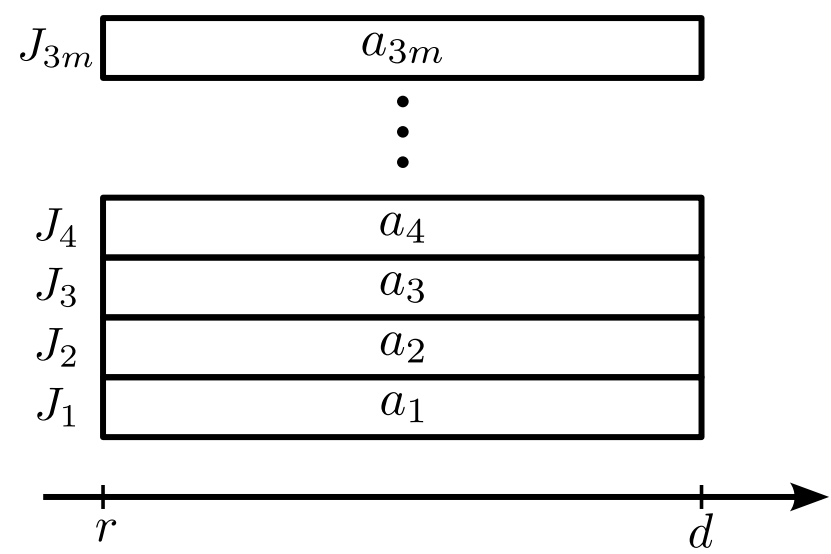

Figura 4.1: Exemplo de instância do problema de escalonamento em $m$ processadores de velocidade variável. Nele temos $3 m$ tarefas, todas com tempo de chegada igual a $r$ e prazo igual a d. Os volumes de processamento estão especificados dentro dos retângulos e correspondem a um inteiro $a_{i}$ de uma instância do problema da 3-Partição. O escalonamento ótimo implicaria dividir as tarefas em $m$ subconjuntos distintos de 3 elementos cada, o que implica em resolver o problema da 3-Partição.

Deste modo, na próxima seção analisaremos o problema um pouco mais restrito. Primeiro, restringiremos o tamanho das tarefas, considerando tarefas unitárias (i.e. $w_{i}=1$ para todas as tarefas $J_{i}$ ). Mostraremos que, mesmo assim, se os tempos de chegada e prazos forem arbitrários, o problema continua NP-Difícil. Em seguida, além de tarefas unitárias, restringiremos o intervalo das tarefas para que elas tenham o que chamaremos de intervalos agradáveis (agreeable deadlines, em inglês) entre elas. Um conjunto de tarefas tem intervalos agradáveis se uma tarefa que começa antes (i.e. tem $r_{i} \leq r_{j}$, para alguma $J_{i} \neq J_{j}$ ) também termina antes (i.e. $d_{i} \leq d_{j}$ ), para todas as tarefas deste conjunto. Estas duas propriedades juntas (tarefas unitárias e com intervalos agradáveis) nos permitirão descrever um algoritmo polinomial que encontra um escalonamento ótimo. 


\subsection{Análise}

Começaremos esta seção provando que o problema para $n$ tarefas unitárias com tempos de chegada e prazos arbitrários continua NP-Difícil. A prova será baseada em uma redução do problema da 3-Partição (Michael e David (1979)). Primeiro, definiremos o problema de decisão:

Instância: Um conjunto de $n$ tarefas $\mathcal{J}=\left\{J_{1}, \ldots, J_{n}\right\}$, especificadas por tempo de chegada $r_{i}$, prazo $d_{i}$ e volume de processamento $w_{i}=1$, e um inteiro $K$.

Questão: Existe um escalonamento em $m$ processadores de velocidade variável tal que o consumo de energia é menor ou igual a $K$ ?

Analogamente, o problema da 3-Partição pode ser definido da seguinte forma:

Instância: Um inteiro $B \in \mathbb{Z}^{+}$e um conjunto de inteiros $A$, com $3 m$ elementos, $m \in \mathbb{Z}^{+}$, com cada $a_{i} \in A$ estritamente entre $\frac{B}{4}$ e $\frac{B}{2}$.

Questão: Existe uma partição de $A$ em $m$ subconjuntos disjuntos $\left\{A_{1}, \ldots, A_{m}\right\}$ de exatamente 3 elementos cada, tal que a soma dos elementos de $A_{i}$ é igual a $B$, para todo $A_{i}$ ?

Construiremos uma instância do nosso problema a partir de uma instância do problema da 3-Partição. Considere uma instância do problema da 3-Partição, isto é, um conjunto $A$ de $3 m$ inteiros como especificado acima. Para cada elemento $a_{i}$, criaremos uma tarefa $J_{i}$, com $r_{i}=\sum_{j<i} a_{j}$ e $d_{i}=r_{i}+a_{i}$. Além destas tarefas, criaremos $m$ tarefas $J_{n+i}, \ldots, J_{n+m}$, com $r_{n+i}=0$ e $d_{n+i}=3 d_{n}$. A Figura 4.2 mostra um exemplo desta construção. Mostraremos que um escalonamento ótimo para esta instância implica em uma solução ótima para a instância do problema da 3-Partição, e vice-versa.

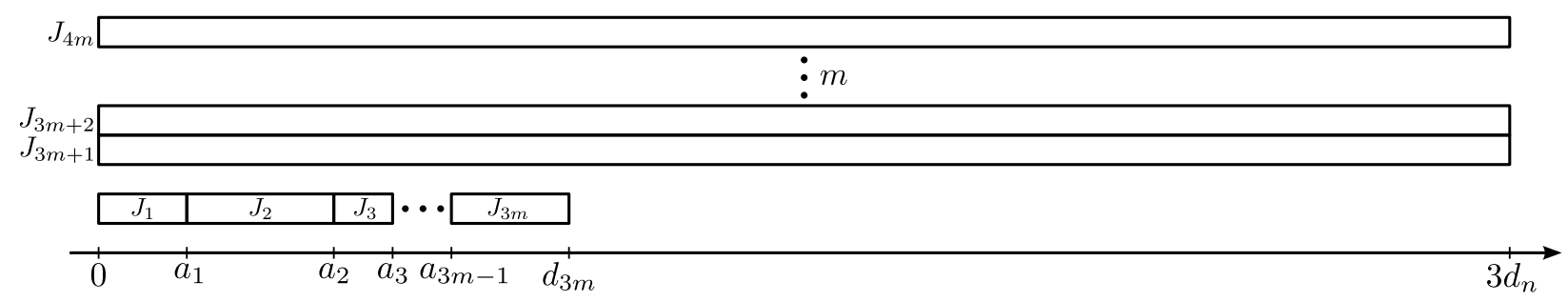

Figura 4.2: Exemplo de instância do problema construído a partir do problema da 3-Partição. Nele, temos $4 \mathrm{~m}$ tarefas unitárias. As primeiras $3 \mathrm{~m}$ tem intervalos disjuntos, com $r_{i}=\sum_{j<i} a_{j} e$ $d_{i}=r_{i}+a_{i}$, para uma tarefa $J_{i}$. As tarefas $J_{3 m+1}, \ldots, J_{4 m}$ tem $r_{i}=0$ e $d_{i}=3 d_{3 m}$.

Primeiro, provaremos o seguinte lema:

Lema 4.2.1 Em um escalonamento ótimo, cada processador executará somente uma tarefa de tamanho $3 d_{n}$.

Prova Por contradição. Suponha que duas tarefas de tamanho $3 d_{n}$ fossem escalonadas em um mesmo processador. O consumo de energia mínimo para executar cada uma destas tarefas é dado por:

$$
\left(\frac{2}{3 d_{n}}\right)^{\alpha} \frac{3 d_{n}}{2}=\left(\frac{2}{3 d_{n}}\right)^{\alpha-1}
$$


Além disso, um dos $m$ processadores ficaria sem tarefas para executar no intervalo $\left[d_{n}, 3 d_{n}\right)$, já que existem $m$ tarefas de tamanho $3 d_{n}$ e duas seriam executadas em um mesmo processador. Agora, se executássemos uma das duas tarefas escalonadas no mesmo processador neste que estaria sem tarefas, o consumo de energia da tarefa migrada para este intervalo seria de

$$
\left(\frac{1}{2 d_{n}}\right)^{\alpha-1}
$$

que é menor que o consumo em seu processador original, o que contradiz o fato do escalonamento ser ótimo.

Agora, considere as tarefas $J_{1}, \ldots, J_{n}$. Como ilustrado na Figura 4.2 , seus intervalos de processamento são disjuntos, tendo intersecção somente com os intervalos das tarefas grandes. Mostraremos que, em um escalonamento ótimo, estas tarefas serão executadas sozinhas durante todo o seu intervalo. Para isto, precisaremos antes mostrar um lema que estabelece o mínimo de funções como as que estamos lidando.

Lema 4.2.2 Seja c >0 e $\alpha>1$. Então, a função

$$
f(x)=\left(\frac{1}{x}\right)^{\alpha-1}+\left(\frac{1}{c-x}\right)^{\alpha-1},
$$

com $x \in(0, c)$ tem valor mínimo no ponto $x=\frac{c}{2}$.

Prova Calculando a derivada de $f(x)$, temos:

$$
f^{\prime}(x)=(1-\alpha)\left(\left(\frac{1}{x}\right)^{\alpha}+\left(\frac{1}{c-x}\right)^{\alpha}\right),
$$

e, portanto, $x=\frac{c}{2}$ é o mínimo no intervalo $(0, c)$.

Agora, provaremos o lema que mostra que uma tarefa $J_{i}, i \leq n$ será executada sozinha durante todo o seu intervalo.

Lema 4.2.3 Em um escalonamento ótimo, as tarefas $J_{1}, \ldots, J_{n}$ são executadas sozinhas durante todo o seu intervalo de processamento.

Prova Considere que uma tarefa $J_{i}$ não é executada durante todo o seu intervalo, que chamaremos de $I$, isto é, ela será executada em um intervalo $|I|-\epsilon$. Pela construção da instância, não existe outra tarefa $J_{j}, j \leq n$, cujo intervalo tem intersecção com $J_{i}$. Considere a tarefa "grande" $J_{k}$ que será executada no mesmo processador que $J_{i}$. O consumo de energia do processador que executar estas duas tarefas será dado por

$$
\left(\frac{1}{|I|-\epsilon}\right)^{\alpha-1}+\left(\frac{1}{3 d_{n}-|I|+\epsilon}\right)^{\alpha-1} \text {. }
$$


Usando o Lema 4.2.2, $\operatorname{com} x=|I|-\epsilon$, vemos que o valor mínimo desta função seria atingido quando $|I|-\epsilon=\frac{3 d_{n}}{2}$ e que o valor desta função vai diminuindo a medida que $|I|-\epsilon$ vai se aproximando de $\frac{3 d_{n}}{2}$. Deste modo, temos que

$$
\left(\frac{1}{|I|-\epsilon}\right)^{\alpha-1}+\left(\frac{1}{3 d_{n}-|I|+\epsilon}\right)^{\alpha-1}>\left(\frac{1}{|I|}\right)^{\alpha-1}+\left(\frac{1}{3 d_{n}-|I|}\right)^{\alpha-1}
$$

e que o menor valor possível é quando $\epsilon=0$. Isto mostra que em um escalonamento ótimo, $J_{i}$ será executada durante todo o seu intervalo sozinha.

Com estes dois lemas, conseguimos provaremos o seguinte teorema:

Teorema 4.2.4 Em um escalonamento ótimo, o consumo de energia é dado por

$$
E_{O P T}=\sum_{i=0}^{n}\left(\frac{1}{\left|I_{i}\right|}\right)^{\alpha-1}+m\left(\frac{1}{3 d_{n}-B}\right)^{\alpha-1}
$$

Prova O primeiro termo (a somatória) é dado pelo consumo de energia das tarefas $J_{1}, \ldots, J_{n}$, pelo Lema 4.2.3. Basta provarmos que as tarefas $J_{n+1}, \ldots, J_{n+m}$ necessitarão de $\left(\frac{1}{3 d_{n}-B}\right)^{\alpha-1}$ cada uma no escalonamento ótimo. Considere, então, as $m$ tarefas grandes, $J_{n+1}, \ldots, J_{n+m}$. O consumo de energia delas, se cada uma for escalonada em um processador será dado por:

$$
E=\left(\frac{1}{3 d_{n}-B_{1}}\right)^{\alpha-1}+\left(\frac{1}{3 d_{n}-B_{2}}\right)^{\alpha-1}+\cdots+\left(\frac{1}{3 d_{n}-B_{m}}\right)^{\alpha-1}
$$

onde cada termo é o consumo de uma tarefa $J_{i}, i>n$. O valor $B_{i}$ nesta equação é à soma dos tamanhos dos intervalos das tarefas pequenas escalonadas no processador que for executar $J_{i}$. Note que

$$
\sum_{i=1}^{m} B_{i}=m B
$$

Mas, pelo Lema 4.2.2, temos que a equação do consumo de energia dada acima assume seu valor mínimo quando $B_{1}=B_{2}=\cdots=B_{m}$, isto é, quando $B_{i}=B$, para todo $n+1 \leq i \leq n+m$. Isto é possível pois as tarefas pequenas tem seus intervalos disjuntos. Logo, o consumo de energia de um escalonamento ótimo é dado por

$$
E_{O P T}=\sum_{i=0}^{n}\left(\frac{1}{\left|I_{i}\right|}\right)^{\alpha-1}+m\left(\frac{1}{3 d_{n}-B}\right)^{\alpha-1}
$$

O Teorema 4.2.4 mostra que encontrar um escalonamento ótimo para esta instância significa encontrar uma partição das tarefas pequenas em $m$ subconjuntos de 3 elementos cada, tal que a soma dos tamanhos de seus intervalos seja $B$. Mas isto equivale, exatamente, a encontrar uma solução para o problema da 3-Partição. Analogamente, com uma partição 
do conjunto de inteiros $A$ em $m$ subconjuntos de 3 elementos cada, cada um com soma igual a $B$, conseguiríamos encontrar um escalonamento ótimo simplesmente alocando as tarefas de um subconjunto $A_{i}$ em um processador, além de uma tarefa de tamanho $3 d_{n}$. Isto conclui a prova.

\subsubsection{Tarefas com Intervalos Agradáveis}

Nesta seção, consideraremos um problema ainda mais restrito que apenas tarefas unitárias. Um conjunto de tarefas tem intervalos agradáveis se uma tarefa que começa antes também termina antes. Em outras palavras, para $J_{i}$ e $J_{j}, i \neq j$, se $r_{i} \leq r_{j}$, então $d_{i} \leq d_{j}$. A Figura 4.3 mostra um exemplo de instância cujas tarefas tem intervalos agradáveis. Esta é uma restrição que parece natural em muitos ambientes práticos. Veremos que, se um conjunto de tarefas unitárias respeitarem esta restrição, existe um algoritmo polinomial para encontrar um escalonamento ótimo. Descreveremos este algoritmo e em seguida o analisaremos.

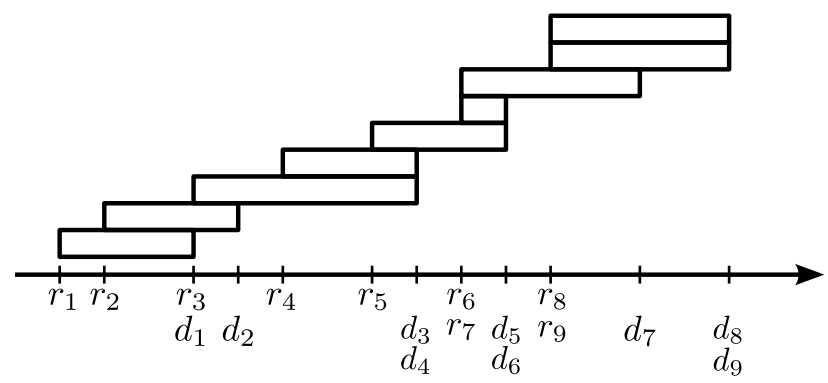

Figura 4.3: Exemplo de instância com tarefas que possuem intervalos agradáveis, isto é, para $J_{i} e$ $J_{j}, i \neq j$, se $r_{i} \leq r_{j}$, então $d_{i} \leq d_{j}$.

Considere, então, uma instância do problema em que as tarefas unitárias tem intervalos agradáveis e considere que as tarefas estão ordenadas de maneira crescente de tempo de chegada. Caso duas tarefas tenham o mesmo tempo de chegada, a que tem menor prazo vem primeiro. Em novo caso de empate, qualquer uma das duas pode vir antes. Provaremos que se escalonarmos as tarefas ordenadas desta maneira nos processadores seguindo a estratégia Round Robin e depois usar o algoritmo YDS para cada processador teremos um escalonamento ótimo.

A estratégia Round Robin funciona da seguinte maneira: dada uma lista de tarefas e uma lista de processadores, a estratégia coloca a tarefa $J_{i}$ no processador $i \bmod m$. A Figura 4.4 mostra esta estratégia aplicada a uma instância com 9 tarefas e 3 processadores.

Considere o pseudocódigo do algoritmo que chamaremos de $R R$ :

$\operatorname{ALGORITMO~RR}\left(J_{1}, \ldots, J_{n}\right)$

01. ordene as tarefas $J_{i}$ em ordem crescente de $r_{i}$

02. atribua a tarefa $J_{i}$ ao processador $i \bmod m$.

03. calcule o escalonamento ótimo para cada processador usando o algoritmo YDS 


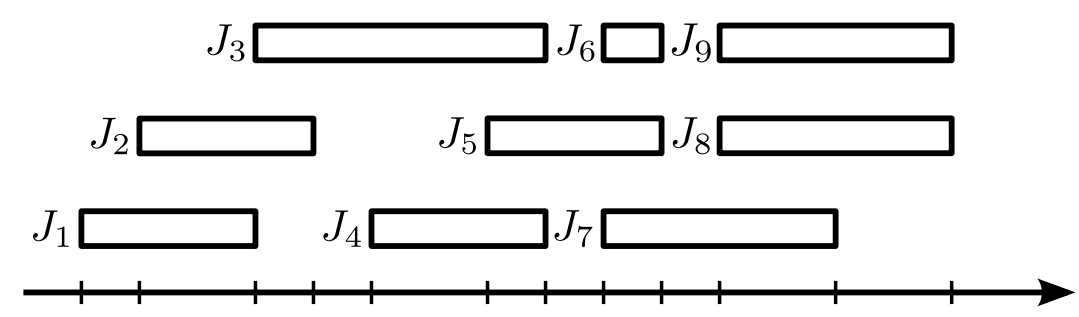

Figura 4.4: Exemplo de escalonamento gerado pelo Algoritmo RR 4.2.1. Ele simplesmente ordena as tarefas segundo seus tempos de chegada (e prazos, em caso de empate) e aloca a tarefa $J_{i}$ para o processador $i \bmod m$.

No artigo de Albers et al. (2007), os autores mostram o seguinte teorema, cuja prova omitiremos aqui.

Teorema 4.2.5 (Albers et al. (2007)) O Algoritmo RR encontra um escalonamento ótimo para um conjunto de $n$ tarefas unitárias cujos intervalos são agradáveis.

\subsection{Conclusão}

Neste capítulo estudamos o problema de escalonar $n$ tarefas especificadas por tempo de chegada, prazo e volume de processamento em $m$ processadores de velocidade variável, com o objetivo de minimizar a soma dos consumos de energia de cada processador. Vimos que este problema é NP-Completo caso as tarefas tenham volume de processamento arbitrário, mesmo se todas as tarefas tiverem tempos de chegada e prazos iguais $\left(r_{i}=r\right.$ e $d_{i}=d, r$ e $d$ constantes e $1 \leq i \leq n)$.

Em seguida, analisamos o problema para o caso em que as tarefas são unitárias, isto é, tem volume de processamento igual a $1\left(w_{i}=1\right)$. Provamos que, mesmo neste caso mais restrito, se os tempos de chegada e prazos forem arbitrários, o problema continua NP-Completo. Estes resultados são muito importantes para o problema que estudaremos no capítulo seguinte.

Finalmente, mostramos que se as tarefas forem unitárias e seus os intervalos de execução forem agradáveis, existe um algoritmo polinomial, denominado algoritmo RR, que encontra uma solução ótima.

No próximo capítulo, consideraremos um problema que combina os já vistos até agora, isto é, um problema de escalonamento entre organizações que possuem processadores de velocidade variável e estão interessadas em escalonar as tarefas de maneira conjunta para minimizar o consumo de energia. Como no Capítulo 2, elas possuem restrições egoístas que afetam a qualidade da solução possível e deixam o problema mais difícil. 


\section{Capítulo 5}

\section{Escalonamento em Organizações com Processadores de Velocidade Variável}

Neste capítulo, consideraremos, novamente, um problema de escalonamento envolvendo múltiplas organizações, como no Capítulo 2. Uma organização nada mais é que uma entidade que possui tanto recursos quanto tarefas e quer otimizar uma função de seu interesse.

Organizações, neste contexto, modelam entidades reais comuns na atualidade. Exemplos incluem empresas privadas que possuem clusters de computadores para executar tarefas computacionais, ou instituições de pesquisa ou ensino, que estão interessadas em usar computadores para fazer experimentos. Em ambos os casos, a otimização dos recursos é de fundamental importância.

Consideraremos um conjunto de organizações que tem interesse em se juntar em um sistema integrado, compartilhando tanto recursos quanto tarefas na esperança de diminuir ainda mais potencias gastos. Em particular, estamos interessados em organizações que querem otimizar o consumo de energia de seus computadores.

Exatamente por quererem compartilhar recursos e tarefas na esperança de diminuir o consumo de energia, cada organização possui o que chamaremos de restrição egoista. Esta restrição diz respeito ao gasto local comparado com o que pode ser atingido globalmente. Em outras palavras, uma organização opta por não participar de tal sistema se seus gastos aumentassem em relação ao que ela poderia fazer sozinha. Obviamente, estas restrições dificultam o problema, já que nem todas as soluções agora serão consideradas viáveis.

O modelo de energia que adotaremos é o já discutido Dynamic Speed Scaling, exposto tanto no Capitulo 3 quanto no Capitulo 4. Como vimos, este modelo foi bastante estudado tanto no contexto de um único processador de velocidade variável quanto no contexto de vários processadores. O gasto de energia neste modelo é definido como uma função da velocidade do(s) processador(es) a cada instante. Originalmente, a motivação para este modelo se baseava nos processadores atuais, que possuem a capacidade de ajustar sua velocidade para economizar energia, baseado em alguma heurística. No contexto de múltiplas organizações atuais, um outro cenário pode ser considerado. Considere que uma organização 
possui um cluster com muitas máquinas e que cada uma pode ser desligada individualmente. Se considerarmos o cluster como um todo e $s$ como sendo a velocidade de processamento deste cluster, poderíamos variar $s$ de maneira quase contínua, se o número de máquinas no cluster for grande. Visto desta maneira, este problema pode ter muitas implicações práticas.

Como nos trabalhos já apresentados de Dynamic Speed Scaling, consideraremos que o consumo de energia de um cluster (ou máquina) está intimamente associado à velocidade $s$ em que as tarefas são executadas, através de uma função potencia.

Nas próximas seções, definiremos o modelo formalmente e apresentaremos os resultados conhecidos.

\subsection{Definições}

Neste modelo, temos $m$ organizações denotadas por $O^{(1)}, \ldots, O^{(m)}$. Cada organização possui $n^{(k)}$ tarefas $\mathcal{J}^{(k)}=\left\{J_{1}^{(k)}, \ldots, J_{n}^{(k)}\right\}$, especificadas por tempo de chegada $r_{i}^{(k)}$, prazo $d_{i}^{(k)}$ e volume de processamento $w_{i}^{(k)}$, como nos capítulos anteriores. Cada organização possui, ainda, um processador de velocidade variável para executar as tarefas.

A qualquer momento, o escalonador pode modificar a velocidade de processamento para qualquer valor $s \in[0,+\infty)$. Associado a esta velocidade, temos novamente uma função potencia $P(s)=s^{\alpha}, \alpha>1$ sendo uma constante. Definiremos o consumo de energia de um processador como a integral temporal da função potencia e o consumo de energia de um escalonamento como a soma dos consumos de cada processador.

Denotaremos o consumo de energia de uma organização $O^{(k)}$, em um escalonamento $\mathcal{S}$ por $E_{\mathcal{S}}^{(k)}$. Este consumo é dado pela energia necessária para executar as tarefas de $O^{(k)}$, não importando aonde ela for executada. Como veremos adiante, este consumo está associado a densidade do intervalo na qual a tarefa será executada. Denotaremos o consumo de energia global de um escalonamento $\mathcal{S}$ como $E_{\mathcal{S}}$.

Este modelo, assim como o modelo do Capítulo 2, possui um conjunto de restrições egoístas. Informalmente, uma organização optaria por não participar de um sistema cujo escalonamento global acabasse por piorar o consumo de energia local. Denotaremos por $E_{\text {local }}^{(k)}$ o consumo de energia de $O^{(k)}$ caso ela estivesse sozinha, isto é, optasse por não participar do sistema. A restrição egoísta de $O^{(k)}$ garante que nenhum escalonamento será realizável se isto ocorrer.

Formalmente, temos:

Restrições Egoístas Considere que $O^{(k)}$ faz parte de um sistema como definido acima. Neste caso, nenhum escalonamento $\mathcal{S}$ é realizável se $E_{\text {local }}^{(k)}<E_{\mathcal{S}}^{(k)}$.

Com estas notações, o problema pode ser definido da seguinte maneira:

$$
\operatorname{minimizar} E_{\mathcal{S}} \text { sujeito a } E_{\mathcal{S}}^{(k)} \leq E_{\text {local }}^{(k)}, \forall k \text {. }
$$


Na próxima seção analisaremos o impacto das restrições egoístas na qualidade da solução possível, bem como os possíveis benefícios da cooperação entre organizações. Analisaremos também a complexidade do problema e provaremos que ele é NP-Difícil, mesmo se os tempos de chegada e prazos de todas as tarefas forem iguais, com volume de processamento arbitrário.

\subsection{Análise}

\subsubsection{Impacto das Restrições Egoístas}

Começaremos esta seção discutindo o impacto das restrições egoístas na qualidade da solução possível. As restrições egoístas neste contexto, a exemplo das restrições locais do MOSP original (Seção 2.1), inviabilizam qualquer solução que piore o que uma organização poderia fazer sozinha. Mostraremos, através de um exemplo, que este impacto é proporcional ao número de organizações e também à constante $\alpha$.

Considere o seguinte exemplo com $m$ organizações. As organizações $O^{(1)}, \ldots, O^{(m-1)}$ possuem apenas uma tarefa, especificada por $r_{1}^{(k)}=0, d_{1}^{(k)}=1$ e $w_{1}^{(k)}=\epsilon, \epsilon<1$. Já a organização $O^{(m)}$ possui $m$ tarefas, também com $r_{i}^{(m)}=0$ e $d_{i}^{(m)}=1$, mas com $w_{i}^{(m)}=w$. A Figura 5.1(a) mostra um exemplo desta instância.
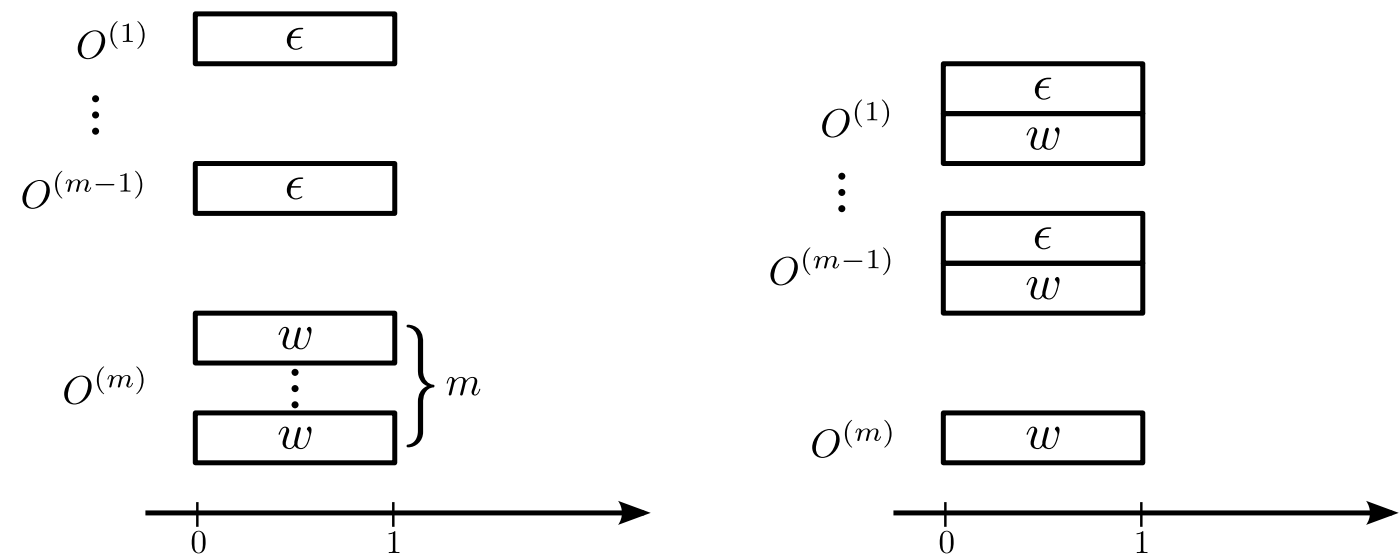

Figura 5.1: Exemplo de instância do MOSP-ENERGY, com $m$ organizaçôes. As organizações $O^{(k)}$, $1 \leq k \leq m-1$, tem uma tarefa cada, de tamanho $\epsilon<1$. A organização $m$ tem $m$ tarefas de tamanho $w$ cada. Com as restrições egoistas, o único escalonamento possível é a própria instância original, mostrado em (a). Em (b), vemos o escalonamento ótimo caso não houvessem restrições egoístas. A razão entre o consumo de energia do escalonamento de (a) e (b) define quão pior as restrições egoístas podem deixar a solução.

Antes de prosseguir, primeiro falaremos do consumo de energia local de cada organização. Uma vez que uma organização possui um conjunto de tarefas para executar, calcularemos a energia necessária para executá-las usando o Algoritmo YDS (3.2). Como visto no Capítulo 3 , este algoritmo calcula um escalonamento ótimo para $n$ tarefas e um processador de velocidade variável usando a estratégia de calcular repetidamente o intervalo de densidade máxima (Definição 3.1) do conjunto de tarefas. Uma vez determinado o intervalo de densidade 
máxima, o escalonador executa apenas as tarefas do intervalo calculado, com velocidade igual à densidade calculada, durante todo aquele intervalo. Deste modo, a restrição egoísta $E_{\text {local }}^{(k)}$ é determinada usando o Algoritmo YDS para o conjunto inicial de tarefas de $O^{(k)}$.

Vamos, também, discutir o consumo de energia de uma organização $O^{(k)}$, dado um escalonamento $\mathcal{S}$. Considere a Figura 5.2(a). Nela, temos duas organizações, $O^{(1)}$ e $O^{(2)}$. Olharemos apenas para o intervalo $\left[t, t^{\prime}\right)$. Considere que a tarefa $J_{3}^{(1)}$ de $O^{(1)}$ foi migrada para $O^{(2)}$. Deste modo, no intervalo $\left[t, t^{\prime}\right)$ de $O^{(2)}$ temos quatro tarefas, $J_{3}^{(1)}, J_{2}^{(2)}, J_{3}^{(2)}$ e $J_{4}^{(2)}$, com os respectivos volumes de processamento dados por 8, 3, 4 e 3, como mostrado na Figura 5.2(b). Em alguma iteração do Algoritmo YDS, o intervalo $\left[t, t^{\prime}\right)$ será o de densidade máxima, com uma densidade igual à

$$
\Delta_{\left[t, t^{\prime}\right)}=\frac{w_{3}^{(1)}+w_{2}^{(2)}+w_{3}^{(2)}+w_{4}^{(2)}}{t^{\prime}-t}=\frac{18}{3}=6 .
$$

Isto significa que no escalonamento ótimo para estas tarefas, durante o intervalo $\left[t, t^{\prime}\right)$ o processador executará apenas as tarefas $J_{3}^{(1)}, J_{2}^{(2)}, J_{3}^{(2)}$ e $J_{4}^{(2)}$, com velocidade $\Delta_{\left[t, t^{\prime}\right)}=6$. O consumo de energia do intervalo $\left[t, t^{\prime}\right)$ é dado, então, por:

$$
E_{\Delta_{\left[t, t^{\prime}\right)}}=\left(\Delta_{\left[t, t^{\prime}\right)}\right)^{\alpha}\left|t^{\prime}-t\right|=6^{\alpha} 3
$$

Definiremos o consumo de energia de cada tarefa deste intervalo medindo, de certa forma, a "contribuição" que a tarefa dá para que o consumo seja aquele. Esta "contribuição" é calculada dividindo o consumo de energia do intervalo pela densidade do mesmo e multiplicando o resultado pelo volume de processamento da tarefa. Deste modo, o consumo de $J_{3}^{(1)}$ será dado por:

$$
E_{J_{3}^{(1)}}=E_{\Delta_{\left[t, t^{\prime}\right)}} \frac{\Delta_{\left[t, t^{\prime}\right)}}{w_{3}^{(1)}}=6^{\alpha} \frac{8}{6} .
$$

Analogamente, teremos o consumo de $J_{2}^{(2)}, J_{3}^{(2)}$ e $J_{4}^{(2)}$ dados por:

$$
\begin{aligned}
& E_{J_{2}^{(2)}}=E_{\Delta_{\left[t, t^{\prime}\right)}} \frac{\Delta_{\left[t, t^{\prime}\right)}}{w_{2}^{(2)}}=6^{\alpha} \frac{3}{6} . \\
& E_{J_{3}^{(2)}}=E_{\Delta_{\left[t, t^{\prime}\right)}} \frac{\Delta_{\left[t, t^{\prime}\right)}}{w_{3}^{(2)}}=6^{\alpha} \frac{4}{6} . \\
& E_{J_{4}^{(2)}}=E_{\Delta_{\left[t, t^{\prime}\right)}} \frac{\Delta_{\left[t, t^{\prime}\right)}}{w_{4}^{(2)}}=6^{\alpha} \frac{3}{6} .
\end{aligned}
$$

Note que a soma dos consumos das tarefas iguala o consumo calculado do intervalo. Desta maneira, o consumo de energia de uma organização $O^{(k)}$ em um escalonamento $\mathcal{S}$ é dado pelo consumo de energia das suas tarefas, não importando aonde elas forem executadas.

Dadas estas definições, conseguiremos mostrar, através do exemplo da Figura 5.1, uma característica importante das nossas restrições egoístas: se uma organização receber tarefas 

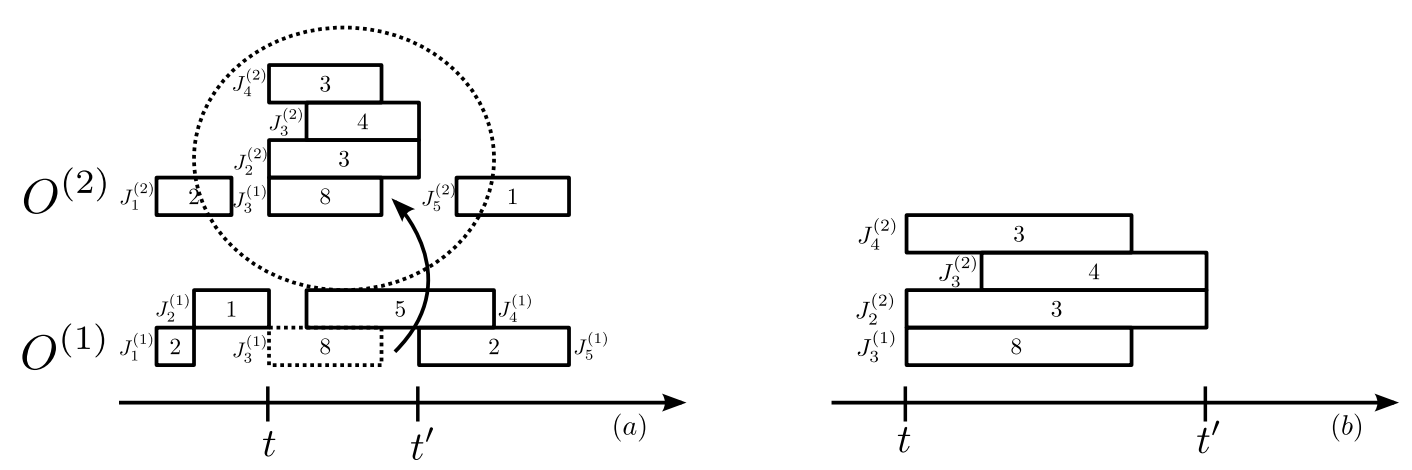

Figura 5.2: Exemplo de como a migração de uma tarefa entre organizações pode aumentar o consumo de energia da organização que a recebe. Em (a), temos uma instância com duas organizações, $O^{(1)} e$ $O^{(2)}$. A tarefa $J_{3}^{(1)}$ será migrada para $O^{(2)}$. Em (b), vemos o intervalo $\left[t, t^{\prime}\right)$ em destaque, com 3 tarefas de $O^{(2)}, J_{2}^{(2)}, J_{3}^{(2)}$ e $J_{4}^{(2)}$ e a tarefa migrada de $O^{(1)}, J_{3}^{(1)}$. Como a tarefa $J_{3}^{(1)}$ aumenta a densidade do intervalo $\left(t, t^{\prime}\right)$ de $O^{(2)}$, todas as tarefas de $O^{(2)}$ neste intervalo passam a requerer mais energia para serem executadas.

de outras para executar e os intervalos destas tarefas coincidirem com algum intervalo de suas próprias tarefas, a densidade deste intervalo aumentará, como mostrado na Figura 5.1(b). Esta densidade maior fará com que a velocidade mínima no intervalo necessária para executar todas as tarefas também aumente, e por consequência, o consumo das tarefas originais da organização aumentará, o que pode causar a violação da restrição egoísta. Deste modo, no exemplo em questão, nenhuma tarefa de $O^{(m)}$ pode ser migrada, já que seus intervalos coincidem com os intervalos das tarefas das outras organizações. Além disso, nenhuma tarefa das outras organizações podem ser migradas também já que elas também aumentariam a densidade do intervalo das outras (a menos que duas delas troquem as tarefas, caso em que não muda o consumo de energia global).

Vamos, então, calcular o consumo de energia do escalonamento mostrado na Figura 5.1(a). Como já dito acima, este é o único escalonamento possível com as restrições egoístas. Cada organização $O^{(1)}, \ldots, O^{(m-1)}$ terá um consumo de energia igual a

$$
E_{\mathcal{S}_{1}}^{(k)}=\left(\frac{\epsilon}{1}\right)^{\alpha} 1=\epsilon^{\alpha}
$$

para $k$ entre 1 e $m-1$.

Já o consumo de $O^{(m)}$ será dado por:

$$
E_{\mathcal{S}_{1}}^{(m)}=\left(\frac{m w}{1}\right)^{\alpha} 1=m^{\alpha} w^{\alpha}
$$

O consumo total deste escalonamento é, então, de:

$$
E_{\mathcal{S}_{1}}=\sum_{1}^{m-1} \epsilon^{\alpha}+m^{\alpha} w^{\alpha} .
$$

Vamos calcular, agora, o consumo de energia do escalonamento da Figura 5.1(b). Nele, 
as $m$ tarefas de $O^{(m)}$ foram migradas, uma para cada organização $O^{(1)}, \ldots, O^{(m)}$. Neste escalonamento, o consumo de $O^{(k)}$, com k entre 1 e $m-1$ é dado por:

$$
E_{\mathcal{S}_{2}}^{(k)}=\left(\frac{w+\epsilon}{1}\right)^{\alpha} 1=(w+\epsilon)^{\alpha}
$$

Já o consumo de energia de $O^{(m)}$ é dado por

$$
E_{\mathcal{S}_{2}}^{(m)}=\left(\frac{w}{1}\right)^{\alpha} 1=w^{\alpha}
$$

O consumo total de $\mathcal{S}_{2}$ é então:

$$
E_{\mathcal{S}_{2}}=\sum_{1}^{m-1}(w+\epsilon)^{\alpha}+w^{\alpha} .
$$

Para determinar o impacto das restrições egoístas na qualidade da solução, basta calcular a razão do consumo de energia destes dois escalonamentos. Teremos, então:

$$
\frac{E_{\mathcal{S}_{2}}}{E_{\mathcal{S}_{1}}}=\frac{\sum_{1}^{m-1} \epsilon^{\alpha}+m^{\alpha} w^{\alpha}}{\sum_{1}^{m-1}(w+\epsilon)^{\alpha}+w^{\alpha}} .
$$

Se $\epsilon \rightarrow 0$, teremos que

$$
\lim _{\epsilon \rightarrow 0}(w+\epsilon)^{\alpha}=w^{\alpha}
$$

e

$$
\lim _{\epsilon \rightarrow 0} \epsilon^{\alpha}=0
$$

Logo, a razão entre o consumo de energia dos dois escalonamento ficaria

$$
\frac{E_{\mathcal{S}_{2}}}{E_{\mathcal{S}_{1}}}=\frac{m^{\alpha} w^{\alpha}}{(m-1) w^{\alpha}+w^{\alpha}}=\frac{m^{\alpha} w^{\alpha}}{m w^{\alpha}}=m^{\alpha-1} .
$$

Deste modo, concluímos que as restrições egoístas podem piorar a solução do MOSPENERGY em até $m^{\alpha-1}$ vezes.

\subsubsection{Benefícios da Cooperação}

Nesta seção, mostraremos que a cooperação entre as organizações pode levar a um escalonamento cujo consumo de energia é bem menor do que a soma dos consumos caso as organizações executassem suas tarefas sozinhas. Este exemplo, além de mostrar que a cooperação entre organizações pode ser vantajosa, servirá como base para as heurísticas que desenvolveremos nas próximas seções.

Considere o seguinte exemplo: temos $m$ organizações, $O^{(1)}, \ldots, O^{(m)}$, cada uma com $m$ tarefas de tamanho $w>1$. Todas as $m$ tarefas de uma organização tem o mesmo tempo de chegada e prazo, definidos da seguinte forma: para a organização $1, r_{i}^{(1)}=0$ e $d_{i}^{(1)}=1$. Para 
as outras $k$ organizações, $2 \leq k \leq m, r_{i}^{(k)}=d_{i}^{(k-1)}$ e $d_{i}^{(k)}=r_{i}^{(k)}+1$. A Figura 5.3 exemplifica esta instância.

Este exemplo é exatamente o oposto do anterior. Cada organização está extremamente carregada durante um intervalo de tempo em que as outras estão sem tarefas para executar. Neste cenário, migrar uma tarefa não aumenta os gastos de energia da organização que a recebe, ou seja, a restrição egoísta da organização que recebe a tarefa não é violada. Além disso, o consumo de energia da organização que migra a tarefa diminui, já que a tarefa será executada em um intervalo com densidade menor e, portanto, com velocidade menor.

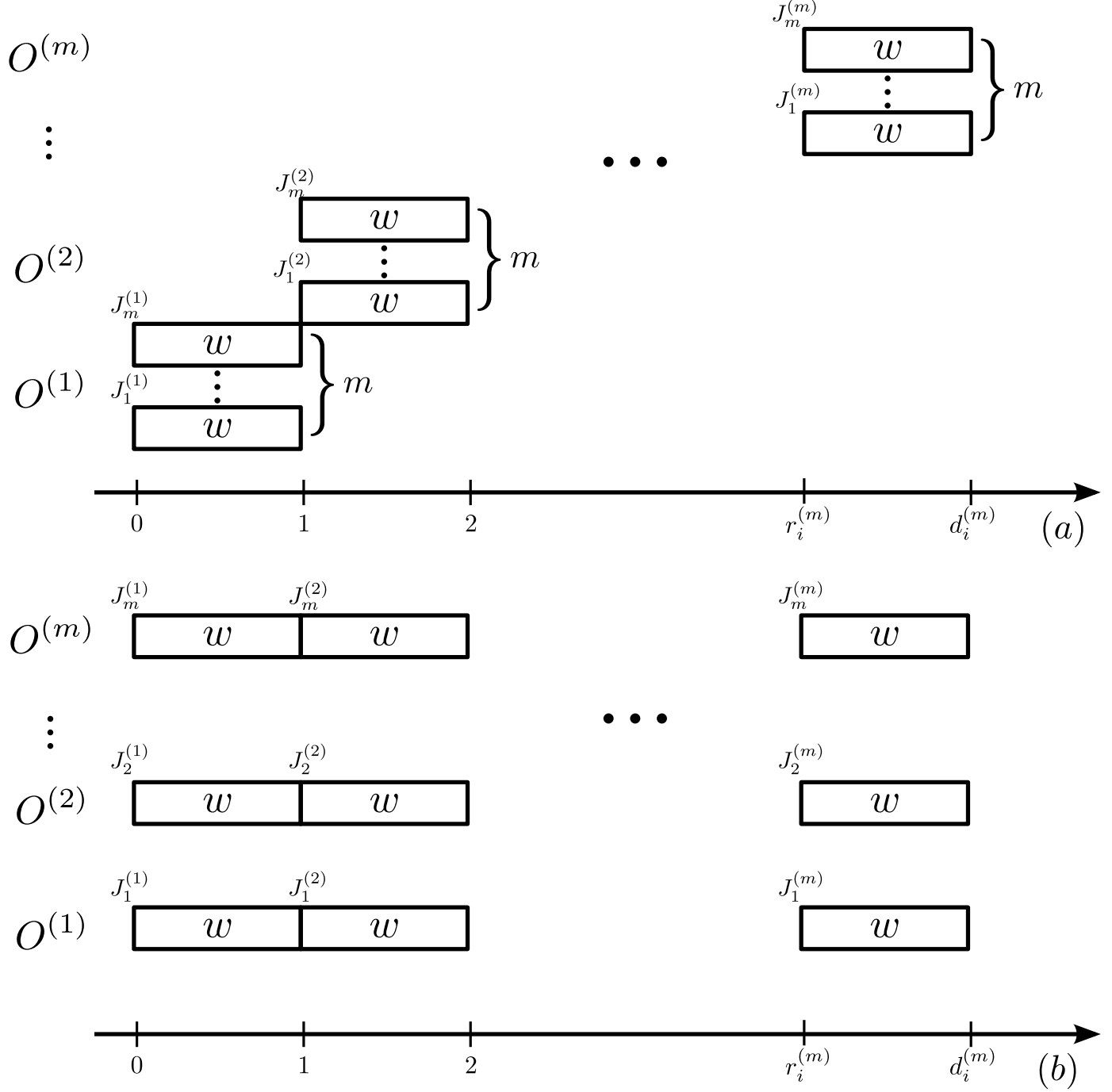

Figura 5.3: Exemplo de instância em que a cooperação entre as organizações diminui o consumo de energia global sem violar as restrições egoistas. Temos $m$ organizações, $O^{(1)}, \ldots, O^{(m)}$, cada uma com $m$ tarefas de tamanho $w>1$. As tarefas de uma organização tem todas o mesmo intervalo de processamento, e estes intervalos são disjuntos entre as organizações. Em (a), temos a instância original. Em (b), temos o escalonamento ótimo para esta instância. Note que o escalonamento de (b) não viola as restrições egoistas de nenhuma organização.

Vamos calcular o consumo de energia do escalonamento $\mathcal{S}_{1}$ mostrado na Figura 5.3(a). 
Para uma organização $k$, temos:

$$
E_{\mathcal{S}_{1}}^{(k)}=\left(\frac{\sum_{1}^{m} w}{1}\right)^{\alpha} 1=(m w)^{\alpha} .
$$

Deste modo, o consumo total do escalonamento $\mathcal{S}_{1}$ é:

$$
E_{\mathcal{S}_{1}}=\sum_{1}^{m}(m w)^{\alpha}=m(m w)^{\alpha}=m^{\alpha+1} w \alpha .
$$

Vamos, agora, considerar o escalonamento da Figura 5.3(b). Este escalonamento distribui as tarefas de cada organização entre todas as outras, como discutido acima. Note que, como os intervalos das tarefas são disjuntos, cada tarefa é executada sozinha na organização que a recebe, com velocidade menor do que era executada em sua organização original.

Vamos, então, calcular o consumo de energia deste novo escalonamento $\mathcal{S}_{2}$. Para uma organização $O^{(k)}$, temos:

$$
E_{\mathcal{S}_{2}}^{(k)}=\sum_{1}^{m}\left(\left(\frac{w}{1}\right)^{\alpha} 1\right)=m(w)^{\alpha} .
$$

O consumo de energia total do escalonamento $\mathcal{S}_{2}$ ficaria, então:

$$
E_{\mathcal{S}_{2}}=\sum_{1}^{m} m(w)^{\alpha}=m^{2}(w)^{\alpha}
$$

Agora, vamos calcular a razão entre os consumos de energia:

$$
\frac{E_{\mathcal{S}_{2}}}{E_{\mathcal{S}_{1}}}=\frac{m^{2}(w)^{\alpha}}{m^{\alpha+1} w \alpha}=\frac{1}{m^{\alpha-1}} .
$$

Este exemplo mostra que em um sistema com $m$ organizações que cooperam entre si para diminuir o consumo de energia de suas máquinas, o escalonamento resultante de tal cooperação pode ser $m^{\alpha-1}$ vezes melhor que se elas não cooperassem, mesmo com as restrições egoístas.

Além disso, este exemplo evidencia uma fato importante sobre a migração de tarefas. Se uma tarefa for migrada de uma organização para outra, mas seu intervalo de execução não coincidir com intervalos das tarefas da organização original, a migração desta tarefa não viola a restrição egoísta da organização que a recebe. Este será um fato importante que levaremos em consideração nas heurísticas que fizemos para encontrar soluções boas para o problema.

Com o exemplo da seção anterior, mostramos que as restrições egoístas impedem que o qualquer algoritmo que encontre uma solução para o problema consiga garantir que as soluções encontradas sejam melhores do que $m^{\alpha-1}$ vezes a solução que poderia ser atingida sem as restrições egoístas. Apesar disso, com o exemplo desta seção, mostramos que a cooperação entre organizações pode levar a uma solução global $m^{\alpha-1}$ vezes melhor do que a solução de cada organização sozinha. Na próxima seção, provaremos que o problema MOSP-ENERGY é 
NP-Difícil. Isto concluirá a análise de complexidade do problema.

\subsubsection{Complexidade}

Nesta seção, provaremos que o problema de decisão do MOSP-ENERGY é NP-Difícil, através de uma redução do problema da Partição (Garey e Johnson (1979)). Primeiro, começaremos definindo o problema de decisão para o MOSP-ENERGY. Em seguida, provaremos formalmente este resultado. Esta prova concluirá a análise de complexidade do problema.

Vamos considerar o seguinte problema de decisão:

Instância: um conjunto de $m$ organizações como as definidas acima e um inteiro $K$.

Questão: Existe um escalonamento $\mathcal{S}$ tal que as restrições egoístas $E_{\mathcal{S}}^{(k)} \leq E_{\text {local }}^{(k)}$ para todo $k$ são respeitadas e o consumo de energia do escalonamento $E_{\mathcal{S}}$ é menor ou igual a $K$ ?

Mostraremos o seguinte teorema:

\section{Teorema 5.2.1 O problema MOSP-ENERGY é NP-Difícil.}

Prova É fácil ver que o problema pertence a NP. A prova é baseada na redução do problema conhecido como o problema da Partição(Garey e Johnson (1979)):

Instância: um conjunto de inteiros $A=\left\{a_{i}, \ldots, a_{n}\right\}$

Questão: Existem dois subconjuntos disjuntos $A_{1}$ e $A_{2}$ de $A$ tal que $\sum_{a_{i} \in A_{i}} a_{i}=$ $\sum_{a_{j} \in A_{j}} a_{j}$ ?

Dada uma instância do problema da PARTIÇÃO, construiremos uma instância do MOSPENERGY com 2 organizações da seguinte maneira: seja $t$ e $t^{\prime}$ dois inteiros representando diferentes prazos, com $t<t^{\prime}$ e $D$ um inteiro representando um volume de processamento. Discutiremos seus valores depois.

A organização $O^{(1)}$ possui apenas uma tarefa, $J_{1}^{(1)}$, com $r_{1}^{(1)}=0, d_{1}^{(1)}=t$ e $w_{1}^{(1)}=D$. A organização $O^{(2)}$ tem $n+1$ tarefas, $J_{1}^{(2)}, \ldots, J_{n+1}^{(2)}$. A primeira tarefa $J_{1}^{(2)}$ é idêntica a única tarefa de $O^{(1)}$. As outras $n$ tarefas são especificadas por $r_{i}^{(2)}=0, d_{i}^{(2)}=t^{\prime}$ e $w_{i}^{(2)}=a_{i}$.

Seja $\beta=\sum_{a_{i} \in A} a_{i}$. Definimos o inteiro $K$ da seguinte forma:

$$
K=\frac{2 D^{\alpha}}{t^{\alpha-1}}+\frac{\left(\frac{\beta}{2}\right)^{\alpha}}{\left(t^{\prime}-t\right)^{\alpha-1}}+\frac{\left(\frac{\beta}{2}\right)^{\alpha}}{\left(t^{\prime}-t\right)^{\alpha-1}}
$$

e escolhemos os valores de $D, t$ e $t^{\prime}$ tal que $\frac{D}{t}>\frac{D+\beta}{t^{\prime}}$ é satisfeita. Escolhendo $D \geq 5 \beta$ e $t^{\prime} \geq 3 t+1$ satisfaz a equação.

Podemos facilmente construir uma instância do MOSP-ENERGY a partir do conjunto $A$ em tempo polinomial, como ilustrado na Figura 5.4(a). Nesta instância, o consumo de energia local de $O^{(1)}$ é facilmente computável usando o algoritmo YDS, sendo tal consumo dado por $E_{\text {local }}^{(1)}=\frac{D^{\alpha}}{t^{\alpha-1}}$

Agora, encontraremos $E_{\text {local }}^{(2)}$. Este valor também é facilmente encontrado pelo algoritmo YDS. Como dito na Seção 3.1, o algoritmo funciona encontrando o intervalo de densidade máxima, isto é, o intervalo $I=\left[t_{0}, t_{1}\right)$ tal que a soma do volume de processamento das 


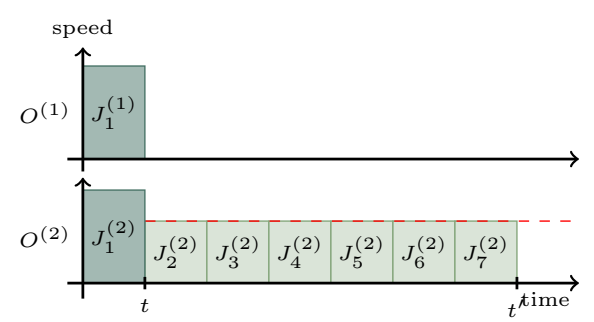

(a) Instância inicial.

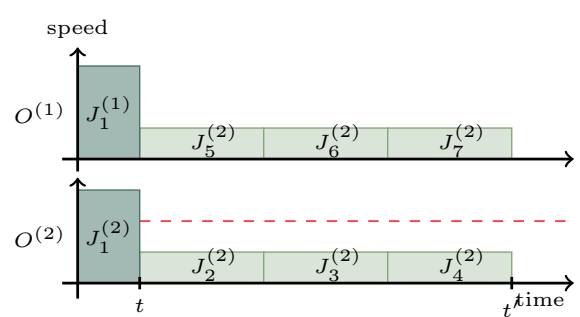

(b)

Escalonamento depois da migração de algumas tarefas de $O^{(2)}$ para $O^{(1)}$.

Figura 5.4: Redução do problema MOSP-EnERGY a partir do problema da PARTIÇÃo.

tarefas inteiramente contidas neste intervalo dividido pelo tamanho do intervalo é máxima. A velocidade do processador é então ajustada de acordo com essa densidade. Pelas escolhas de $D, t$ e $t^{\prime}$, o intervalo de densidade máxima de $O^{(2)}$ é o intervalo $[0, t)$, cuja única tarefa é $J_{1}^{(2)}$. Esta, então, é escalonada e o algoritmo passa para a próxima iteração. O próximo intervalo de densidade máxima é composto pelas $n$ tarefas restantes e o consumo de energia local de $O^{(2)}$ é dado por $E_{\text {local }}^{(2)}=\frac{D^{\alpha}}{t^{\alpha-1}}+\frac{\beta^{\alpha}}{\left(t^{\prime}-t\right)^{\alpha-1}}$.

Agora, precisamos mostrar que tal transformação é realmente uma redução. Primeiro, suponha que o conjunto $A$ possa ser dividido em dois subconjuntos disjuntos, $A_{1}$ e $A_{2}$ tal que a soma de seus elementos sejam iguais. Para respeitar as restrições egoístas das organizações, ambos $J_{1}^{(1)}$ e $J_{1}^{(2)}$ não podem ser migrados. As únicas tarefas que podem são as $J_{2}^{(2)}, \ldots, J_{n+1}^{(2)}$. Iremos dividir estas tarefas em dois conjuntos $\mathcal{J}_{1}$ e $\mathcal{J}_{2}$ de maneira que se $a_{i} \in A_{i}$, então a tarefa $J_{i+1}^{(2)} \in \mathcal{J}_{1}$. As tarefas $a_{j} \in A_{2}$, colocaremos em $\mathcal{J}_{2}$.

Podemos migrar um dos conjuntos, digamos $\mathcal{J}_{1}$, para $O^{(1)}$. Como consequência da nossa hipótese sobre os valores de $D, t$ e $t^{\prime}$, essa migração não altera $E_{\text {local }}^{(1)}$. Depois da migração, o consumo de energia de $O^{(2)}$ fica:

$$
E_{\mathcal{S}}^{(2)}=\frac{D^{\alpha}}{t^{\alpha-1}}+\frac{\left(\sum_{J_{i}^{(2)} \in \mathcal{J}_{1}} w_{i}^{(2)}\right)^{\alpha}}{\left(t^{\prime}-t\right)^{\alpha-1}}+\frac{\left(\sum_{J_{j}^{(2)} \in \mathcal{J}_{2}} w_{j}^{(2)}\right)^{\alpha}}{\left(t^{\prime}-t\right)^{\alpha-1}}
$$

Já que $\sum_{J_{i}^{(2)} \in \mathcal{J}_{1}} w_{i}^{(2)}=\sum_{J_{j}^{(2)} \in \mathcal{J}_{2}} w_{j}^{(2)}=\frac{\beta}{2}$, o consumo de energia global para este escalonamento é igual a:

$$
E_{\mathcal{S}}=E_{\mathcal{S}}^{(1)}+E_{\mathcal{S}}^{(2)}=\frac{2 D^{\alpha}}{t^{\alpha-1}}+\frac{2\left(\frac{\beta}{2}\right)^{\alpha}}{\left(t^{\prime}-t\right)^{\alpha-1}}=K
$$

Desta forma, as restrições são respeitadas e o consumo de energia global é $K$.

Suponha, agora, que existe um escalonamento viável para esta instância tal que o o consumo de energia global é menor ou igual a $K$. Este custo implica que algumas das tarefas de $O^{(2)}$ devem ter migrado. Podemos dividir as tarefas de $O^{(2)}$ em dois conjuntos $\mathcal{J}_{1}$ e $\mathcal{J}_{2}$ de maneira que se a tarefa foi migrada para $O^{(1)}$ então ela pertence a $\mathcal{J}_{1}$, ou a $\mathcal{J}_{2}$, caso contrário. Agora, dividiremos o conjunto $A$ em dois subconjuntos $A_{1}$ e $A_{2}$ de maneira que, se $J_{i+1}^{(2)} \in \mathcal{J}_{1}$, então $a_{i} \in A_{1}$ e se $J_{i+1}^{(2)} \in \mathcal{J}_{2}$ então $a_{i} \in A_{2}$. O consumo de energia global deste 
escalonamento é dado por

$$
E_{\mathcal{S}}=\frac{2 D^{\alpha}}{t^{\alpha-1}}+\frac{\left(\sum_{J_{i}^{(2)} \in \mathcal{J}_{1}} w_{i}^{(2)}\right)^{\alpha}}{\left(t^{\prime}-t\right)^{\alpha-1}}+\frac{\left(\sum_{J_{j}^{(2)} \in \mathcal{J}_{2}} w_{j}^{(2)}\right)^{\alpha}}{\left(t^{\prime}-t\right)^{\alpha-1}}
$$

Como $E_{\mathcal{S}} \leq K$, deduzimos através das duas ultimas equações que:

$$
\begin{aligned}
\frac{\left(\sum_{J_{i}^{(2)} \in \mathcal{J}_{1}} w_{i}^{(2)}\right)^{\alpha}}{\left(t^{\prime}-t\right)^{\alpha-1}}+\frac{\left(\sum_{J_{j} \in \mathcal{J}_{2}} w_{j}^{(2)}\right)^{\alpha}}{\left(t^{\prime}-t\right)^{\alpha-1}} & \leq \frac{2\left(\frac{\beta}{2}\right)^{\alpha}}{\left(t^{\prime}-t\right)^{\alpha-1}} \\
\Longrightarrow \quad\left(\sum_{J_{i}^{(2)} \in \mathcal{J}_{1}} w_{i}^{(2)}\right)^{\alpha}+\left(\sum_{J_{j}^{(2)} \in \mathcal{J}_{2}} w_{j}^{(2)}\right)^{\alpha} & \leq 2\left(\frac{\beta}{2}\right)^{\alpha}
\end{aligned}
$$

Como $x^{\alpha}+y^{\alpha}$ é uma função convexa e $x+y=\beta$, então temos, pela definição de convexidade, que $x^{\alpha}+y^{\alpha}$ assume seu valor mínimo quando $x=y$. Além disso, temos que $x^{\alpha}+y^{\alpha} \geq 2\left(\frac{\beta}{2}\right)^{\alpha}$.

Logo, temos:

$$
2\left(\frac{\beta}{2}\right)^{\alpha} \leq\left(\sum_{J_{i}^{(2)} \in \mathcal{J}_{1}} w_{i}^{(2)}\right)^{\alpha}+\left(\sum_{J_{j}^{(2)} \in \mathcal{J}_{2}} w_{j}^{(2)}\right)^{\alpha} \leq 2\left(\frac{\beta}{2}\right)^{\alpha}
$$

Pelas escolhas dos subconjuntos $A_{1}$ e $A_{2}$, temos então que $\sum_{a_{i} \in A_{1}} a_{i}=\sum_{J_{i}^{(2)} \in \mathcal{J}_{1}} w_{i}^{(2)}=\frac{\beta}{2}$.

Em outras palavras, dividimos o conjunto $A$ em dois subconjuntos disjuntos cuja soma é igual. Isto conclui a prova.

\subsection{Heurísticas}

Como vimos até agora, o problema de escalonar tarefas em processadores de velocidade variável que pertencem a várias organizações independentes é um problema difícil. Mesmo assim, os potenciais ganhos no consumo de energia que um bom escalonamento pode trazer são significativos. Este dois fatos juntos nos motivaram a criar e experimentar várias heurísticas de migração de tarefas que resultam em escalonamentos viáveis (e.g. que respeitam as restrições egoístas) e que tem consumo de energia menor do que o que as organizações conseguiriam fazer sozinhas.

Nesta seção, consideramos um problema simplificado do MOSP-ENERGY. Nesta variação do problema, as tarefas são todas unitárias, isto é, tem $w_{i}=1$. Além disso, consideramos que todas as tarefas tem tempo de chegada $r_{i}=0$. Nossa motivação foi encontrar heurísticas que nos dessem garantias de desempenho, primeiro considerando este cenário mais simples, antes de estendê-lo para cenários mais complexos. Mesmo assim, analisar estas heurísticas se provou um desafio, dada a natureza complexa do problema.

Começaremos introduzindo o conceito que chamamos de borda do escalonamento. Esta ideia, quando aplicada as heurísticas, nos permite ter certeza que as restrições egoístas não são violadas. Em seguida, apresentaremos três heurísticas para o problema com duas organizações, 
que chamamos de gulosa, probabilística e força-bruta. Cada uma delas foi implementada e testada na prática, e exibiremos os resultados comparativos na sequencia.

Para o problema com $m$ organizações, também fizemos uma heurística inspirada no algoritmo ILBA 2.3.1 ("Iterative Load Balancing Algorithm"), introduzido no Capítulo 2. Este algoritmo, que diz respeito ao problema MOSP original, tenta balancear a carga de trabalho das várias organizações considerando uma de cada vez, em várias iterações. Mostraremos que a nossa versão para o problema MOSP-ENERGY produz um escalonamento que pode economizar cerca de $25 \%$ de energia quando comparado ao que as organizações poderiam fazer sozinhas, que consideramos um ganho significativo.

Ao final desta seção, discutiremos outras variações para o problema que poderiam ser consideradas e pesquisas futuras.

\subsubsection{Considerações Preliminares}

Nesta seção discutiremos como podemos garantir que nossas heurísticas não violarão as restrições egoístas de cada organização. Falaremos sobre como o algoritmo YDS se comporta para a instância simplificada e introduziremos o conceito de borda do escalonamento, que nada mais é que o conjunto de organizações que estão sem tarefas para executar durante algum intervalo de tempo. Este conjunto tem grande importância nas heurísticas que descreveremos adiante.

Primeiro, vamos considerar um exemplo do algoritmo YDS aplicado a uma organização neste cenário simplificado. Considere o exemplo da Figura 5.5. Nele temos uma organização com dez tarefas unitárias, todas com $r_{i}=0$. Exatamente por todas elas terem tempo de chegada zero, o intervalo de densidade máxima para este conjunto de tarefas começa em zero. Neste caso, o intervalo de densidade máxima é o intervalo $[0,6)$, com densidade igual a $\frac{5}{6}$. Após encontrar o intervalo de densidade máxima, o algoritmo altera os tempos de chegada de cada tarefa para o término do intervalo, como mostrado na Figura 5.5(b) e começa uma nova iteração. Note que esta nova iteração é idêntica a iteração anterior, tendo todas as tarefas que sobraram com o mesmo tempo de chegada. Este fato simplifica muito o algoritmo, diminuindo a sua complexidade. Na prática isso se mostrará muito importante para os nossos experimentos, que tomarão decisões baseadas em resultados da execução do YDS na hora de migrar tarefas.

Dito isto, podemos discutir em que condições nossas heurísticas optarão por migrar tarefas. Considere uma instância do MOSP-ENERGY simplificado, como mostrado na Figura 5.6. Sem perda de generalidade, consideramos as organizações ordenadas pelo prazo da tarefa mais longa que ela executará, que chamaremos de $d_{\text {max }}^{(k)}$. Vamos considerar uma organização qualquer, por exemplo, $O^{(2)}$. Considere que vamos executar o algoritmo YDS para esta organização. O primeiro intervalo de densidade máxima será o intervalo [0,2), com densidade igual a um, composto pelas tarefas $J_{1}^{(2)}$ e $J_{2}^{(2)}$. Para este intervalo, não podemos migrar nenhuma das duas tarefas, já que todas as outras organizações também tem tarefas neste 

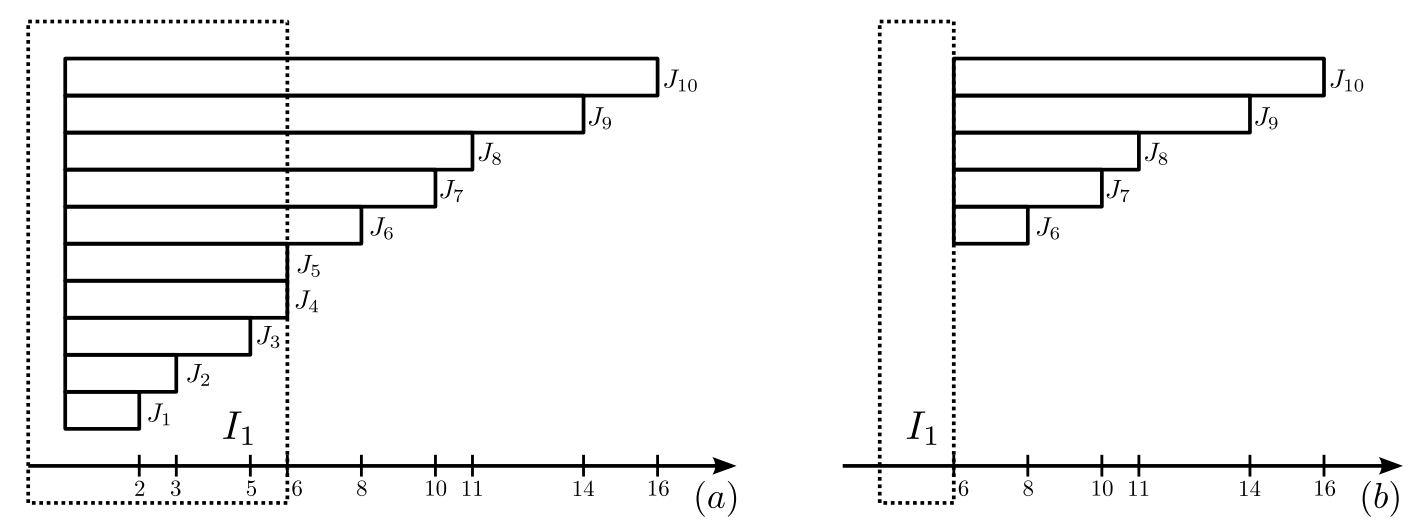

Figura 5.5: Exemplo de aplicação do algoritmo YDS em um conjunto de tarefas como as que compõe o problema simplificado. Em (a) temos a instância inicial, com 10 tarefas unitárias, todas com tempo de chegada $r_{i}=0$. O intervalo $I_{1}=[0,6)$ em destaque é o intervalo de densidade máxima. Em (b), vemos as tarefas que não pertencem a I com seus tempos de chegada ajustados. O algoritmo YDS para esta instância tem complexidade muito menor do que para uma instância genérica, já que determinar o intervalo de densidade máxima é muito mais fácil.

mesmo intervalo e receber tarefas aumentaria a densidade do intervalo para elas, aumentando o consumo de energia de suas tarefas.

Vamos, agora, considerar o segundo intervalo de densidade máxima de $O^{(2)}$. Este intervalo é o $[2,8)$, composto pelas tarefas $J_{3}^{(2)}, J_{4}^{(2)}$ e $J_{5}^{(2)}$. Considere a organização $O^{(1)}$. Esta organização tem $d_{\text {max }}^{(1)}=4$, isto é, após o instante de tempo quatro, a organização não possui mais tarefas para executar. Logo, a partir deste instante, é possível que ela execute tarefas de outras organizações sem aumentar seus próprios custos. Voltando ao segundo intervalo de densidade máxima de $O^{(2)}, I_{2}^{(2)}=[2,8)$, vemos que este intervalo intersecta $d_{m a x}^{(1)}$. Nesta caso, diremos que $O^{(1)}$ está na borda do escalonamento para o intervalo que estamos considerando de $O^{(2)}$.

Borda A borda do escalonamento para um intervalo de densidade máxima de uma organização $O^{(i)}$ é definida como o conjunto de organizações $O^{(k)}$ cujo $d_{\max }^{(k)}$ está dentro do intervalo de densidade máxima, isto é, $d_{\max }^{(k)} \in\left[t, t^{\prime}\right)$, para algum intervalo de densidade máxima $\left[t, t^{\prime}\right)$ de $O^{(i)}$.

Considere, então, que queremos migrar uma tarefa de uma organização $O^{(k)}$ para uma das organizações da borda, para algum intervalo de densidade máxima de $O^{(k)}$. Se migrarmos uma tarefa deste intervalo para uma organização $O^{(i)}$ ajustando seu tempo de chegada para $d_{m a x}^{(i)}$, não violaremos a restrição egoísta de $O^{(i)}$. Deste modo, a borda de um escalonamento para uma organização $O^{(k)}$ denota exatamente o conjunto de outras organizações que poderiam receber tarefas de $O^{(k)}$ (possivelmente tendo que ajustar o tempo de chegada das tarefas a serem migradas) sem piorar as suas próprias, e com isso, sem ter suas restrições egoístas violadas.

Note que a definição de $d_{\max }^{(k)}$ leva em conta as tarefas que serão executadas em $O^{(k)}$ e não só as tarefas originalmente de $O^{(k)}$, isto é, se alguma tarefa for migrada para $O^{(k)}$ cujo prazo é maior que o $d_{m a x}^{(k)}$ original, este assumirá um novo valor, dado pelo prazo da tarefa migrada. 


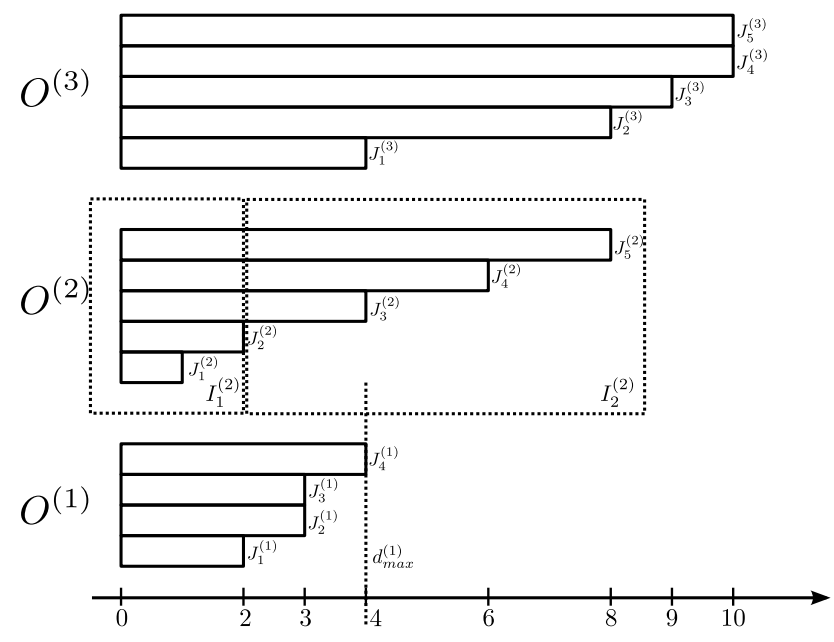

Figura 5.6: Exemplo de instância do problema simplificado com 3 organizações. Para instâncias deste problema sempre consideraremos as organizações numeradas em ordem crescente de prazo máximo do conjunto de tarefas que a organização executará, denotado por $d_{\text {max }}^{(k)}$. Em destaque, temos os intervalos de densidade máxima de $O^{(2)}$, denotados por $I_{1}^{(2)}$ e $I_{2}^{(2)}$. Note que não podemos migrar as tarefas de $I_{1}^{(2)}$, já que a intervalo de execução da tarefa migrada coincidiria com os intervalos de execução de tarefas da organização que a receber. Já para $I_{2}^{(2)}$, tarefas poderiam ser migradas para $O^{(1)}$, modificando o tempo de chegada da tarefa migrada para $d_{\text {max }}^{(1)}$, garantindo assim que a restrição egoista de $O^{(1)}$ não seja violada.

As heurísticas apresentadas a seguir diferirão apenas em como elas tratam a borda para os vários intervalos de densidade máxima. Apresentaremos primeiro as três para o caso de instâncias com apenas duas organizações, juntamente com os resultados dos experimentos realizados usando-as em workloads gerados aleatoriamente (discutiremos como estes workloads são gerados adiante). Em seguida, apresentaremos a heurística para $m$ organizações e também discutiremos os resultados experimentais desta.

\subsubsection{Heurísticas para Duas Organizações}

Começaremos descrevendo heurísticas para instâncias do problema com apenas duas organizações. Como dito acima, as heurísticas consideradas diferem apenas no trato da borda, isto é, ao encontrar um intervalo de densidade máxima cuja borda não seja vazia, as heurísticas diferem na estratégia usada para migrar as tarefas. Nesta seção, denotaremos por $I_{i}^{(k)}$ o i-ésimo intervalo de densidade máxima da organização $k$.

Considere uma instância do MOSP-ENERGY simplificado com apenas duas organizações. Sem perda de generalidade, consideraremos que $d_{\max }^{(1)} \leq d_{\max }^{(2)}$, isto é, consideraremos que $O^{(2)}$ tem ao menos uma tarefa que cujo prazo é maior ou igual ao das tarefas de $O^{(1)}$. Vamos, então, encontrar os intervalos de densidade máxima de $O^{(2)}$ um a um. Considere, então, o primeiro intervalo de densidade máxima de $O^{(2)}$, dado por $I_{1}^{(2)}$. Se ele não estiver na borda $a^{1}$, escalonamos as tarefas deste intervalo na própria $O^{(2)}$. Caso, contrário, se a borda contiver

\footnotetext{
${ }^{1}$ Pela simplicidade, muitas vezes nos referiremos a borda como uma região, ao invés de um conjunto; a frase "o intervalo $\left[t, t^{\prime}\right)$ não está na borda" significa que a borda para o intervalo $\left[t, t^{\prime}\right.$ ) é vazia.
} 
$O^{(1)}$, isto é, $d_{\max }^{(1)} \in I_{1}^{(2)}$, definiremos uma estratégia gulosa para migrar as tarefas:

Heurística Gulosa Dado um intervalo de densidade máxima $I_{j}^{(k)}$ cuja borda é composta por uma organização $O^{(i)}$, a heurística gulosa tenta migrar a maior tarefa do intervalo $I_{j}^{(k)}$ para $O^{(i)}$, ajustando o tempo de chegada da tarefa para $d_{m a x}^{(i)}$ caso necessário, enquanto esta migração melhorar o consumo de energia das tarefas do intervalo.

Vamos exemplificar o comportamento desta heurística. Considere a Figura 5.7. Em (a), temos a instância original, com duas organizações. A organização 1 tem $d_{m a x}^{(1)}=4$. Vamos começar a encontrar os intervalos de densidade máxima de $O^{(2)}$. Como visto em (b), o primeiro intervalo de densidade máxima é dado por $I_{1}^{(2)}=[0,3)$. Este intervalo não está na borda, isto é, seu prazo é menor que $d_{\max }^{(1)}$. Desta forma, nenhuma tarefa pode ser migrada e as tarefas deste intervalo serão executadas em $O^{(2)}$. O segundo intervalo de densidade máxima é $I_{1}^{(2)}=[3,9)$, com densidade igual a $\frac{4}{6}$. Este intervalo está na borda. A heurística gulosa tenta, então, migrar a maior tarefa deste intervalo, isto é, $J_{7}^{(2)}$. Note que o tempo de chegada da tarefa é $r_{7}^{(2)}=3$, mas como $d_{m a x}^{(1)}=4$, este tempo tem que ser ajustado para que não haja sobreposição entre os intervalos de execução dela e das tarefas de $O^{(1)}$. A heurística, então, executará o algoritmo YDS (para as duas organizações) para determinar se esta migração diminuirá o consumo de energia de $O^{(2)}$ (já sabemos que o consumo de $O^{(1)}$ ficará inalterado). Esta migração é ilustrada na Figura 5.7(c). Feita a primeira migração, a heurística repete o processo para a segunda maior tarefa do intervalo, isto é, tenta migrar e verifica se melhorou. Em caso afirmativo, o processo continua. Quando a heurística verificar que a migração da próxima tarefa não melhora o consumo de energia de $O^{(2)}$ ela para. Neste momento, $d_{\text {max }}^{(1)}$ é ajustado para o prazo da maior tarefa que será executada em $O^{(1)}$ agora. As tarefas restantes de $I_{2}^{(2)}$ são escalonadas em $O^{(2)}$ e a heurística passa a considerar o próximo intervalo de densidade máxima de $O^{(2)}$ se houver.

Vamos, agora, considerar a próxima heurística, que chamamos de heurística probabilística. Esta heurística trata a borda atribuindo uma probabilidade para cada tarefa que pode ser migrada (i.e. que tem $d_{i}^{(2)}>d_{\text {max }}^{(1)}$ ) e depois migrando as tarefas de acordo com esta probabilidade.

As probabilidades serão atribuídas de acordo com o tamanho da tarefa, já que uma tarefa maior terá mais chance de economizar energia sendo migrada do que uma menor. Vamos definir como as probabilidades serão então atribuídas:

Heurística Probabilística Dado um intervalo de densidade máxima $I_{j}^{(2)}$ cuja borda é composta pela organização $O^{(1)}$, a heurística probabilística atribui probabilidades para as tarefas de $I_{j}^{(2)}$ da seguinte maneira:

$$
p_{j}= \begin{cases}\frac{d_{j}^{(2)}-d_{\max }^{(1)}}{\sum_{j}\left(d_{j}^{(2)}-d_{\max }^{(1)}\right)} & \text { se } d_{j}^{(2)}>d_{\max }^{(1)} \\ 0 & \text { caso contrário. }\end{cases}
$$




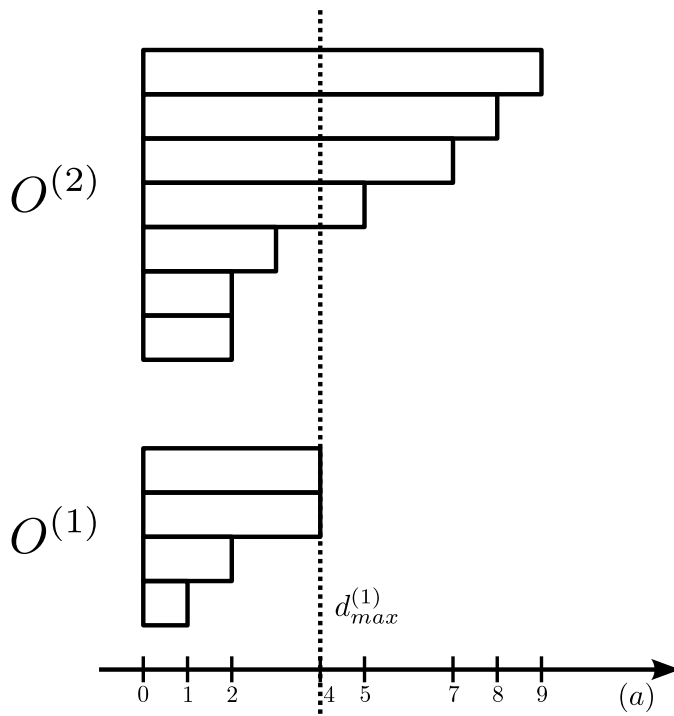

$O^{(2)}$

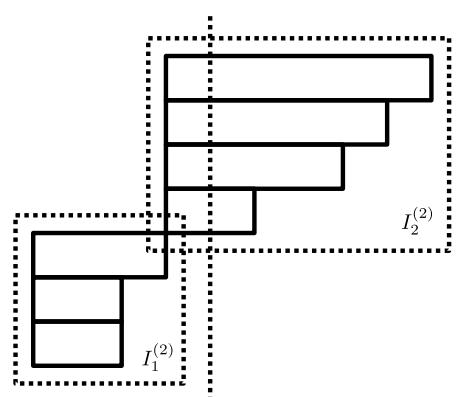

$O^{(1)}$

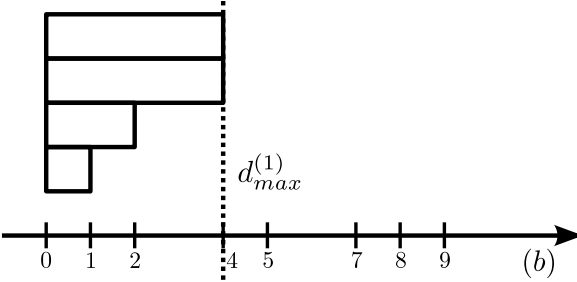

$O^{(2)}$

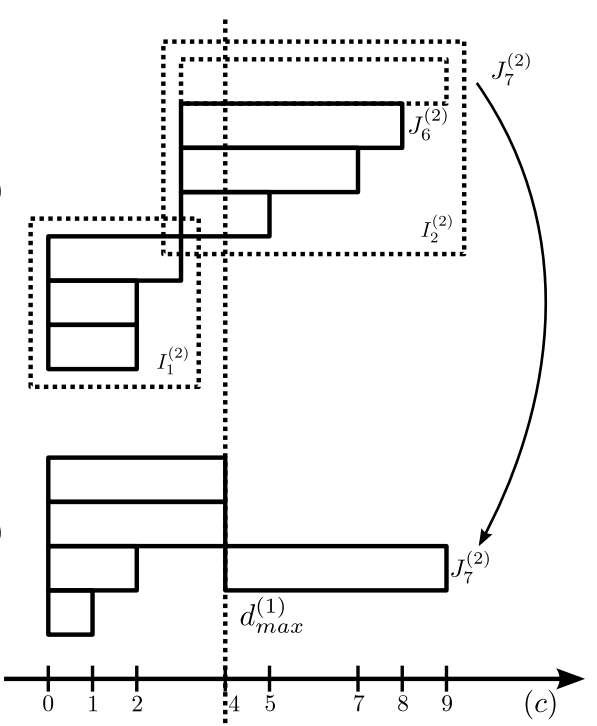

$O^{(2)}$

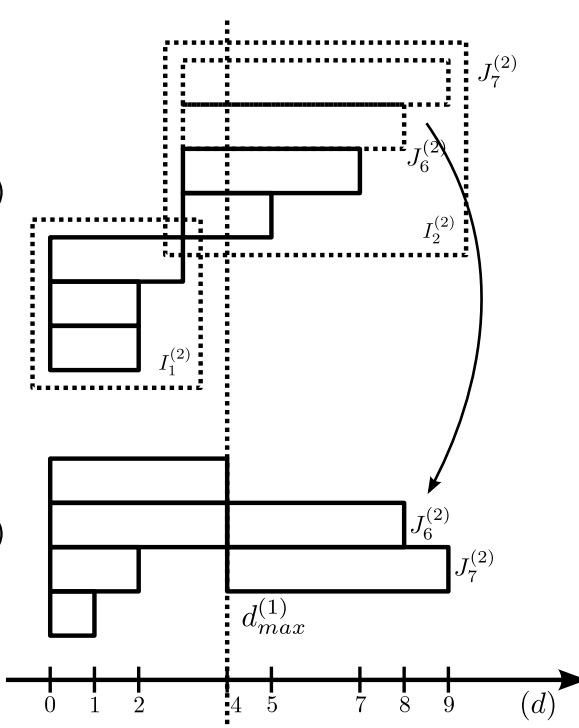

Figura 5.7: Exemplo de execução da heurística gulosa para uma instância do problema simplificado. Em (a), temos a instância inicial, com 2 organizações, $O^{(1)}$ e $O^{(2)}$. A heurística começa identificando o primeiro intervalo de densidade máxima de $O^{(2)}$, dado por $I_{1}^{(2)}$. Como ele não está na borda do escalonamento (i.e. a borda é vazia), suas tarefas são escalonadas em $O^{(2)}$ mesmo, como mostramos em (b). Em seguida, o próximo intervalo de densidade máxima $I_{2}^{(2)}$ é considerado. Para este intervalo, $O^{(1)}$ está na borda. A heurística tenta, então, migrar a maior tarefa de $I_{2}^{(2)}, J_{7}^{(2)}$ para $O^{(1)}$, ajustando seu tempo de chegada para $d_{\max }^{(1)}$, como mostrado em (c). Como, no caso, o consumo de energia de $O^{(2)}$ é diminuído pela migração, a heurística tenta migrar a próxima maior tarefa, $J_{6}^{(2)}$, como mostramos em (d). A migração também é viável e a tarefa será executada em $O^{(1)}$. Nenhuma outra tarefa de $I_{2}^{(2)}$ pode ser migrada melhorando o consumo de energia, caso em que a heurística escalona as tarefas restantes em $O^{(2)}$ e para. 
A heurística, então, decide migrar as tarefas baseada nestas probabilidades.

Vamos considerar um exemplo de como a heurística atribui as probabilidades. Considere a Figura 5.8. Nela, temos a mesma instância do exemplo anterior para a heurística gulosa. Considere novamente o intervalo de densidade máxima $I_{2}^{(2)}$, cuja borda não é vazia. Temos 4 tarefas neste intervalo, $J_{4}^{(2)}, J_{5}^{(2)}, J_{6}^{(2)}$ e $J_{7}^{(2)}$. Informalmente, a equação $d_{i}^{(2)}-d_{\text {max }}^{(1)}$ indica qual é o tamanho do intervalo de execução para a tarefa $J_{i}^{(2)}$ se ela for migrada para a nova organização. Dito isto, a heurística calculará, então, as seguintes probabilidades:

$$
\begin{aligned}
& p_{4}=\frac{d_{4}^{(2)}-d_{\max }^{(1)}}{\sum_{i}\left(d_{i}^{(2)}-d_{\max }^{(1)}\right)}=\frac{9-4}{1+3+4+5}=\frac{5}{13} \\
& p_{5}=\frac{d_{5}^{(2)}-d_{\max }^{(1)}}{\sum_{i}\left(d_{i}^{(2)}-d_{\max }^{(1)}\right)}=\frac{4-4}{1+3+4+5}=\frac{4}{13} \\
& p_{6}=\frac{d_{6}^{(2)}-d_{\max }^{(1)}}{\sum_{i}\left(d_{i}^{(2)}-d_{\max }^{(1)}\right)}=\frac{3-4}{1+3+4+5}=\frac{3}{13} \\
& p_{7}=\frac{d_{7}^{(2)}-d_{\max }^{(1)}}{\sum_{i}\left(d_{i}^{(2)}-d_{\max }^{(1)}\right)}=\frac{1-4}{1+3+4+5}=\frac{1}{13}
\end{aligned}
$$
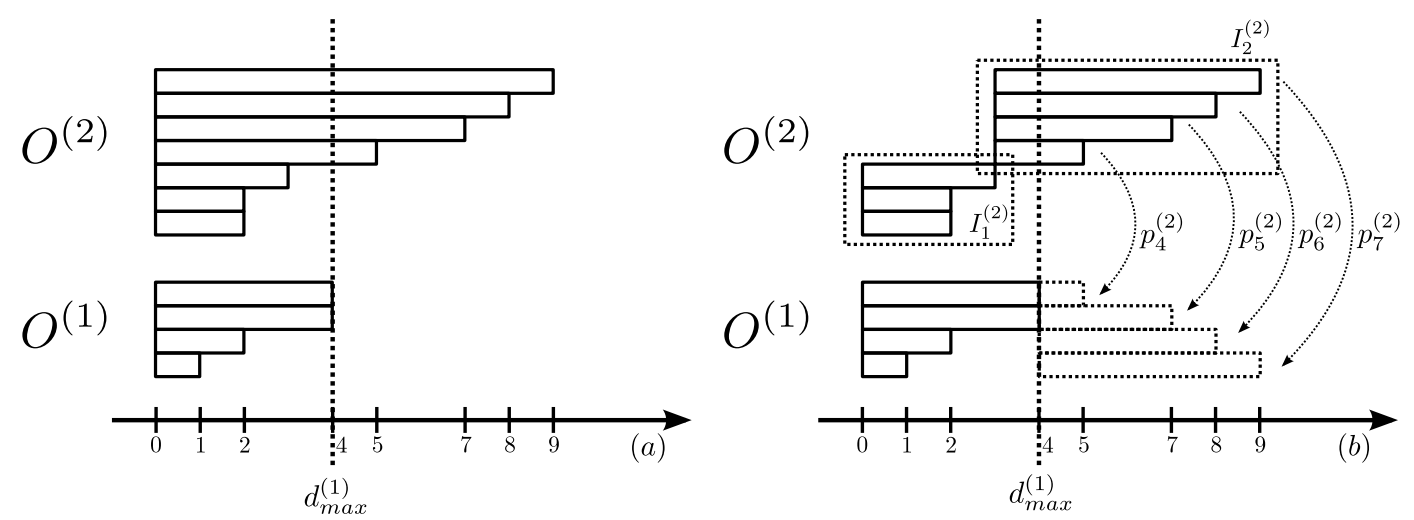

Figura 5.8: Exemplo de execução da heurística probabilística para uma instância do problema simplificado. Em (a), temos a instância inicial, com 2 organizações, $O^{(1)}$ e $O^{(2)}$. A heurística, a exemplo da gulosa, identifica os intervalos de densidade máxima de $O^{(2)}$ um a um e determina a borda para eles. Caso a borda seja vazia, como para $I_{1}^{(2)}$, nada é feito. Já para $I_{2}^{(2)}$, cuja borda é composta pela organização $O^{(1)}$, a heurística calcula as probabilidades das tarefas serem migradas baseadas no prazo que elas terão para serem executadas em $O^{(1)}$, como visto em (b). Determinadas as probabilidades, a heurística decide migrar ou não as tarefas.

A heurística probabilística tem a vantagem de ser rápida na prática, já que não envolve executar o algoritmo YDS algumas vezes para cada intervalo de densidade máxima. Além disso, como as probabilidades são atribuídas de maneira que as tarefas maiores tem mais chance de serem migradas, espera-se que seu desempenho seja comparável com o da heurística gulosa. 
Por último, temos a heurística que chamamos de força-bruta. Esta estratégia trata a borda exatamente da maneira que o nome diz: divide as tarefas do intervalo de densidade máxima em dois conjuntos disjuntos e migra um, repetindo este processo para todos os possíveis subconjuntos disjuntos do intervalo. Para cada um, a heurística calcula o consumo de energia e migra, efetivamente, o melhor. Esta heurística foi pensada e implementada para fins de comparação apenas, já que claramente ela é exponencial no número de tarefas do intervalo de densidade máxima considerado. Mesmo assim, seus resultados experimentais são de grande ajuda na avaliação das outras heurísticas.

\subsubsection{Heurística para $m$ Organizações}

Nesta seção discutiremos uma heurística para o problema simplificado com $m$ organizações. Esta heurística será baseada na ideia da heurística para o MOSP original conhecida como ILBA ("Iterative Load Balancing Algorithm", 2.3.1) cuja ideia é distribuir a carga de tarefas a serem executas entre as várias organizações em iterações, começando das organizações com menos tarefas e terminando nas organizações mais carregadas. Novamente usaremos o conceito da borda do escalonamento para garantir que as restrições egoístas serão satisfeitas.

Vamos, então, descrever como esta heurística funciona. Considere uma instância do MOSP-EnERGy simplificado com $m$ organizações. Sem perda de generalidade, consideramos que as organizações estão numeradas em ordem crescente de $d_{\max }^{(k)}$. Esta heurística funciona em uma série de iterações. Na iteração $k$, tentaremos balancear a carga da organização $O^{(k)}$, distribuindo suas tarefas para as organizações $O^{(1)}, \ldots, O^{(k-1)}$. Como nas heurísticas para duas organizações, começamos a processar uma organização $O^{(k)}$ usando o algoritmo YDS e encontrando seus intervalos de densidade máxima.

Vamos, então, descrever formalmente uma iteração $k$. Nesta iteração, encontramos repetidamente os intervalos de densidade máxima de $O^{(k)}$ e calculamos a borda do escalonamento para este intervalo. Se a borda estiver vazia, nenhuma tarefa poderá ser migrada e passamos para o próximo intervalo de densidade máxima. No caso da borda não ser vazia para um intervalo $I_{l}^{(k)}$, tentaremos migrar as tarefas de $O^{(k)}$ para as organizações da borda. Considere que estas organizações estão ordenadas de forma crescente de $d_{\max }^{(i)}$, com $1 \leq i \leq k-1$. De fato, um novo valor $d_{m a x}^{(i)}$, que no inicio do processo de migração é igual a $d_{\max }^{(i)}$. A heurística tentará migrar a maior tarefa de $I_{l}^{(k)}$ para a primeira organização da borda. A exemplo da heurística gulosa da seção anterior, a migração só será efetivada se, de fato, diminuir o consumo de energia de $O^{(k)}$. Note que pode haver uma alteração no tempo de chegada da tarefa a ser migrada, como nas heurísticas para duas organizações, para que seu tempo de execução não coincida com os tempos de execução das tarefas da organização que a está recebendo. Caso o consumo de energia depois da migração seja melhor do que antes, a tarefa é efetivamente migrada e alteramos o valor de $d_{\text {max }}^{\prime(i)}$ para refletir a mudança.

Em seguida, a heurística tenta migrar a segunda maior tarefa de $I_{l}^{(k)}$ para a primeira organização da borda, considerando os valores $d_{m a x}^{\prime(i)}$. Note que esta organização pode não ser 
mais a mesma que recebeu a tarefa anterior, já que esta teve ser $d_{\text {max }}^{\prime(i)}$ aumentado. Novamente, se valer a pena migrar, a heurística migra a tarefa para $O^{(i)}$ fazendo as alterações necessárias em seu tempo de chegada (a alteração é feita sempre considerando $d_{m a x}^{(i)}$, e não $d_{m a x}^{(i)}$ ) e continua o processo. Note que uma organização pode receber várias tarefas migradas neste processo. Assim que não valer mais a pena migrar, a heurística escalona as tarefas restantes em $O^{(k)}$, atualiza os valores $d_{\max }^{(i)}$ para $d_{\max }^{\prime(i)}$ e encontra o próximo intervalo de densidade máxima, $I_{l}^{(k)}$, repetindo este processo enquanto houver tarefas em $O^{(k)}$ para serem escalonadas.

A Figura 5.9 ilustra o funcionamento da heurística. Considere que estamos na iteração 4, isto é, estamos considerando balancear a carga da organização $O^{(4)}$. Começaremos, então, encontrando o primeiro intervalo de densidade máxima $I_{1}^{(4)}$. Pela Fig. 5.9(a), $I_{1}^{(4)}=[0,6)$. Neste ponto, calcularemos a borda do escalonamento para este intervalo, isto é, determinaremos o conjunto de organizações entre $O^{(1)}, O^{(2)}, O^{(3)}$ tal que $d_{\max }^{(k)}$ pertence ao intervalo $I_{1}^{(4)}$. No caso da instância da figura, todas as organizações tem $d_{\text {max }}^{(k)}$ maior que 6 , fato que impede a migração das tarefas, que serão, então, escalonadas em $O^{(4)}$ mesmo. O próximo intervalo de densidade máxima $I_{2}^{(4)}$ será considerado. Neste instância, este intervalo é o $I_{2}^{(4)}=[6,17)$. Novamente, calcularemos a borda para este intervalo. Para este intervalo, tanto $O^{(1)}$ quanto $O^{(2)}$ e $O^{(3)}$ fazem parte da borda, com $d_{\max }^{(1)}=9, d_{\max }^{(2)}=10$ e $d_{\max }^{(3)}=10$. Neste ponto, a heurística escolhe a maior tarefa de $I_{2}^{(4)}$, isto é, $J_{11}^{(4)}$ para migrar para $O^{(1)}$, ajustando seu tempo de chegada para 9. Feitos os cálculos do consumo de energia, vemos que esta migração vale a pena. Atualizamos, então, $d_{\max }^{\prime(1)}$ para o prazo de $J_{11}^{(4)}$, isto é, $d_{\max }^{\prime(1)}=17$. Repetimos o processo de tentar migrar a próxima tarefa de $I_{2}^{(4)}$ para a primeira organização segundo $d_{\text {max }}^{\prime(k)}$, neste caso sendo $O^{(2)}$. Desta vez, migramos $J_{10}^{(4)}$, que de fato diminui o consumo de energia de $O^{(4)}$ e atualizamos $d_{m a x}^{\prime(2)}$. Novamente repetimos o processo, e novamente vale a pena migrar $J_{10}^{(4)}$, desta vez para $O^{(3)}$, que fica com $d_{m a x}^{(3)}=15$.

Agora, tentamos migrar a tarefa $J_{9}^{(4)}$ novamente para $O^{(3)}$, já que $d_{\text {max }}^{(3)}$ é o menor entre $O^{(1)}, O^{(2)}$ e $O^{(3)}$. Feitos os cálculos do consumo de energia, vemos que não vale a pena migrar esta tarefa para $O^{(3)}$. Neste ponto, a heurística para, escalona as tarefas de $I_{2}^{(4)}$ que sobraram em $O^{(4)}$, atualiza os valores de $d_{\max }^{(k)}$ para coincidir com $d_{m a x}^{\prime(k)}$ e calcula o próximo intervalo de densidade máxima de $O^{(4)}$. A Figura 5.9(c) mostra a configuração final do escalonamento após o balanceamento de $O^{(4)}$.

Na próxima seção discutiremos os ambiente de testes criados para avaliar esta heurística, bem como os resultados obtidos. Verificaremos que em algumas circunstâncias, o escalonamento resultante desta heurística pode obter ganhos próximos a $25 \%$ em relação a instância original.

\subsubsection{Resultados Experimentais}

Para testar as nossas heurísticas, experimentos foram feitos usando dados gerados de maneira aleatória, em cenários que simulam ambientes tipicamente encontrados em clusters reais. Em particular, dois cenários foram considerados. 


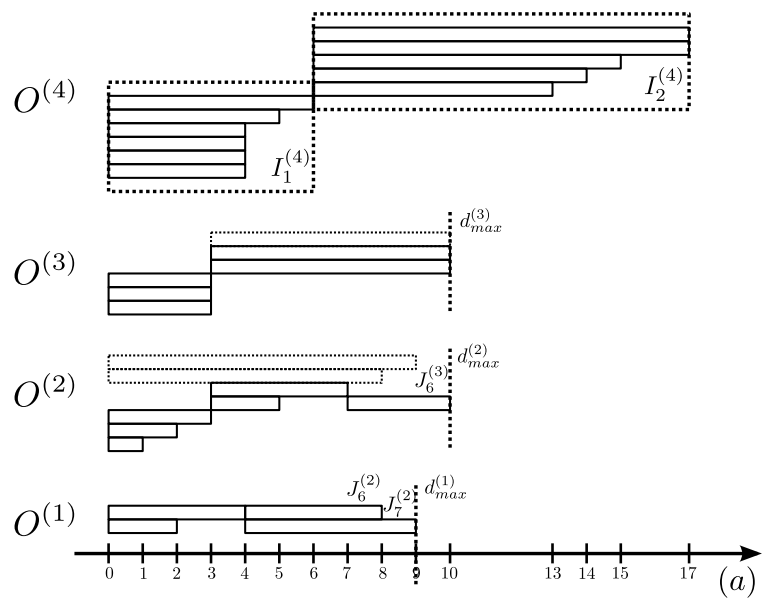

$O^{(4)}$

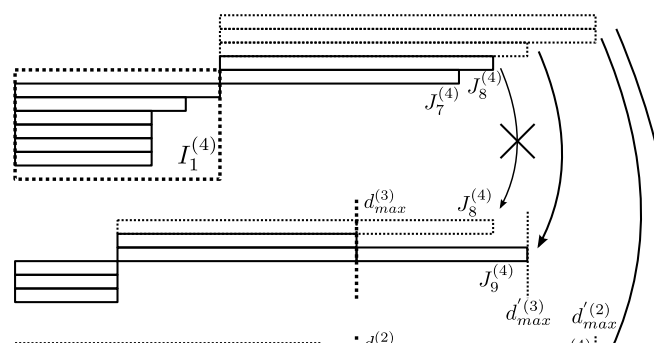

$O^{(2)}$

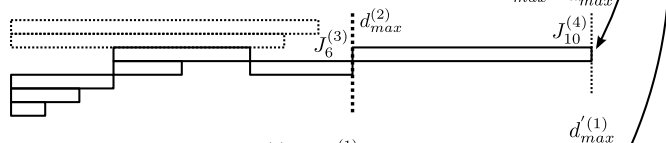

$O^{(1)}$
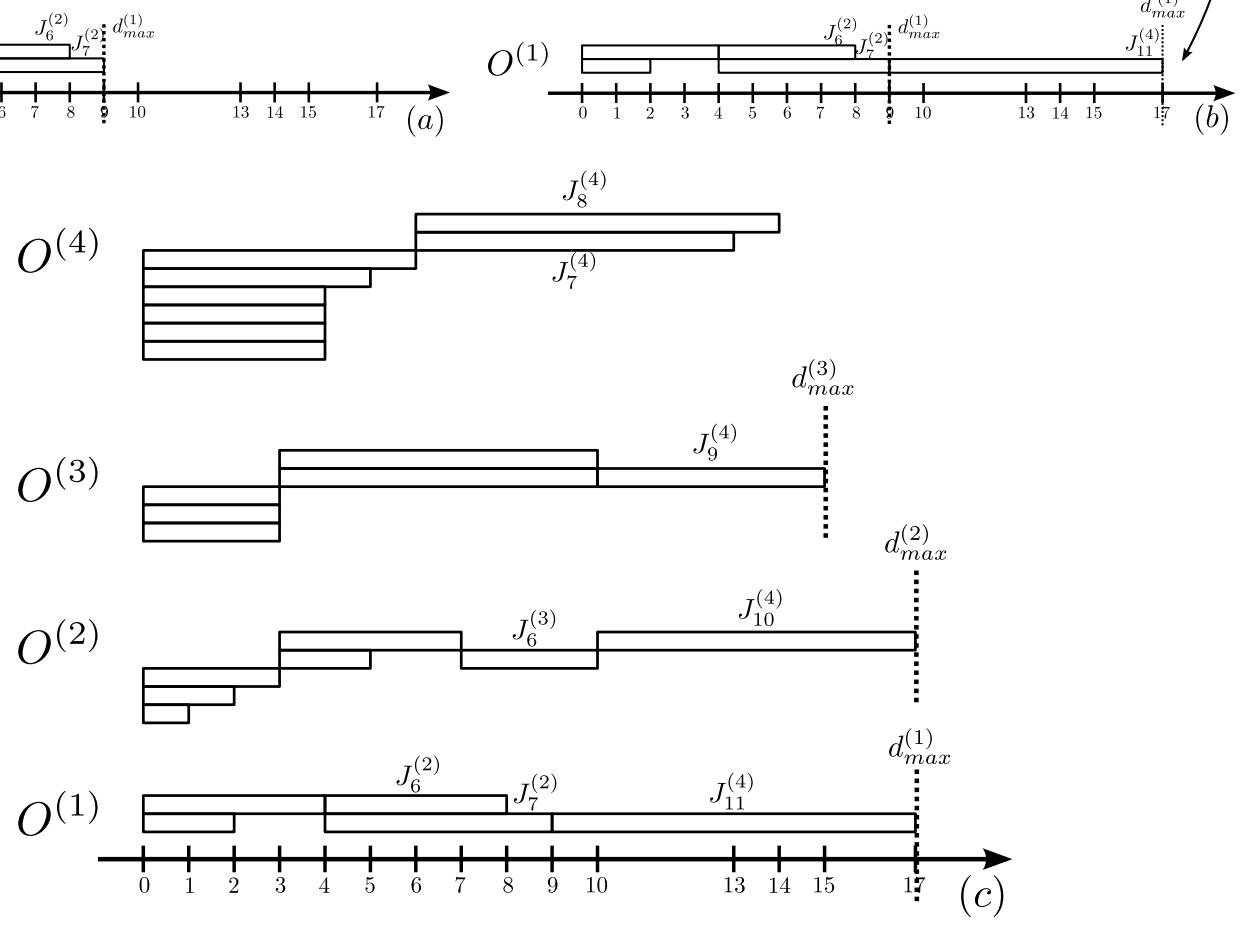

Figura 5.9: Exemplo de uma iteração da heurística para $m$ organizações. Neste exemplo, temos quatro organizações e estamos considerando a iteração que irá balancear $O^{(4)}$. Em (a), temos a instância no inicio da iteração. Note que algumas tarefas de $O^{(2)}$ e $O^{(3)}$ já foram migradas em iterações anteriores. A heurística começa determinando o primeiro intervalo de densidade máxima, $I_{1}^{(4)}$ e calcula a borda para este intervalo. Neste caso, a borda é vazia e as tarefas são escalonadas em $O^{(4)}$. A heurística passa, então, a considerar o segundo intervalo de densidade máxima, $I_{2}^{(4)}$. Para este intervalo, a borda é composta pelas 3 outras organizações e os valores de $d_{\max }^{(k)}$ são $d_{\max }^{(1)}=9$, $d_{\text {max }}^{(2)}=10$ e $d_{\max }^{(3)}=10$. Neste momento, atribuimos valores a $d_{\max }^{(1)}, d_{\text {max }}^{(2)}$ e $d_{\text {max }}^{\prime(3)}$ iguais aos seus respectivos $d_{\text {max }}^{(k)}$ e a heuristica tenta migrar as tarefas de $I_{2}^{(4)}$ uma a uma, começando da maior, para a organização que tem o menor $\dot{d}_{m a x}^{\prime(k)}$, atualizando este valor a medida que as tarefas são migradas, como mostrado em (b). Em (c), vemos o resultado final após a iteração acabar. 
No primeiro, o número inicial de tarefas em cada organização foi gerado de acordo com uma distribuição Zipf com expoente 1,4267, e os prazos gerados de acordo com uma distribuição uniforme. No segundo, o prazo de cada organização foi fixado de acordo com a mesma distribuição Zipf, e as tarefas distribuídas de maneira uniforme entre as organizações. Neste, todas as tarefas tem prazo igual ao prazo estipulado para a organização. Enquanto o primeiro cenário, proposto por Dutot et al. (2011) modela melhor a distribuição de tarefas entre organizações em ambientes distribuídos, o segundo modela as restrições egoístas como no problema MOSP original, com os prazos representando o makespan inicial das organizações.

As tabelas 5.1 e 5.2 resumem os resultados encontrados em relação a economia de energia total nos testes com as heurísticas para duas organizações e $m$ organizações, respectivamente. Nossos testes preliminares mostram que uma variação no $d_{\max }$ não afeta significantemente os resultados. Desta maneira, os resultados são apresentados com $d_{\max }=50$. Variando o número de tarefas por organização, mostramos quanto cada heurística pode economizar em comparação com a energia total caso nenhuma cooperação houvesse ocorrido. Cada resultado é apresentado como a média de 200 testes.

\begin{tabular}{|c|c|c|c|}
\hline \# Tarefas/Org & \% Gulosa & \% Probabilística & \% Força-Bruta \\
\hline \hline 5 & 0.69 & 1.85 & 2.45 \\
\hline 10 & 0.94 & 2.12 & 3.09 \\
\hline 15 & 2.29 & 1.61 & 3.21 \\
\hline 20 & 1.79 & 1.27 & 4.97 \\
\hline 50 & 0.78 & 0.67 & 7.44 \\
\hline 100 & 0.32 & 0.30 & 3.08 \\
\hline
\end{tabular}

Tabela 5.1: Resultados para duas organizações em relação a economia de energia total do sistema. Nós mostramos o desempenho das diferentes heurísticas quando comparadas a não ter nenhuma cooperação, para quantidades diferentes de tarefas por organização.

\begin{tabular}{|c|c|c|}
\hline $\mathrm{m}$ & \# Tarefas/Org & Energia Economizada (\%) \\
\hline \hline 10 & 5 & 11.87 \\
\hline 10 & 10 & 6.81 \\
\hline 10 & 15 & 5.47 \\
\hline 10 & 20 & 4.64 \\
\hline 10 & 30 & 2.86 \\
\hline \hline $\mathrm{m}$ & \# Tarefas/Org & Energia Economizada (\%) \\
\hline \hline 20 & 5 & 15.64 \\
\hline 20 & 10 & 9.81 \\
\hline 20 & 15 & 6.11 \\
\hline 20 & 20 & 5.04 \\
\hline 20 & 30 & 3.24 \\
\hline
\end{tabular}

Tabela 5.2: Resultados para $m=10$ e $m=20$.

Os resultados mostram que para duas organizações, a economia de energia é limitada pelas restrições egoístas. A heurística gulosa é melhor que a probabilística quando a razão 
entre o número de organizações e tarefas é maior.

Os resultados para as heurísticas no segundo cenário são apresentados nas tabelas 5.3 e 5.4. Neste cenário, nossa heurística apresenta economia de energia de até $27,45 \%$.

\begin{tabular}{|c|c|c|c|}
\hline \# Tarefas/Org & \% Gulosa & \% Probabilística & \% Força-Bruta \\
\hline \hline 5 & 4.22 & 5.86 & 6.72 \\
\hline 10 & 4.12 & 3.19 & 5.94 \\
\hline 15 & 2.08 & 2.96 & 6.81 \\
\hline
\end{tabular}

Tabela 5.3: Resultados experimentais para duas organizações no segundo cenário em relação a economia de energia total do sistema.

\begin{tabular}{|c|c|c|}
\hline $\mathrm{m}$ & \# Tarefas/Org & Energia Economizada (\%) \\
\hline \hline 10 & 5 & 17.99 \\
\hline 10 & 10 & 19.10 \\
\hline 10 & 15 & 19.13 \\
\hline \hline $\mathrm{m}$ & \# Tarefas/Org & Energia Economizada (\%) \\
\hline \hline 20 & 5 & 20.08 \\
\hline 20 & 10 & 25.50 \\
\hline 20 & 15 & 27.45 \\
\hline
\end{tabular}

Tabela 5.4: Resultados experimentais para $m=10$ e $m=20$ organizações no segundo cenário.

\subsection{Conclusão}

Neste capítulo estudamos o problema combinado de escalonamento em múltiplas organizações com o objetivo de minimizar o consumo de energia, no modelo em que os processadores tem velocidade variável. Este modelo, no melhor do nosso conhecimento, não havia sido proposto antes.

Provamos que as restrições egoístas, para o problema com $m$ organizações, afetam a qualidade da solução de maneira proporcional a $m^{\alpha-1}$. Provamos, também, que é possível economizar energia na mesma proporção, mesmo com estas restrições. Este resultado, por si só, justifica o estudo mais detalhado do problema. Em seguida, provamos que o problema genérico para $m$ organizações com tarefas totalmente arbitrárias é NP-Completo. Este resultado já era esperado, baseado no conhecimento prévio dos problemas dos Capítulos 2 e 4.

Passamos a considerar um problema simplificado, com tarefas unitárias e tempo de chegada iguais a zero. Para este problema, propomos quatro novas heurísticas, três delas para o problema para duas organizações e uma para o problema com $m$ organizações, inspirada na heurística ILBA (Iterative Load Balancing Algorithm, Seção 2.3.1). Mostramos, através de experimentos para dois cenários de testes, que esta heurística pode gerar economias significativas no consumo de energia de organizações, sempre respeitando as restrições egoístas. 


\section{Capítulo 6}

\section{Conclusões}

Estudamos, neste trabalho, um modelo de cooperação que permite que organizações egoístas compartilhem seus recursos de maneira a minimizar a soma dos consumos de energia, garantindo, ao mesmo tempo, que seus desempenhos locais não piorem.

Dois problemas de escalonamento famosos servem de base para este modelo: o Problema de Escalonamento em Processadores de Velocidade Variável (Dynamic Speed Scaling) e o Problema de Escalonamento em Múltiplas Organizações (Multi-Organization Scheduling Problem).

No Capítulo 5 desenvolvemos o modelo combinado e provamos fatos importantes:

i) as restrições egoístas tem um grande impacto na qualidade das soluções, proporcional ao número de organizações elevado a uma constante;

ii) ganhos significativos podem ser atingidos através do escalonamento cooperativo destas organizações, também proporcionais ao número destas que aderirem ao sistema;

iii) o problema que descrevemos é NP-Completo, isto é, não existe algoritmo polinomial para encontrar a solução ótima, a menos que $P=N P$;

iv) desenvolvemos heurísticas que encontram soluções para cargas de trabalho tipicamente encontradas em ambientes práticos e validamos, através de experimentos que simulam estes ambientes, que nossas heurísticas conseguem bons resultados, chegando até a $27,45 \%$ de economia.

Os estudos apresentados neste capítulo resultaram na publicação de um artigo científico na conferência europeia chamada Euro-Par 2014, ocorrida em Porto, Portugal:

- Cohen, Johanne, Daniel Cordeiro, and Pedro Luis F. Raphael. "Energy-Aware MultiOrganization Scheduling Problem."Euro-Par 2014 Parallel Processing. Springer International Publishing, 2014. 186-197.

Concluimos que o desenvolvimento do modelo apresentado neste trabalho pode trazer muitos benefícios, não só no avanço da Teoria de Escalonamento, mas também no avanço de 
tecnologias empregadas no gerenciamento de energia em grandes aglomerados de computadores. Finalizamos apresentando, na próxima seção, algumas das possíveis pesquisas futuras nesta área.

\subsection{Sugestões para Pesquisas Futuras}

O modelo apresentado neste trabalho permite ser estendido e estudado em muitos eixos. Consideraremos alguns:

i) provar que o problema de escalonamento para $m$ organizações que possuem um processador de velocidade variável e $n^{(k)}$ tarefas unitárias com tempos de chegada e prazos arbitrários é NP-Completo. Há fortes indícios de que este seja o caso (ver Seção 4.2);

ii) estudar o caso em que as tarefas tem o mesmo tempo de chegada e prazo, mas volume de processamento arbitrário;

iii) estudar o problema para tarefas unitárias com intervalos de execução agradáveis. Quando não há sem restrições egoístas, este problema pode ser resolvido em tempo polinomial pelo Algoritmo RR (Alg. 4.2.1);

iv) desenvolver heurísticas para casos mais gerais do problema e realizar experimentos para validá-las;

v) estudar o problema com modelos de energia diferentes. O Problema de Escalonamento em Processadores de Velocidade Variável foi estudado considerando que a velocidade do processador pode assumir valores tanto no intervalo contínuo $[0,+\infty)$, quanto em um conjunto discreto de velocidades possíveis. Estes modelos são mais próximos da realidade e encontrar boas heurísticas para resolvê-los teriam grande importância prática. 


\section{Referências Bibliográficas}

Albers et al. (2007) Susanne Albers, Fabian Müller e Swen Schmelzer. Speed scaling on parallel processors. Em Proceedings of the nineteenth annual ACM symposium on Parallel algorithms and architectures, páginas 289-298. ACM. Citado na pág. 27, 33

Chandrakasan et al. (1992) Anantha P Chandrakasan, Samuel Sheng e Robert W Brodersen. Low-power cmos digital design. IEICE Transactions on Electronics, 75(4):371-382. Citado na pág. 19

Cohen et al. (2010) Johanne Cohen, Daniel Cordeiro, Denis Trystram e Frédéric Wagner. Analysis of multi-organization scheduling algorithms. Em Euro-Par 2010-Parallel Processing, páginas 367-379. Springer. Citado na pág. 3, 5, 17

Cohen et al. (2011) Johanne Cohen, Daniel Cordeiro, Denis Trystram e Frédéric Wagner. Multi-organization scheduling approximation algorithms. Concurrency and computation: Practice and experience, 23(17):2220-2234. Citado na pág. 9

Dutot et al. (2011) P-F Dutot, Fanny Pascual, Krzysztof Rzadca e Denis Trystram. Approximation algorithms for the multiorganization scheduling problem. Parallel and Distributed Systems, IEEE Transactions on, 22(11):1888-1895. Citado na pág. 55

Garey e Johnson (1979) Michael R. Garey e David S. Johnson. Computers and Intractability: A Guide to the Theory of NP-Completeness. W. H. Freeman. ISBN 0716710455. Citado na pág. 43

Graham (1969) Ronald L. Graham. Bounds on multiprocessing timing anomalies. SIAM journal on Applied Mathematics, 17(2):416-429. Citado na pág. 15

Michael e David (1979) R Garey Michael e S Johnson David. Computers and intractability: a guide to the theory of np-completeness. WH Freeman $\&$ Co., San Francisco. Citado na pág. $5,9,29$

Pascual et al. (2007) Fanny Pascual, Krzysztof Rzadca e Denis Trystram. Cooperation in multi-organization scheduling. Em Euro-Par $200^{` 7}$ Parallel Processing, páginas 224-233. Springer. Citado na pág. 5, 7

Yao et al. (1995) Frances Yao, Alan Demers e Scott Shenker. A scheduling model for reduced cpu energy. Em Foundations of Computer Science, 1995. Proceedings., 36th Annual Symposium on, páginas 374-382. IEEE. Citado na pág. 3, 19, 20 